\title{
Postoperative pain in children : assessment and intervention
}

Citation for published version (APA):

Hamers, J. P. H. (1995). Postoperative pain in children : assessment and intervention. [Doctoral Thesis, Maastricht University]. Rijksuniversiteit Limburg. https://doi.org/10.26481/dis.19951012jh

Document status and date:

Published: 01/01/1995

DOI:

10.26481/dis.19951012jh

Document Version:

Publisher's PDF, also known as Version of record

\section{Please check the document version of this publication:}

- A submitted manuscript is the version of the article upon submission and before peer-review. There can be important differences between the submitted version and the official published version of record.

People interested in the research are advised to contact the author for the final version of the publication, or visit the DOI to the publisher's website.

- The final author version and the galley proof are versions of the publication after peer review.

- The final published version features the final layout of the paper including the volume, issue and page numbers.

Link to publication

\footnotetext{
General rights rights.

- You may freely distribute the URL identifying the publication in the public portal. please follow below link for the End User Agreement:

www.umlib.nl/taverne-license

Take down policy

If you believe that this document breaches copyright please contact us at:

repository@maastrichtuniversity.nl

providing details and we will investigate your claim.
}

Copyright and moral rights for the publications made accessible in the public portal are retained by the authors and/or other copyright owners and it is a condition of accessing publications that users recognise and abide by the legal requirements associated with these

- Users may download and print one copy of any publication from the public portal for the purpose of private study or research.

- You may not further distribute the material or use it for any profit-making activity or commercial gain

If the publication is distributed under the terms of Article $25 \mathrm{fa}$ of the Dutch Copyright Act, indicated by the "Taverne" license above, 


\section{POSTOPERATIVE PAIN IN CHILDREN \\ ASSESSMENT AND INTERVENTION}




\title{
POSTOPERATIVE PAIN IN CHILDREN ASSESSMENT AND INTERVENTION
}

\author{
Proefschrift
}

ter verkrijging van de graad van doctor

aan de Rijksuniversiteit Limburg te Maastricht, op gezag van de Rector Magnificus, Prof. mr. M.J. Cohen, volgens het besluit van het College van Dekanen, in het openbaar te verdedigen op donderdag, 12 oktober 1995 om 14.00 uur

door

Johan Peter Herman Hamers

geboren te Kerkrade in 1966 
Promotores:

Prof. dr. H. Huijer Abu-Saad

Prof. dr. M.A. van den Hout

Co-promotor:

Dr. R.J.G. Halfens

Beoordelingscommissie:

Prof, dr. H.G. Schmidt (voorzitter)

Prof. dr. R.H. Kulliten

Prof. dr. P.J. McGrath (Dalhousie University Halifax, Canada)

Prof. dr. H. Philipsen

Prof. dir. L. Shortridge (Pace University New York, U.S.A.)

CIP-GEGEVENS KONINKLIJKE BIBLIOTHEEK, DEN HAAG

Hamers, Johan Peter Herman

Postoperative pain in children: assessment and

intervention / Jahan Peter Herman Hamers. - $\left[S_{.1} \mid\right.$. :

5.17.1. - Ill.

Thesis Aliksuniversiteit Limburg Maastricht. - With ref. -

With summary in Dutch.

ISBN 90-9008680-3

Subject headings: postoperative pain; children

Produktie: Datawyse | Universitaire Pers Maastricht

In de drukkosten van dit proefschrift werd bijgedragen door de Faculteit der Gezondheidswetenschappen, de vakgroep Verplegingswetenschap en Astra Pharmaceutica B.V. 
CHAPTER ॥ Are children given insufficient pain-relieving medication postoperatively?

CHAPTER III The diagnostic process and decision making in nursing, a literature review

CHAPTER IV Factors influencing nurses" pain assessment and intervention in children

CHAPTER $V$ The influence of children's vocal expressions, age, medical diagnosis and information obtained from parents on nurses" pain assessments and decisions regarding interventions

CHAPTER $\mathrm{VI}$ Differences in pain assessment and decisions regarding the administration of analgesics between novices, intermediates and experts in pediatric nursing

CHAPTER VII The effect of paracetamol, fentanyl, and systematic assessments on children's pain following (adeno) tonsillectomy

Summary

Samenvatting

Dankwoord 
${ }^{2}+3$ 


\section{Introduction}


Introduction 


\section{INTRODUCTION}

In the last few decades increasing attention has been paid to (postoperative) pain assessment and pain-relieving intervention in children (McGrath, 1990; Ross Ross, 1988). Until quite recently, the assumption was that infants were insensitive to pain, and certain operations on infants were consequently performed without anesthesia (Swafford \& Allan, 1968). Swafford and Allan reported that only two aut of 60 pediatric patients in a general surgical ward required analgesic drugs, while 26 out of 180 patients admitted to an intensive care unit in a 4-month period received narcotics. They concluded that pediatric patients selidom need medication for the relief of pain after general surgery, because they tolerate discomfort well (Swafford \& Allan, 1968). Anand and Aynsley-Green (1985), however, found that the human preterm neonate when subjected to surgical stress under minimal anesthesia mounts a substantial and prolonged catabolic reaction (i.e., hyperglycaemia, increasing blood lactate and pyruvate levels) in the postoperative period impeding the recovery process.

One reason for assuming that infants do not feel pain and that pain perception increases with age was the immaturity of infants (Elander et al., 1991; Schechter, 1989l. Pain was thought to be dependent on the degree of myelination present; the less the myelination, the less the perception of pain. This assumption, however, is no longer valid. Research has demonstrated that pain can be transmitted by unmyelinated $\mathrm{C}$-fibers and that pain sensation is not dependent on the presence of myelination of sensory fibers (Fields, 1987; Fitzgerald \& Anand, 1994; Melzack \& Wall, 1982). Furthermore, there is evidence that the basic connections in nociceptive and pain pathways are formed before birth (Fitzgerald, 1993). The human neonate has the neuronal apparatus to detect painful stimuli but perhaps in a less organized way than the human adult (Fitzgerald, 1993).

There are a number of other reasons why analgesics were withheld from children. Firstly, it was assumed that children easily become addicted to narcotic analgesics (Eland, 1990; Eland \& Anderson, 1977; McGrath, 1990). A study of adults by Porter and Jick (1980), however, suggested that addiction is extremely rare after hospitalbased use of narcotics; only four out of 11882 patients became addicted to the narcotic analgesics they had been given. There are no studies of children to confirm the assumption that they become addicted more easily (Schechter \& Allan, 1986; Shannon \& Berde, 1989). Therefore, it is according to Schechter (1989) inhumane and incorrect to withhold adequate pain relief from a suffering patient on the theoretical grounds of addiction.

it was also thought that children were sensitive to the respiratory depressant of narcotics, as the assumption was that they metabolize analgesics differently from adults (Eland \& Anderson, 1977; Eland, 1990; Schechter, 1989). It has become clear that older children have essentially adultwike morphine pharmacodynamics (Yaster \& Deshpande, 1988; Yaster \& Maxwell, 1994), whille there is no evidence for increased respiratory depression (Eland, 1990; Schechter, 1989). Newborns and 
small infants do have however, different pharmacokinetics and pharmacodynamics in comparison to older children and adults (Koren \& Jacobsen, 1993).

The conclusion is that several assumptions about pediatric pain and its treatment held in the past have shown to be incorrect. On the basis of recent developments, the American Acaderny of Pediatrics (1987) has recommended that the criteria for analgesila and anesthesia in adults also be used for pediatric patients.

In the literature (Eland, 1990; Gadisch et al., 1988) the assumption is that children's postoperative pain is still undertreated. In the present dissertation we first investigated whether this assumption is based on empirical data. To this end we conducted a critical analysis of the studies that were frequently cited as supporting the assumption (Beyer et al., 1983; Eland \& Anderson, 1977; Mather \& Mackie, 1983; Schechter et al., 1986). Analysis of these and some related studies yielded hardly any verifiable empirical data in support of the assumption of undermedication. The literature did reveal, however, a number of indications that support this assumption. For example, nurses sometimes seem to underestimate children's pain (Wong \& Baker, 1988; Zalon, 1993), while they postpone the administration of medication, or interpret pro re nata (p.r.n.) to be as little as possible (Eland et al., 1991; Mather \& Mackie, 1983). Despite the lack of verifiable empirical data, it can be concluded that it is quite possible that children are sometimes undertreated. The care of children in pain is undoubtedly capable of improvement. This can be achieved by improving the assessment as well as the management of pain, which are both addressed in this dissertation. 


\section{ASSESSMENT}

According to Goldman and Lloyd-Thomas (1991) the undertreatment of pain in children can be attributed in part to the difficulty of assessing and measuring children's pain. This explains why the assessment and measurement of pain in children have been the focus of many studies in the last decade. Since pain is conceptualized as having sensory, behavioral, and cognitive components (Melzack \& Casey, 1968; McGrath \& Unruh, 1987), different strategies can be used to assess and measure pain. Self-report and observational techniques are generally recommended (Haberkern et al., 1991). Numerous studies were conducted to develop and validate self-report measures and scales to observe behavior (for an overview of measures see e.g., Huijer Abu-Saad, 1987, 1990; McGrath, 1987; McGrath \& Unruh, 1987; Wong \& Baker, 1988). Nevertheless, there still is not one universally accepted, wellstandardized measure of pain assessment in children (Schechter, 1989). Furthermore, the routine use of such pain assessment techniques in the clinical setting still needs to be developed (Goldman \& Lloyd-Thomas, 1991; Haberkern et al., 1991). In other words, pain assessment in the clinical setting still depends on the diagnostician.

In hospitals, nurses are generally the ones who spend most time with the patient and as a result are instrumental in the assessment and alleviation of a patient's pain (Davis, 1990). Therefore, factors that influence nurses' decisions to alleviate pain in pediatric patients play a crucial role in the effectiveness of pain relief (Davis, 1990). Unclear still is which factors play a key rale in nurses" decisions on the presence or absence of pain and the need for intervention (Broome \& Slack, 1990).

\section{MANAGEMENT}

Correct pain assessment resulting in the decision to administer the prescribed analgesic does not guarantee adequate pain management. Prescription of inadequate or ineffective analgesics will undoubtedly also lead to undertreatment of pain. Kokke et al. (1993) found differences in prescription of analgesics between physicians. Furthermore, the literature reported that the doses of analgesics prescribed to children are often too small (on a per kilogram basis) (Berde, 1989; Mather \& Mackie, 1983). Moreover, of importance to stress is that the effectiveness of medication in the treatment of postoperative pain in children is also unknown (Mather \& Mackie, 1983). This can be illustrated by postoperative pain management after (adeno)tonsillectomy, which has been reported as a frequently executed (Hoogendoorn, 1988; Kruyt, 1994) and very painful (Bone \& Fell, 1988; Kokke et al., 1993) operation in children. In the last decade, several studies on the efficacy of different analgesics after (adeno)tonsillectomy (Boelen-Van der Loo \& Driessen, 1992; Bone \& Fell, 1988; Dommerby \& Rasmussen, 1984; Gaudreault et al., 1988; Lindgren \& Saarnivaara, 1985; Pasquale et al., 1993; Watters et al., 1988) failed to detect which (dose of) analgesic was adequate for the relief of pain during the first few 
hours after surgery. Although pain assessment may be correct in this case, pain management is probably not effective. These findings stress the importance of studies examining the efficacy of analgesics after surgery.

\section{RESEARCH QUESTIONS}

Undoubtedly, children do experience pain after surgery. Unclear is whether children's postoperative pain is undertreated. A critical analysis of the literature revealed however, inadequate empirical data to support the undertreatment of children's pain. The question of undertreatment of pain is however rather complex and involves factors related to the assessment and management of pain. Since nurses play a major role in assessing and alleviating pain, exploring the factors which influence the nurses" decisions will contribute to a better undertsanding of this phenomen in the practice setting.

In addition to the above, the effective management of pain in children is dependent on the use of appropriate pain protocols which are scientifically tested. To that effect, this dissertation will contribute to the improvement of the care of children who are in postoperative pain by adressing the following questions:

- Do children receive adequate analgesics for postoperative pain relief?

- Which factors influence nurses' acute pain assessments and interventions in children?

- Which pain protocol relieves postoperative pain in children following (adeno)tonsillectomy adequately?

The answers to these questions will be discussed in separate chapters.

The second chapter of this dissertation addresses the question whether children receive sufficient analgesics postoperatively. By means of a critical analysis of the literature the assumption was examined that whether children are undermedicated is based on empirical data.

Chapters $\| I, I V, V$, and $V I$ focus on factors influencing nurses decisions regarding pain assessment and intervention. These four chapters represent five different studies.

Chapter III is a review of the literature on decision-making and factors influencing the decision-making process in general. The aim of this chapter was to summarize what is known about decision-making in nursing.

Chapter IV covers two qualitative studies that explored factors influencing nurses' pain assessments and interventions in children, and to generate hypotheses about the impact of these factors. These hypotheses were to be tested in subsequent studies (see Chapters $V$ and VI).

Chapter $V$ examines the influence of the medical diagnosis, the child's age and expressions, and the parents' role on nurses" pain assessments and the administration of non-narcotic analgesics. 
Chapter VI presents a study that was to answer the question whether qualified pediatric nurses differ from intermediates and novices with regard to postoperative pain assessment and pharmacological interventions in hospitalized children.

Chapter VII deals with the improvement of the treatment of postoperative pain in children following (adeno)tonsillectomy. This chapter describes an intervention study which evaluated the efficacy of two pain protocols currently used in a university hospital. This study examined both the efficacy of a high loading dose $(30-50 \mathrm{mg} / \mathrm{kg})$ of paracetamol combined with a placebo versus paracetamol $(30-50 \mathrm{mg} / \mathrm{kg}) \mathrm{com}$ bined with fentanyl $(1 \mathrm{mcg} / \mathrm{kg})$, and the influence of systematic pain assessments on childrens' pain following (adena) tonsillectomy.

This dissertation concludes with a general discussion (Chapter VIII).

Of importance to note is that the chapters in this dissertation have been published or submitted for publication in different journals. This has the advantage that chapters can be read separately, but a certain amount of overlap is inevitable.

Another consequence of publication in different journals is the use of both American and British English as well as different referencing styles. In this dissertation, however, one uniform style for the references has been used. 


\section{Are children given insufficient pain-relieving medication postoperatively?'}




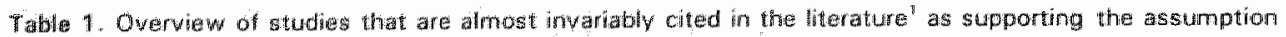

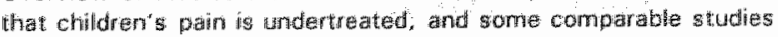

\section{Authoris}

Eand Ariderson $(1977)$

Beycer all. 1983

\section{Mather Backita 19831}

Scheschter at $119.86)$

Fositier \& Hewter $(1990)$

Elander et al. (1991)

Boelerm Van der Loo\& Driessen (1992)

Hander Meslistom 119921

dohnuston et at $11992 j$
Sample

Anethod

25 thifuren $15-8$ years old reason for andsum dithethet kind of diagnoses ranging from lourns to nephrectomy

50 ahildren $10-14$ years old and 50 adults $135-60$ yorrs od reasion for admissian: opon theart sugery

170 children lmean age $=$ years, ad 5 if from 2 hosplitals, reason for admission: different kind of operations, warying from ibdominal to ENT-rurgery

90 children 10.13 years old and 90 adula 118 . 64 years old reasor for fimission:

kernias, appendectomies, burns and fractures

169 children $(4-13$ years old $)$ reason for achnission: operations or diagnoses from which it might be expectied that children experience pain

32 children $10-1$ years old). reason for admission: major surgery le.g., kidney or heart operations?

64 children lage was not defined precisely).

reason for admission:

fradenotonsillactorny

50 children 10.16 years old and 50 achults $\{>16$ years old $\}$ rason for admission:" hezrt siturgery

150 children 44 - 14 years oid raason for admissiom: different diagnases, haspitalized children were randomly selected uncliear, probably reurospective

retrospective lchart review com parison of analgesic prescriptions with admingtration of analgesics

cross-sectional, children were asked whether they were experiencing pain, whille rlata were roth lected regarding analgesic prescription and admuistrathort retrospective (chart reviews), the number of doses of analgesics administerd were indexed

cross-sectional, nulirses ware asked to the chill's pain, furthermare aralgesic prescriptions and administrations were recorded

descriptive study which hnclluded a retrospectiwe chart rewiew and intarviews with 20 parerts and nurses

climical tribl to examine the efficacy of three pain protocols, each of which emploved differemt foloses of analgesics, children were asked to report the pain they experienced

retrospective (chart review)

survey, ctildren were asked about then pain experience fintensity. quality and affectiwe consequences of pain! 
- half of the group of children never were given any medication for pain relief during their hospitalization

- less analgesics were administared than prescribed

- children were given less analgesics than adults

children were given less opioid analgesics than adults

thowever, there were no differences in prescription and administration of nomopioid medication

generally adults were given more analgesios tham children: the younger the patient, the fewer the postoperative analgesic administered

- the uncidence of moderate or severe pain reported by children in the postoperative period was high

- the prescribing patterns of the medical staft were far from tiniform

- the interpretation of the analgesic medication orders by nursing staft often contributed to poor analgesia

- adults with the same pathophysiolagic problems received more nercotics than children; especially in appendectomies, burns and fractures

- there were no differences in the administration of non-narcotics

- nurses gave medication $39 \%$ of the time when medication was a option

- there were no systematic relationships between murses' ratings for pain and the choice to medicate; mediciations were sometimes administered when the nurse rated the pain as 0 ino pain, while they other times with helcd medications despite assignment of the highest possible pain rating

- 7 out of 32 children did not receive any analgesics

- lless than half of the children did receive a narcotic for pain relief

- 1 hour after the operation none of the protocols did relieve children"s pain adequately

- patterns of post-operatiwe analges ic administration differed between children and adults; adiults were given more analgesicks

- mainly infants and patients over 70 years of age were giwen significantly fewer doses of analgesics than patients in other age groups

$57 \%$ of the children reported usual (in contrast to least and worsit pain? pain intensity as moderate or severe, whille half of these group received no analgesia

children who had undergone surgery were much more likely to receiva an analgesic than nonsurgical patients, regardless of similar proportions rem ponting severe pain internsity

almost all of the children reporting pain reported distress because of pain lfeeling "yucky", atraid, sad, angryl, whille more than half of these group reported difficulty in mowing because of the pain

\section{$?$}

yes

(besed on childrein's salf. reportsl

?

$?$

$?$

Yes

(based on children"s selfreports i

$?$

yes

(based on children's sielf. reports) 
A study by Elander and Hellström (1992) confirms the results of the study by Beyer et al.; children are given less analgesics after heart surgery than adults. In the discussion of the results of their study, however. Elander and Hellstrom indicate that this does not mean that pain is relieved insufficiently in children. For, according to these authors, the results could also reflect the postoperative need for pain relief. The aim of the study by Elander et al. (1991) was to gain insight into the types and doses of analgesics administered to infants after major surgery, such as heart and renal surgery. Although the presentation of the results of this study is not very clear, one of the findings is that several children were not given any pain medication at all. But these data do not warrant the conclusion that children are given too little medication either. The pain may have been relieved sufficiently.

To put it briefly, the above-mentioned studies do not answer the question whether children are given insufficient pain medication for adequate postoperative pain relief. These studies do underline the necessity of further research into this issue. The studies by Mather and Mackie (1983), Boelen-Van der Loo and Driessen (1992), and Johnston et al. (1992) are exceptions among the studies in Table 1. The study by Mather and Mackie examined the incidence of postoperative pain in children and the effectiveness of analgesics; the patients were asked whether they felt any pain, and if so, how much. The researchers concluded that the incidence of pain was high. For instance, only $25 \%$ of the children were pain-free on the day of the operation and $40 \%$ complained of moderate to severe pain. The results found by Mather and Mackie (1983) suggest that children are given insufficient pain-relieving medication postoperatively, for $75 \%$ of the children were not pain-free. This study was not confined to one or several types of surgery, however, but included all types of surgery that the researchers came across during their investigation. Unclear is whether it was necessary and/or advisable to alleviate pain completely in all cases. On the other hand, it seems unlikely that it was not possible to relieve pain in $75 \%$ of the children.

Mather and Mackie's (1983) conclusion that patients are given insufficient painrelieving medication does not mean that prescribed medication was not administered, but that the dose or the type of medication was not sufficiently effective. The authors do indicate, however, that the interpretation of the instruction p.r.n. by nurses contributes to the administration of llittle pain medication.

A study by Boelen-Van der Loo and Driessen (1992) examined the effectiveness of three protocols for the relief of pain in children undergoing (adenoltonsillectomy. The three protocols were (I) paracetamal $240 \mathrm{mg}$, (III) paracetarnol $500 \mathrm{mg}$, and (III) paracetamol $500 \mathrm{mg}$ + codeine $10 \mathrm{mg}$ every 4 hours, starting 1 hour before surgery. The children were asked to indicate on the Oucher-scale (Beyer et al., 1993) whether they folt any pain at all as well as pain intensity. This test resulted in scores from $O$ (no pain at all) to 100 (extreme pain). Pain treatment was considered to have insufficient effect if mean pain scores exceeded 30 . One hour after surgery none of the three protocols was effective, 3 and 6 hours after surgery the first protocol still was not sufficiently effective. The conclusion that pain relief one hour after surgery is insufficient is again connected with the dose or type of medication.

Finally, Johnston et al. (1992) assessed the pain experience of randomly selected children in the hospital. Children were asked to rate their worst, usual and least pain intensity (in a 24 hour period) on a 10-point-ladder. The pain intensity scores were 
grouped into four categories: no pain, and mild $(1-3)$, moderate $(4-7)$, and severe 18 10) pain. The results indicated that more than $87 \%$ of children reported having had pain within 24 hours and, of those, $19 \%$ reported their usual pain intensity as se vere. Only $38 \%$ of the childrem had received analgesic medication during this period. Furthermore, children who had undergone surgery were three to fourtimes more likely to have received narcotic analgesic than nonsurgical patients, although similar proportions in both groups reported moderate to severe pain. The authors conclude that children's need for analgesics should be reassessed, as their study indicates that hospitalized children may be experiencing severe levels of pain, even though they do not belong to groups known to have pain, such as surgical patients.

\section{Are children given insufficient analgesics postoperatively?}

There are several indications that less medication is administered to children after surgery than prescribed. Although most physicians assume that the pain experience of 2-year old children closely resembles that of adults, this is usually not reflected in their attitudes to pharmacological pain management policies (Schechter \& Allen, 1986). A study of attitudes among pediatricians, general practitioners, and surgeons showed that surgeons, in particular, are hesitant about prescribing opiates for postoperative pain relief (Schechter \& Allen, 1986). Kolkke et al. (1993) found that caregivers (physicians and nurses) have different expectations concerning pain intensity after surgery. When 71 caregivers were asked to indicate on a Visual Analog Scale (VAS) (Huskisson, 1983), range 0-10, how painful circumcision is. their answers differed widely: according to 19 caregivers this operation is almost painless (VAS score 0-3), while 21 caregivers thought that this intervention is extremely painful (VAS score 7-10). It seems logical that the pain treatment policies of these groups will vary as a result. Physicians who are of the opinion that 'the pain is not so bad" or who are hesitant about prescribing analgesics, are more likely to prescribe pain-relieving medication on a p.r.n. basis.

When analgesics are prescribed on a p.r.n. basis, the final decision whether or not an analgesic should be administered is, in practice, usually taken by nurses. Most indications that children are given insufficient pain rellef are, therefore, related to nurse characteristics, such as attitude and knowledge about pain relief methods. For instance, nurses sometimes say that pain can never be removed completely (Arkesteyn et al., 1990; Burokas, 1985; Gadish et al., 1988) or that a little pain does not matter and is sometimes unavoidable (Hamers et al. . 1993). It is also suggested that nurses (sometimes unjustly) fear the side effects of medication, such as addiction or respiratory depression (Ferrell et al., 1991; Schechter et al., 1986). These results support the finding that nurses postpone the administration of medication prescribed p.r.n. as long as possible (Hamers ett al., 1993; Mather \& Mackie, 1983).

Studies by Beyer et al. (1990), Vlaeyen (1991) and Mclnerney et al. (1993) have demonstrated that subjective pain and expressions of pain are only weakly correlated. This means that the expression of pain probably is not a reliable indicator of subjective pain. Nevertheless, expressions of pain play an important role in the assessment of pain intensity by nurses. According to a study by Hamers et al. 
11994) the child's expression is a deciding factor in the estimation of pain and the administration of analgesics; nurses estimate the pain of a child that expresses its pain vocally as more intense and they indicate that they give an analgesic sooner than to a child that does not express its pain vocally land for instance lies in bed withdrawn). Wallace (1989) and Hamers et al. (1993) report similar findings. These results might indicate that nurses sometimes administer insufficient pain-relieving medication to some children because the pain in these children is underestimated. Finally, as was indicated in the preceding section, several retrospective studies have found that children are given lless pain-relieving medication after certain types of surgery le.g. heart surgery) than adults (Beyer et al., 1983; Eland \& Anderson. 1977; Schechter et al., 1986). The American Academy of Pediatrics (1987) has recently recommended that the criteria for anesthesia and analgesia in adults also be used for children. Assuming that children have the same amount of pain as adults in the same situations it would seem likely on the basis of the above-mentioned studies that pain in children is alleviated insufficiently.

\section{Conclusion}

Clearly presented in the preceding sections is that there are several indications that pain in children is alleviated insufficiently. There are, in particular, indications of insufficient administration of prescribed medication and, to a lesser degree, of inadequate prescription. However, there are hardly any "hard", verifiable empirical data available in support of the assumption that children are given insufficient medication postoperatively. This finding underlines the importance of research into the incidence and prevalence of pain in children.

In spite of the lack of hard empirical data, the above-mentioned indications should be taken seriously. Subsequently, the question arises what measures would be necessary for effective pain relief. This question will be answered in the following section.

\section{Measures for effective pain management}

On the basis of several indications that children are given insufficient pain-relieving medication, different measures that can lead to effective pain relief can be considared.

(1) Insufficient administration of prescribed medication. In brief, three indications. that children are not given sufficient medication (less than prescribed) were mentioned above. First, pain may be assessed incorrectly by nurses; the pain is underestimated and consequently relieved insufficiently. Second, nurses' knowledge about pain and pharmacological pain management does not always seem to be up to date, so that it is not unlikely that pain is relieved insufficiently. Finally, the influence of nurses' attitudes towards especially pharmacological pain management should not be underestimated. Several studies (Elander et al., 1991; Mather \& Mackie, 1983) have shown that nurses postpone the administration of medication prescribed p.r.n. as long as possible. 
To ensure that sufficient prescribed medication is administered, different measures could be taken for all of the above-mentioned indications. For instance, it would be possible to standardize nurses" pain assessments: systematic pain assessment by means of pain rating scales. Refresher courses for nurses in pharmacological pain treatment would be another possibility. Finally, attitudes could be studied more extensively, which would make it possible to determine how attitudes can be changed so as to improve pain relief in children.

These measures have been recommended in the literature before le.g., Burokas, 1985; Ellis, 1988; Ross et al., 1991). A disadvantage of these measures (though they are very important) is that they will only affect certain aspects of pain assessment and intervention by nurses, so that they may not have sufficient effect if they are introduced separately. Moreover, it is impossible to introduce all these interventions and to measure their effects in the short term; refresher courses and attitude research, in particular, are time-consuming.

Nevertheless, there is a measure that will affect all of the above-mentioned points and can be introduced relatively easily, and in a short space of time: 'standard medication". This means that postoperative medication is no longer prescribed on a p.r.n. basis, but becomes standard procedure, e.g. four times a day during the first 24 hours. This recommendation has been made before too (e.g. McCaffery \& Beebe, 1989; McGrath, 1990; McGrath \& Unruh, 1987). Standard administration of analgesics does not leave room for "underestimation" of pain, for it is obligatory to administer medication. Also, the administration of analgesics will not be postponed anymore.

(2) Inadequate prescription. The introduction of standard medication does not guarantee sufficiently effective pain relief, however. As was indicated before, some studies (Boelen-Van der Loo \& Driessen, 1992; Mather \& Mackie, 1983) suggest that prescriptions of medication for children are inadequate. In these cases effective pain relief could be brought about by adaptation of the prescription of medication on the basis of protocols; other analgesics should be prescribed or, if possible the doses should be increased. But before this measure is taken, research should make it absolutely clear after which types of surgery prescriptions are inadequate.

\section{CONCLUSIONS}

This review of the literature leads to the conclusion that there is not enough empirical evidence that children are given too little pain-relieving medication postoperatively. There are sufficient indications that this might be the case, however. Strikingly, most of the indications are connected with nurses" decisions, like the estimation or assessment of pain and the decision whether or not prescribed medication is to be administered.

The results of this review of the literature underline the importance of research into the incidence and prevalence of pain in children. Because there are several indications that pain in children is alleviated insufficiently, certain measures to optimize pain relief are suggested. First, pain assessment by nurses should be standardized. Second, standard prescription of (different doses or types of) postoperative pain 
medication during a fixed period of time is recommended instead of prescription on a p.r.n. basis. Finally, the recommendation is that the effect of these measures be studied, preferably for each type of surgery separately. 


\section{REFERENCES}

American Academy of Pediatrics (1987). Neonatal anesthesia. Pediatrics, $80,446$.

Arkesteyn, S.. Huijer Abu-Saad, H. \& Halfens, R. (1990). De attitude van verpleegkundigen (Nurses" attitudes). Tijoschrift Voor Ziekenveroleging, 100, 396-398.

Beyer, J.E., DieGood, D.E., Ashley, L.C. \& Russell, G.A. (1983). Patterns of postoperative analgesic use with adults and children following cardiac surgery. Pain, 17, 71-81.

Bever, J.E., McGrath, P.J. \& Berde, C.B. 11990/. Discordance between self-report and behavioral pain measures in children aged 3-7 years after surgery. Journal or Pan and Symptom Management, 5, 350-356.

Beyer, J.E. Villarruel, A.M. \& Denyes, M. 11993). The oucher, the new user's manual and technical report. University of Colorado Health Sciences Center, Colorado.

Boelen-Van der Loo, W.J.C. \& Driessen, F.G.W.H.M. (1992). Pijnpreventie en pijnbestrijding bij (adenoltonsillectomie (Prevention and management of pain following (adeo)tonsillectomyl. Nederlands Tijdschrift woor de Geneeskunde, 136, 1409-1413.

Burokas, L. (1985). Factors affecting nurses' decisions to medicate pediatric patients after surgery. Heart \& Lung, 14, 373=379.

Eland, J.M. (1990). Pain in children. Nursing Clinics of North America, 25, 871-884.

Eland, J.M. \& Anderson, J.E. \{1977). The experience of pain in children. In A. Jacox (Ed.). Pain. A source book for nurses and other health professionals. Little Brown, Boston, pp. 453-473.

Elander, G., Lindberg. T. \& Quarnström, B. [1991). Pain relief in infants after major surgery: a descriptive study. Journal of Pediatric Surgery, 26, 128-131.

Elander, G. \& Hellström, G. (1992). Analgesic administration in chilldren and adults following open heart surgery. Scandinawian Journal of Caring Sciences, 6, 17-21.

Ellis, J.A. (1988). Using pain scales to prevent undermedication. Maternal Child Nursing. 13 , $180-182$.

Ferrell, B.R., Eberts, M.T., McCaffery, M. \& Grant, M. (1991). Clinical decision making and pain'. Cancer Nursing, 14, 289-297.

Foster, R.L. \& Hester, N.O. (1990). The relationship between pain ratings and pharmacologic interwentions for children in pain. In: D.C. Tyler \& E.J. Krane. Pediatric pain. Advances in Pain Research and Therapy, 15,31-35. Raven, New York.

Gadish, H.S., Gonzalez, J.L. \& Hayes, J.S, 119881. Factors affecting nurses" decisions to administer pediatric pain medication postoperatively. Journal of Pediatric Nursing, 3, 383-390.

Hamers, J.P.H., Huijer Abu-Saad, H. \& Halfens, R.J.G. 11993). Factoren die verpleegkun digen beinwloeden bij het inschatten van pijn bij kinderen en bij het toepassen van pijnverlichtende interwenties (Factors influencing nurses' pain assessments and pain relleving intervantions in children). Vexpleegkunde, 8, 141-157.

Hamers, J.P.H. Huijer Abu-Saad, H., Van den Hout. M.A. \& Halfens, R.J.G. (1994). Children's vocal expressions, and not medical diagnosis, age or information from parents detertnine nurses " pain assessment and interventions. Abstractbook, pp. 146. Third International Sympasium on Pediatric Pain, Philadelphila.

Huskisson, E.C. (1983). Visual Anolgue scales. In: R. Melzack (Ed.). Pain measurement and assessment. Raven, New York, pp. 33-37.

Johnston, C.C., Abbott, F.V., Gray-Donald, K., Jeans, M.E. (1992). A survey of pain in hospitalized patients aged 4-14 years. Clinical dournal of Pain, 8, 154-163.

Kokke, F.T.M., Van der Heide, D.H. \& Boelen-van der Loo, W.J.C. (1993). Postoperatieve pijnbestrijding in drie Nederlandse ziekenthuizen: een pilotstudie (Postoperative pain management in three Dutch hospitals: a pillot study). Tijdschrift woor Kindergeneeskunde, 61, 48-51.

Mather, L. \& Mackie, J. (1983). The incidence of postoperative pain in children. Pain, 15. $271-282$.

McCaffery. M. \& Beebe, A. 11989). Pain, clinical manual for nursing practice. Mosby, St. Louis. 
McGrath, P.A. (1990). Pain in children. Natwre, assessment, and treatment. Guilford, New York.

McGrath, P.J. \& Unruh, A.M. 11987), Parn in children and adolescents. Elsevier, Amsterdam.

Mclnerney, $M$. Champion, $D$. Horley, $K$., et at. 11993). The limitations of pain severity judgment from observed behavior in children. IASP Abstractbook, pp. 512. 7 th World Congress on Pain, Paris.

Ross, R.S. Bush, J.P., Crumette, B.D. (1991). Factors affecting nurses decisions to adrninister PRN analgesic medication to children after surgery: an analog investigation. Joumal of Pediatric Psycitology, 16, 154-167.

Sichechter, N.L. \& Alen, D. 11986). Physicians" attitudes towards pain in children. Developmental and Behavioral Pediatrics, $7,(6), 350-354$.

Schechter, N.L. Allen, D.A. \& Hanson, K. (1986). Status of pediatric pain control: a comparison of hospital analgesic usage in children and adults. Pediatrics, 77, 11-15.

Vlaeven, J.W.S. 119911. Chronic low back pain. Assessment and treatment from a bohavioral rehabilitation perspective. Swets \& Zeitlinger, Ansterdam.

Wallace, M. P. (1989). Temperament: a variable in children's pain management. Pediatric Nursing, $15,118-121$. 


\section{The diagnostic process and decision-making in nursing a literature review ${ }^{1}$}




\section{SUMMARY}

In clinical practice professional nurses appear to make different judgments regarding particular nursing situations. The purpose of this literature review is to gain insight into the way nurses make decisions related to nursing diagnoses and interventions. Literature on decision-making can be divided into that which focuses on how decisions are made, i.e., information-processing model, and that which focuses on how decisions ought to be made, i.e., mathematical models. Most of the literature about decision-making in nursing in particular appears to focus on the former, specifically on the stages and strategies in the decision-making process and on factors influencing this process. These factors include the problem task (cues), the decision maker (his or her knowledge, experience, personal variability), and discipline. However, to date, most of the research that has been done with regard to these factors has been restricted to the performance between novice and expert. We conclude that further validation of nursing diagnoses is necessary to ensure accuracy in decision-making in nursing. 


\section{INTRODUCTION}

In clinical practice, nurses make decisions all the time. Most of these decisions are related to nursing diagnoses and nursing interventions, and it appears that professional nurses make different judgments regarding specific situations. For example, when two nurses independently enter the hospital room of a crying child, the first nurse may conclude that the child is in pain, while the second nurse may conclude that the child misses his or her family. When two nurses make the same diagnosis, eg, that the child is in pain, the first nurse may decide to give pain medication, and the other may opt for distraction or music therapy. In other words, given the same data, nurses tend to make different diagnoses, and as a reisult, they choose different interventions. For this reason, it is important to gain insight into the way nurses make decisions related to nursing diagnoses and interventions.

The purpose of this literature review is to summarize what is already known about decision-making in nursing. Specifically, we seek answers to the following questions:

- What is decision-making, and how is it defined in general?

- How is the decision making process described in the nursing literature?

- Which factors influence the decision-making process?

- What is the state of the art in research on decision-making in nursing, especially that related to diagnoses and interventions?

A literature search was first conducted using a computer search. In addition, experts on decision-making were then called upon to recommend extra reading material. Finally, an off-line search was conducted using Med-Line (CD-ROM, 1983-8/1992), and references in books and articles were studied.

\section{What is decision-making?}

While studying the literature, it appears that there is no unequivocal definition of "decision-making" and that there is no consensus regarding the terminology that should be used. In different texts different terms are used. Examples of this are: "(clinical) decision-making" (Weinstein \& Fineberg, 1980; Wright \& Macadam, 19791, "(clinical) judgment" (Elstein, 1976; Feinstein, 1967), "(clinical) inference" (Hammond, 1964; Hammond et al, 1966a, 1966b). "(diagnostic) (clinical) (human) reasoning" (Evans, 1990; Mayer \& Revlin, 1978), and "(medical) (human) problemsolving" (Elstein et al., 1978; Newell \& Simon, 1972). Sometimes, different terms are used synonymously. For example, Kelly $(1964$, p.315) defined inference as "a conclusion or judgment drawn from data", thus using "inference" as a synonym for "judgment". De Graaff (1989) characterizes this situation as "terminological chaos". Nevertheless, attempts have been made to reduce this lack of conceptual clarity. First, some of the above-mentioned concepts point both to the process of malking decisions and to the outcome of such processes. For example, the term "(clinical) 
judgment" is used to describe the process of decision-making (or judgment) as well as the outcome of such a process, the (clinicall judgment, eg, a diagnosis.

Second, and more mportant, in the psychological literature, the different terms refer to different research paradigms and models (Elstein et al., 1978). Cutler (1979) distinguighes clinical versus mathematical methods for problem-solving; Elstein \& Bordage (1988) distinguish two major approaches in the psychology of clinical reasoning: the problem-solving approach and the judgment approach; and Evans 119901 distinguishes deductive from statistical theories of reasoning. These classifications are somewhat similar in that they emphasize the difference between how decisions are made; ie, information-processing model, and how decisions ought to be made, ie, mathematical models.

Atthough models on haw decisions ought to be made provide accuracy and consistency in managing complex and multidimensional data, their applicability to nursing remains questionable (Hammond, 1964: Hammond et al., 1966a, 1966b; Kelly. 1964). In view of that, this article will focus on how decisions are actually made and not on how they ought to be made.

\section{Information-processing model}

In the informatian-processing model, a thuman being is viewed as an informationprocessing system interacting with a problem task. The memory of the informationprocessing system is said to consist of two parts, namely, a short-term memory and a long-term memary.

Simply represented, short-term memory can be compared to a control center in which a limited amount of information (svmbols) is held, normally no more than five to seven chunks (Simon 1974). Chunks are recognizable stimulus patterns that are not innate but develop through learning (Newell \& Simon, 1972).

Long-term memory can be compared to a large library in which knowledge, both factual (semantic) and experiential (episodic), is stored (Carnevali, 1984) and for which mo evidence exists that it can be filled in a lifetime (Newell \& Simon, 1972). Thus, in lang-term memory, knowledge and past experience are stored that can be retrieved by short-term memory. All processes, namely take their inputs from shortterm memory and leave their outputs in short-term memory (Newell \& Siman, 1972). In addition, the information-processing model distinguishes four components or stages in the reasoning process: (1) cue acquisition, (2) hypothesis generation, (3) cue interpretation, and (4) hypothesis evaluation (Elstein et al., 1978; Elstein \& Bordage, 19881.

In the first stage (cue acquisition), data are collected. Information about cues can be obtained by a variety of methods. In the second stage (hypothesis generation), hypotheses are generated from memory based on only a few cues. The number of hypotheses that is considered simultaneously is usually four or five and rarely exceeds six or seven (Elstein et al., 1978; Elstein \& Bordage, 1988). During the third stage (cue interpretation), cues are interpreted on a three-point scale. Cues are interpreted as tending to confirm or refute a hypothesis or as noncontributory (Elstein \& Bordage, 1988). Finally, in the fourth stage (hypothesis evaluation), the clinician must reach a diagnostic judgment. In many diagnostic problems, reasoning in this evaluation phase can be represented as a process of adding up the pros and 
cons for each alternative and choosing the one favored by the preponderance of the evidence (Elstein \& Bordage, 1988).

\section{The decision-making process in nursing}

A careful review of the literature shows that a number of different authors have dealt with the subject of decision-making in nursing. Most of them seem to focus their attention on the information-processing model in that they present processes in terms of components or stages that are comparable to the one mentioned above. Examples of this are texts on decision-making by Bailey and Claus (1975), Vitale et al. (1978). Ford et al. (1979) and Carnevali (1984). However, some of these author's (Bailey \& Claus, 1975; Carnevali, 1984) use more than four stages in describing the decision-making process (Table 1).

Table 1. Components in a reasoning process according to two different groups af researchors

Elstein, Shuman \& Sprafika (11978)

Cue acquisition

Hypothesis generation

Cue interpretation

Hypothesis evatuation
Carnevali (1984)

Pre encounter data

Entry to the data search field and shaping direction of data gathering

Coalescing of cues into clusters or chunks

Activating possible diagnostic explanations (diag nostic hypothesis)

Hypothesis and data-directed search of the data field

Testing diagnostic hypothesis for goodness of fit

Diagnosis

For example, stages one, two and three, as described by Carnevali (1984) are comparable with stage one as described by Elstein et al. (1978). In fact, Carnevali"s work is a further elaboration of the four stages developed by Elstein and colleagues, which end with the nursing diagnostic phase.

Table 2. Components of the nursing process according to three different growps of ros archers.

Litue \& Carnevall $(1976)$

Assessment

Diagnosis

Prescription

Implementation

Evaluation

\author{
Assessing \\ Planining \\ Implementing \\ Evaluating
}

Yura \& Wath (1978, 1988 )
Carpenito $(1983)$

Assessmerts

Problem ldisntification

Planninirug

Intervention

Exaluation

Other authors describe the decision-making process as a conclusion from data as well as the decisions made on the basis of this conclusion. The problem solving process described by Bailey and Claus (1975) is an example of this. Another example, and also a particular elaboration of this, is the nursing process. The nursing process is a problem-solving process that is presented in terms of several stages and 
components. Yet, the term "nursing process" means different things to different authors (Stevens, 1984). In the literature, different authors use a different number of stages and a different terminology in their description of the nursing process. As an illustration, the stages of the nursing process as described by Little and Carnevali 11976), Yura and Walsh (1978, 1988), and Carpenito (1983) are presented in Table 2. Other examples of different stages in the mursing process are summarized by Bulechek and McCloskey (1985)..

In the rursing process, the concept of nursing diagnosis is critical (McFarland, 1989). Several authors (Carpenito, 1983; Gordon, 1987 ) point to the distinction between diagnosis as the process of problem-solving and diagnosis as the outcome of this process. This differentiation is similar to the one mentioned earlier between decision, judgment, and inference with the final stage in the process being a diagnosis (or clinical fudgment). The components of the diagnostic process according to Gordon (1987) again are comparable with the one mentioned by Elstein et al. (1978) and include (1) collecting information, (2) interpreting the information, (3) clustering the information, and (4) naming the cluster. In fact, Gordon's stages are a translation of the stages of Elstein and colleagues. Like the nursing process the diagnostic process is not unique to nursing.

\section{Factors influencing the decision-making process}

In the literature different factors are mentioned as influencing the decision-making process. These factors are rellated to the problem task, the information-processing system or the decision maker, and the discipline. These factors will be discussed in succession.

\section{Problem task}

As mentioned earlier, in decision-making the decision maker is faced with a problem task that can be a diagnostic task. The complexity of this task infiuences decisionmaking (Corcoran, 1986); the more difficult the task, the more difficult the decisionmaking is and the higher the likelihood that an incorrect decision will be made. According to Tanner (1984), the determinants of task complexity include (1) the number of cues: the greater the number of cues represented, the more complex the task; (2) dependability: the greater the dependability of the available cues, the fewer the number of cues needed and the lless the cognitive strain; (3) redundancy: the greater the redundancy, the easier the task; (4) overlapping cues: the more the cues overlap in differential diagnoses, the more complex the task will be: and (5) irreducible uncertainty: the more irreducible the uncertainty, the more complex the task will be.

According to Gordon $(1987)$, the reliability and validity of data are important in the processing of cues. Of special significance to validity is the relevance of data. The addition of irrelevant information to relevant cues can increase the number of errors made, as well as make the processing of the task more difficult (Gordon, 1980). 


\section{Decision maker}

Characteristics of the information-processing system of of the decision maker may also influence the decision making process. In the literature, three factors are often mentioned: experience, knowledge, and personal variability.

\section{Experience}

Experience is a major factor influencing the decision-making process. This concept has a direct link with the information-processing model. Past experiences are stored in the long-term memory, and these experiences can influence the decision-making process in a positive manner by increasing its accuracy. In particular, they have impact on the hypothesis-generating stage by increasing the ability to recognize significant patterns (Draper, 1986), ie, the "chunking of familiar stimuli" (Larkin et al., 1980). Experience permits the clinician to use more complex chunks in short-term memory (Carnevali, 1984). Experience, among other things, distinguishes the expert from the novice. Thus, experience can be regarded as an important determinant of expertise (Benner, 1982; Corcoran, 1986).

However, experience can also bias the decision-making process, especially in the assessment of probabilities. Tanner (1984) distinguishes three main biases: (1) frequency of occurrence in experience influences the diagnostic process by altering the diagnostic possibilities considerd, (2) recency of experience refers to the tendency to oversample more recent experiences and to undersample or ignore less recent experiences, and (3) profoundness of memory refers to the tendency to oversample events that are dramatic.

\section{Knowledge}

Like experience, knowledge is obviously a major factor that influences the decisionmaking process. Knowledge is also stored in the long-term memory and is a necessary condition for all stages in decision-making. As Carnevali (1984, p.32) states: "one cannot diagnose what one does not recognize or understand". In her study, Corcoran 11986 found, among other things, that lack of knowledge leads to incomplete and erroneous pians (diagnosis and interventions). Knowledge is another significant factor that distinguishes the novice from the expert (Larkin et al., 1980; Tanner, 1984). It is not only the number of facts but also the cross-indexed storage of knowledge that is a characteristic of an expert. The novice may hold isolated bits of information but lack the ciross-indexing and multiple categorization scheme (Tanner, " 984 ).

\section{Personal variability}

Personal variability is the last factor related to the information-processing system or decision maker. It is a collective term for characteristics that vary across decision makers, such as interpersonal skills, and that include communication and perception. Also meant are factors such as the decision maker's physical, mental, and emotional state at the time of the diagnostic reasoning (Carnevali 1984). Prejudice and values 
are included as well and may be related to age, sex, kind of illness, ethnic background, socioeconomic class or religion. If left unexplored, such prejudice may dramatically influence the reasoning process, even to the extent that standards of care may suffer (Wootley, 1990 ).

Personal variability may influence all stages in the decision-making process. In the first stage (cue acquisition), "excessive data-collection may impede the process of clinical inference by overloading the system's capacity" (Elstein \& Bordage, 1988 , p. 118). After all, the capacity of shortterm memory is limited. Collecting too much data may impair the clinician's ability to sort out and focus upon the relevant variables (Elstein \& Bordage, 1988), or, as Evans (1990, p.20) states "overload will lead to errors". In the next stage, hypotheses are generated. Although early hypotheses are essential, they can be misleading. They may direct attention to irrelevant features of the problem, cause the cllinician to engage in a search for inconsequential cues that would otherwise be ignored, or lead the clinician to refrain from a useful search of cues that would otherwise be collected (Elstein \& Bordage, 1988). In the final stages, cue interpretation and hypothesis evaluation, cues are interpreted as tending to confirm or refute a hypothesis or as noncontributory. A factor influencing the decision-making process in these stages is the overemphasis placed on positive findings. Data is usually interpreted and colored by the clinician. "The data best remembered tend to be those that fit the hypotheses generated" (Elstein \& Bordage, $1988, p .116)$. The mast common error in cue interpretation is to assign positive (confirmatory) weight to noncontributory findings (Elstein et al., 1978).

\section{Discipline}

As already mentioned, different authors state that the decision-making process is similar in different professions, although its focus can differ. In this respect, discipline has a major impact on the decision-making process. Here, the concept of discipline points to an isolated body of knowledge (Huijer Abu-Saad, 1990, 1991). Examples of professions with different disciplines are medicine and nursing. Medicine and nursing differ in their bady of knowledge and so does their view on the state of patients. It follows that their judgments and decisions will also differ, at least in different domains. In short, can be stated that discipline demarcates the domain in which decisions are made.

Even whth a discipline subspecialty can influence the decision-making process. In a study in the domain of medicine by Kassirer and Gorry (1978), six expert clinicians were selected to diagnose a case of a patient with a renal problem. Four clinicians were specialized in nephrology, one in gastroenterology, and one in cardiology. The nephrologists gave the correct diagnosis earlier than the two physicians who did not have expertise in the patient's IIness. Kassirer and Gorry (1978) presumed that this could be related to their fleld of chinical expertise.

Finally, within a discipline, different theories can affect the decision making process. These theories view and describe the real world in different ways, thus having an impact on the decisions and judgments made by their users. 


\section{Overview of factors influencing the decision-making process}

From the literature, it can be concluded that different factors are mentioned that influence the decision-making process and, as a result, the outcome of this process. Factors mentioned in the literature were related to the problem task (diagnostic task). the decision maker, and the discipline. These factors can best be presented in a modell (Figure 1).

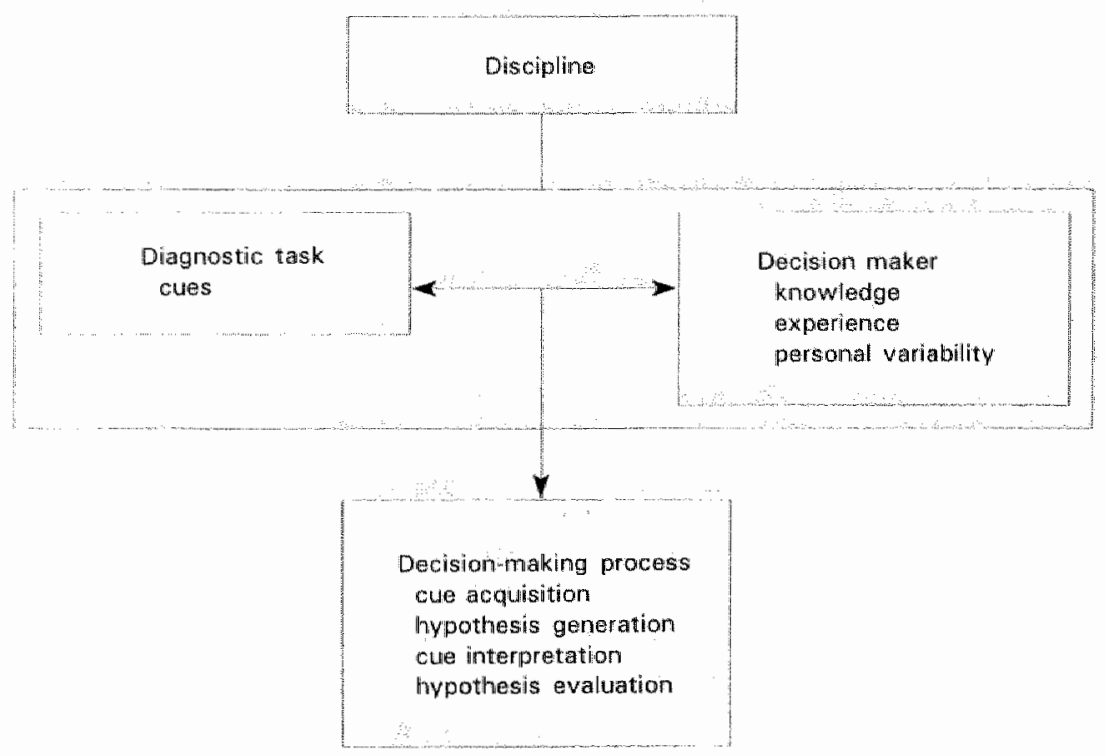

Figure 1. A model of factors influencing the decision-making proctsos

As can be seen in Figure 1, the discipline sets limits on the domain of decisionmaking. It demarcates the domain in which decisions are made. For example, in the discipline of nursing, decisions are directed towards caring, rather than curing. As proposed by the information-processing model, there is an interaction between the decision maker (information-processing system) and the problem task (diagnostic task). As is clear from Figure 1, the outcome of the decision-making process is a function of this interaction. This is further illustrated in the following example: task complexity (determined by characteristics of cues) influences the decision-making pracess and is also dependent on the decision maker's knowledge and experience. An easy task for an experienced decision maker may be a complex task for a decision maker who is a novice. On the other hand, excessive data collection (as a factor of personal variability) may increase the complexity of a task, which in turn influences the decision-making process. 


\section{Research on decision-making in nursing}

As has already often been stated (Corcoran, 1986; Gordon, 1987), little research has been done on decision-making processes in nursing. After the studies of Hammond and colleagues in the 1960s 1 Hammond, 1964; Hammond et al., 1966a, $1966 \mathrm{~b})$, no research was conducted for a period of almost 20 years! Since the early eighties, however, mew studies have been done, most of which focus on how decisions are made and rely either on the information-processing model (Corcoran, 1986, Tanner et al., 1987 ) or on intuition in decision-making (Benner \& Tanner, 1987; Rew, 1988). The different studies in the discipline of nursing are illustrated below. Research on how decisions are made is usually based on the information-processing model. In this domain, two interrelated objects of study can be distinguished: (1) the stages in the decision-making process and the strategies used in the several stages and (2) factors influencing the decision-making process.

When studies focus on stages and strategies in the decision-making process, the purpose is to identify stages in decision-making processes as it relates to nursing. More specifically, these studies examine if whether or not the stages of cue acquisition, hypothesis generation, cue interpretation, and hypothesis evaluation, as proposed by the information-processing model, can be generalized to the discipline of nursing. Furthermore, the purpose is to identify strategies nurses use in the different stages of the decision-making process. The studies by Gordon (1980), Corcoran (1986). Westfall et al. (1986), Padrick et al. (1987), Tanner et all. (1987) and Itano (1989) focus on this. It is worth mentioning that the studies by Westfall et al. (1986) Padrick et al. (1987), and Tanner et all. (1987) are part of one research project. In this project, 43 subjects had to make decisions based on patient simulations consisting of a written case (change-of-shift report), a short videotaped scene, and a set of health data for responding to subjects" specific requests for additional information. The subjects were instructed to think aloud and the verbalizations were tape recorded. In other studies, similar methods (verbal protocol or thinking aloud) were used. However, the content of the simulations differed. On the other hand, Gordon (1980) and Corcoran (1986) used only written cases, and Itano (1989) used actual patients instead of simulations. In addition to the tape recordings, subjects were observed during their task.

The overall conclusion of the different studies is that the stages in the decisionmaking process, as already described, can also be found in nursing. Indeed, as stated earlier (Field, 1987; Woolley, 1990/, decision-making is not unique to nursing. Some results confirm other facts proposed by the information-processing model. For example, adding a lot of irrelevant information reduces accuracy (Gordon, 1980), and oversimplification leads to errors (Corcoran, 1986). It can be said that the results of the studies mentioned above led to confirmation of facts that were already known from research in other disciplines, such as medicine.

In a study of Grobe et al. (1991), seven experienced nurses were instructed to verbalize all of their thoughts during a planning task based on written cases. The authors found an indication that the subjects seem to consider problems and interventions concurrently, rather than as distinct linear steps in a process. 
The second area of research deals with factors influencing clinical decision making. Research on factors influencing decision processes in nursing is mainly focused on the factors of knowledge and experience. As already mentioned. knowledge and experience are properties that distinguish the novice from the expert. For this reason, most studies focus on the differences between the novice and the expert in decisionmaking LCorcoran, 1986; Itano, 1989; Padrick et al., 1987; Tanner et al., 1987; Westfall et al., 1986). Novices and experts then are compared on performance in the different stages of the decision-making process and on accuracy in their decisions. It is assumed that the expert will do the better job. Results have been reported that confirm and refute this assumption. For example, confirmation is the fact that ltano's (1989) study suggested that experienced nurses collect more cues than students. The fact that Westfall et al. (1986) found no difference in the number of hypotheses generated refutes the assumption. Finally, although it is expected that experts acquire more systematic data and make more accurate decisions, only trends in differ. ent studies were found (Corcoran, 1986; Tanner et al., 1987; Westfall et al., 1986). This finding is not so unusual for the sample sizes in the studies mentioned are very small: 11 subjects divided into 6 experts and 5 novices (Corcoran, 1986), 43 subjects divided into 15 beginning junior students, 13 beginning senior students, and 15 staff nurses (Tanner et al., 1987; Westfall et al., 1986), and 26 subjects divided into 13 senior baccialaureate student nurses (BSN) and 13 highly skilled judgment makers (ltano, 1989). The small sample size no doubt has an impact on the statistical power of the studies.

Also of interest is the comparison that several studies (Gordon, 1980; Tanner et al., 1987 ) make on the accuracy of the decision (cq. diagnosis). As mentioned earlier, measuring such a concept is very difficult. First, one does not know what an accurate decision is, and second, there is no consensus yet on the nursing diagnoses found in the literature. Moreover, reliable and valid correlations between cues and nursing diagnoses are lacking. Although researchers recognize this problem (Corcoran, 1986; Gordon, 1980; Lumney, 1992), they still make attempts to measure it. Distinguishing between such categories as "consistent with the consultant's plan", "apprapriate, but not consistent with the consultant's plan", and "incomplete and erroneous" (Corcoran, 1986); measuring the extent to which nurses identify surgical implications instead of nursing diagnoses (Gordon, 1980); or measuring the concept of accuracy on a seven-point scale (Lunnev, 1992) are examples of this. In such cases one may question the validity of the measurement.

Although research on influencing factors has not been done extensively, it is not restricted to studies that compare novices and experts. Sanford et al. (1992), in a secondary analysis, found no differences in clinical judgment abilities in new BSN and non-BSN graduates. Luker and Kenrick (1992) investigated what kind of knowledge nurses rely on in decision making and appeared to be experiential or practicebased knowledge, rather than scientific or research-based knowledge. Although this finding is important, it is not remarkable and is often mentioned in the nursing literature (Hamers et al., 1991; Meleis, 1985). Davitz and Davitz (1980) studied and described, among other things, how nurses in their inferences and judgments on patient suffering, pain, and distress are influenced by such patients characteristics as age, sex, socioeconomic class, and ethnic and religious background. Their results showed that the patients' social class made a difference in the degree of physical 
pain and psychological distress nurses believed that patients experienced. More precisely, lower class patients; both male and femalle, were judged to suffer more pain with the same illness or injury than did middle- or upper-class patients IDavitz \& Davitz, 19801. However, it must be said that the research methods were seldom described by the authors, and so cannot be verified. This leads one to question the validity and reliability of their findings:

Finally, studies on how decisions are made can be found that focus on the role of intuition in decision-making. Benner and Tanner (1987) define intuition as understandirig without a rationale. In the literature, however, different definitions of intuition are used, making it difficult to compare the results of one intuitive reasoning study to another (Radwin, 1990). Intuitive judgment distinguishes the expert from the novice (Benner, 1982; Rew, 1988). The expert no longer relies on an analytic principle, (eg, guidelines) to connect her/his understanding of the situation to an appropriate action (Benner, 1982). The process has become internalized and her/his actions appear to the observer to be intuitive (Field, 1987). Intuition is then seen as an unconscious process of decision-making.

This description of intuition is closely related to research methods used in decisionmaking research. In most studies subjects must make decisions based on simulations or written cases. They are asked to think aloud or are interviewed and, as a result, sometimes they are not able to say what some of their decisions are based on. For example, some just say "because it felt right; it looked goad". An illustration follows: "I was on nights. The patient was not my patient but I went into the room. I knew that the patient was going sour at that point, and $\mid$ elected to call a code. The patient had not stopped breathing, his pulses were still there, but as I told a nurse colleague on the way home, 'l could have bet my last paycheck that he was going to arrest" (Benner \& Tanner, 1987, p.29).

The magic of words is, that when we are unable to explain a phenomen, we sometimes find a name for it, such as intuition (Larkin et al., 1980). However, behind such words usually lies a reality we must discover if we are to understand expert performance. In that respect, research on intuition is still premature, because it is not clear what the reality behind intuition is. In this sense, it is a kind of magic. Larkin et al. (1980) propose the capacity to use pattern-indexed schemata as a large part of what is called intuition. According to Rogers (1983), the failure to study the process of knowing and understanding that underlies practice precludes an adequate description of clinical reasoning, which, in turn, prevents the development of a methodology for systematically improving it.

However, it can be said that the intuitive approach offers insight that may complement the information-processing approach (Field, 1987). Intuitive knowledge and analytic reasoning are not mutually exclusive; they can, and often do, complement each other (Benner \& Tanner, 1987). Benner's descriptions of novices and experts in the study by Itano (1989) may be an example of this. 


\section{DISCUSSION}

In the beginning of this article it is stated that professional nurses appear to make different judgments regarding particular nursing situations. For example, two nurses independently enter the hospital room of a crying child. Nurse one concludes that the child is in pain, and nurse two concludes that the child misses his or her family. When two nurses make the same diagnosis, eg, that the child is in pain, the first nurse may decide to give pain medication, and the other may opt for distraction or music therapy. In other words, when two nurses are confronted with the same patient situation, they often make different diagnoses.

Assuming that it is desirable that nurses, confronted with the same situation, make the same decisions, it is important to get insight into the way decisions are made. This literature review has increased that insight. Based on this study some possible explanations can be given for the fact that nurses in the example make different decisions.

An important explanation could be the complexity of the problem-task. In the exam ple the complexity, among other things, is determined by overlapping cues. For example, crying is related to more than one nursing diagnosis eg, pain, fear and homesickness.

Furthermore, nurse' characteristics may play an important role. Differences in level of education can influence the decision-making. Nurses who are specialized in pediatric nursing possibly have more knowledge on pain symptoms in children, than general nurses.

Nurses' experience may also play a role. A nurse who has recently cared for children who were homesick, may sooner make that dagnosis. Finally, personal variability could have influenced the decisions made. For example, the attitude of a nurse could be such that she chooses to postpone the distribution of medications to children, and for this reason she would select an intervention that does not involve the administration of medication.

Based on the conclusions drawn in this review several implications for further research can be emphasized. In addition to the need for further studies an decisionmaking in nursing involving sufficient sample sizes, research in the future should be directed towards factors that influence the decision making process. Of special interest would be studies focusing on factors related to particular nursing diagnoses. Further validation of nursing diagnoses would not only be of great interest but a must for ensuring accuracy in decision-making in nursing.

Of course, these implications have not only theoretical relevance but also practical relevance. The validation of nursing diagnoses and knowledge about factors influencing decision-making will also improve nursing care as a result of promoting greater consensus in making diagnoses with the same data. After all, the administration of pain medication to a patient who is in pain, for example, should not have to be dependent on the nurse who is caring for him at the moment. Finally, nurses and nursing students should not only be taught how decisions are made using the information processing model but also made aware of factors like excessive data collection, whilch can bias decisions. 


\section{REFERENCES}

Bailey, J.T. \& Claus, K.E. (1975). Decision making in mursing. Tools for change. Mosby. St. Louis.

Benner, P. 119821. From novice to expert. American Journal of Nursing, 82, 402-408.

Benner, $P . \&$ Tanner, $C$. (1987). Clinical judgment: how expert nurses use intuition. Americian Jourial of Nursing, 87, 23-31

Bulachek, G.M. M Mcloskey, J.C. (1985). Nursing diagnosis and intervention. In: G.M. Bulechek \& J.C. Mccloskey (Edsh. Nursing interventions. Treatments for nursing diagnoses. Saunders, Philadelphia, pp. 1-18.

Carneval, D.L. (1984). The diagnostic reasoning process. In." D.L. Carnevali, P.H. Mitchell, N.F. Woods \& C.A. Tannar (Eds.). Diagnostic reasoning in nursing. Lippincott, Philadelphia, pp. 2556.

Carpenito, Lu. (Ed.) (1983). Nursing diagnosis. Application to clinical practice. Lippincott, Philadolphia.

Corcoran, S.A. (1986). Task complexity and nursing expertise as factors in decision making. Nursing Research, 35, 107-112.

Cutler, P. (1979). The problem-solving process (chapter 1-5). In: P. Cutler (Ed.). Problem solving in clintcal medicine. Williams \& Wilkins, Baltimore.

Davitz, L.L. Davitz, J.R. 119801. Nurses responses to patients' suffering. Springer, New York.

De Graaff, E. (1989). Simulation of initial medical problem-solving. Thesis, Haarlem.

Draper, P. (1986). Any use for an American import? Nursing Times, jar. 8, 37-39.

Elsteini, A.S. (1976). Chinical Judgment: Psychologica! Research and Medical Practice. Science, 194, 696-700.

Elstein, A.S., Shulman, L.S. \& Sprafka, S.A. (1978). Medical problem solving. An analysis of chinical reasoning. Harvard University Press, Cambridge.

Elstein, A.S. \& Bordage, G. (1988). Psychology of clinical reasoning. In: J. Dowie \& A. Elstein (Eds.).

Professional judgment. A reader in clinical decision making. University Press, Cambridge, pp. 109-129.

Evans, J.St.B.T. (1990). Bias in human reasaning. Causes and consequences. Lawrence Erlbaum, Hove.

Feinstein, A.R. (1967). Clinical judgrnent. Williams \& Willkins, Baltimore.

Field, P.A. [1987\}. The impact of nursing theory on the clinical decision making process. Journal of Advanced Nursing. 12, 563-571.

Ford, J.A.G., Trygstad Durfand, L.N. B. Nelms, B.C. (1979). Applied decision making for nurses. Mosby, St. Louis.

Gordon, M. (11980). Predictive strategies in diagnostic tasks. Nursing Research, 29, 39-45.

Gordon, M. (1987). Nursing diagnosis, process and application. McGraw-Hill, New York.

Grobe, S.J., Drew, J.A. \& Fonteyn, M.E. 119911. A descriptive analysis of experienced nurses' clinical rasoning during a planning task. Pesearch in Nursing \& Health, 14,305-314.

Hamers, J., Biruggen, H. van der \& Halfens, R. 11991). Tracheotomie, het KENTRAinstrument (Tracheostomy, the kentra-instrument/. Verpleegkunde, 6, 11.19.

Hammond, K.R. (11964). An approach to the study of clinical inference in nursing. Part II. Nursing Research, 13, 315-319.

Hammond, K.R., Kelly, K.J., Schneider, R.J. \& Vancini, M. (1966a). Clinical inference in nursing. Analyzing cognitive tasks representative of nursing problems. Nursing Research, 15, 134. 138.

Hammond, K.R., Kelly, K.J., Schneider, R.J. \& Vancini, M. 11966b). Clinical inference in nursing. Infiormation units used. Nursing Research, 15, 236-243.

Huijer Abu-Saad, H. (11990). Verplegingswetenschap en de verpleegkundige praktijk. Een onderlinge relatie (Nursing science and nursing practice. A mutual relationshipl. Rijksuniversiteit Limburg, Maastricht. 
Huijer Abu-Saad; H. 11991). Verplegingswetenschap en de verpleegkundige praktik; een onderlinge relatie (Nursing Science and nursing practice. A mutual relationship). Verpleegkunde, 5. $181-190$.

(tano, J.K. (1989). A comparison of the clinical judgment process in experienced registered nurses and student nurses. Journal of Nursing Education, $28,120-126$.

Kassirer, J.P. \& Gorry, G.A. (1978). Clinical problem solving: a behavioral analysis. Annats of Internal Medicine, 89, 245-255.

Kelly, K.J. (1964). An approach to the study of clinical inflerence in nursing. Part I \& 131. Nursing Research, 13, 314-315, 319-322.

Larkin, J., McDermott, J., Simon, D.P. \& Simon, H.A. (1980). Expert and novice performance in solving physics problems. Science, 208, 1335-1343.

Little, D.E. \& Carnevali, D.L. (1976). Nursing care planning. Lippincott, Philadelphia.

Luker, K.A. \& Kenrick, M. 11992). An exploratory study of the sources of influence on the clinical decisions of community nurses. Journal of Advanced Nursing, 17, 457-466.

Lunney, M. (1992). Divergent productive thinking factors and accuracy of nursing diagnosess. Research in Nursing \& Health, 15, 303-311.

Mayer, R.E. \& Rewlin, R. (1978). An information processing framework for research on human reasoning. In: R. Revlin \& R. E. Mayer IEds.h. Hiuman reasaning. Wiley, New York.

McFarland, G.K. (1989). Nursing Diagnosis: The critical link in the nursing process. ln: G.K. McFarland \& E.A. McFarlane (Eds.). Nursing diagnosis \& intervention. Planning for patient care. Mosby, St. Louis, pp. 10-26.

Meleis, A.1. (1985). Theoretical nursing: development \& progress. Lippincott, Philadelphia.

Newell, A. \& Simon, H.A. 119721. Human problem solving. Prentice-Hall, Englewood Cliffs.

Padrick, K.P., Tanner, C.A., Putzier, D.J. \& Westfall, U.A. 11987). Hypothesis evaluation: a component of diagnostic reasoning. In: A.M. McLane (Ed.). Classification of nursing diagnoses. Proceedings of the seventh conference. Mosby, St. Louis, pp. 299-305.

Radwin. L.E. (1990). Research on diagnastic reasoning in nursing. Nursing Diagnosis, 1, 70-77.

Rew, L. (1988). Intuition in decision-making. Image: Journal of Nursing Schalarship, 20. $150-154$.

Rogers, J.C. (1983). Clinical reasoning: The ethics, science and art. The American Journal of Occupational Therapy, 37,601-616.

Sanford, M. Genrich, S. \& Nowotny, M. (1992). A study to determine the difference in clinical judgment abilities between BSN and non-BSN graduiates. Journal of Nursing Education, 37 . 70-74.

Simon, H.A. (1974). How big is a chunk? Science, 183, $482-488$.

Stevens, B.J. (1984). Nursing theory. Analysis, application, evaluation. Litte, Brown \& Company. Boston.

Tanner, C.A. 1984). Factors influencing the diagnostic process. In: D.L. Carnevali, P.H. Mitchell, N.F. Woods \& C.A. Tanner (Eds.). Diagnostic reasoning in nursing. Lippincott, Philadolphia, pp. 61 . 82.

Tanner, C.A., Padrick, K.P., Westfall, U.A. \& Putzier, D.J. (1987). Diagnostic reasoning strategies of nurses and nursing students. Nursing Research, 36, 358-363.

Vitale, B.A., Lattemer, N.S. \& Nugent, P.M. 11978). A problem solving approach to mursing care plans. Mosby, St. Louis.

Weinstein, M.C. \& Fineberg, H.V. (Eds.l(1980). Clinical decision analysis. Saunders, Phillaclelphia.

Westfall, U.E., Tanner, C.A., Putzier, D. \& Padrick, K.P. (1986). Actiwating clinical inferences A component of diagnostic reasoning in nursing. Research in Nursing \& Hea/th, 9, 269-277.

Woolley, N. (1990). Nursing diagnosis: exploring the factors which may influence the reasoning process. Journal of Advanced Nursing, 15, $110 \mathrm{~m} 117$.

Wright, H.J. \& Macadam, D.B. (1979|. Clinical thinking and practice. Diagnousis and decision in patient care. Churchill Liwingstone, Edinburgh.

Yura, H. \& Walsh, M.B. 11978). The nursing process: assessing, planning, implementing, evaluating. Appleton Century Crofts, New York. 
Vura, H. Watsh, M.B. 1988). The nursing process: assessing, planning, implementing. evaluating. Appleton \& Lange. Norwalk. 


\section{Factors influencing nurses' pain assessment and intervention in children'}

"Reprinted with permission from: Hamers, J.P.H., Hujier Abu-Saad, H., Van den Hout, M.A., Halfens, R.J.G. \& Schumacher, J.N.M. (1994). Factors influencing nurses' pair assessment and intervention in children. Journal of Adwanced Nursing, 20, 853-860. (Blackwell, Oxford) 


\section{SUMMARY}

Research is lacking on factors influencing nurses ${ }^{*}$ decision-making directed to the diagnosis pain in children and its related interventions. This paper reports on two studies, narnely a qualitative study and its replication, in which we explored factors influencing nurses' pain assessments and interventions in children. Those factors found to influence nurses' decisions were: medical diagnosis, child's expressions, age, and parents, and the nurses' knowledge, experience, attitude, and workload. Some of these factors seem to have more influence than others. For example, the presence of a medical diagnosis seems to legitimate being in pain. Furthermore, it is suggested that mainly vocal expressions, especially crying, influence nurses' decisions to administer analgesics. Finally, nurses ${ }^{\prime}$ negative views on non-narcotic analge* sics were striking.

In this paper, the results of both studies and their relationship to information reported in the literature are further elaborated and discussed, and hypotheses on strength and direction of influence of factors on pain assessment and intervention are generated. 


\section{INTRODUCTION}

In clinical practice professional nurses appear to make different judgments regarding the assessment of pain in children and the implementation of pain-relieving interventions. Assuming that it is desirable for nurses who are confronted with the same situation to make the same decisions, it is important to gain insight into the way decisions are made. A literature review conducted by the authors (Hamers et al., 1994) has shed some light on the subject and provided a framework of factors influencing the decision-making process. The literature review (Hamers et al.., 1994) also reveals that most studies in nursing (Corcoran, 1986; Itano, 1989; Tanner et al., 1987) focus on differences in decision-making between the novice and the expert.

Research on other factors is lacking. For example, it is not known on the basis of which factors or cues nurses conclude that a child is in pain, or on the basis of which factors they implement interventions to relieve pain. Some authors (Broome \& Slack, 1990) stress that future research should be directed at answering questions such as: what criteria do nurses use to decide if a patient is in pain and what factors do nurses consider when choosing medications to relieve pain?

\section{The study}

The purpose of this study is to explore factors inflencing nurses' pain assessments and interventions in children. With this in mind, the research question was formulated: on the basis of what information do nurses assess acute pain in children, and what information do they consider when choosing pain-relieving interventions?

To answer the study question, a qualitative study was conducted (study I) and followed by a replication study (study II). In this article both studies, in which different researchers participated, are described.

\section{METHODS STUDY I}

\section{Subjects}

The subjects $(n=10)$ were a convenience sample of nurses $(7$ women and 3 men, average age 30 years) working on a paediatric ward in both a general and a university hospital in the southern part of the Netherlands. Seven nurses were specialized in paediatrics; the other three had received training in this area. Experience in nursing varied between 1 and 14 years, that in paediatrics between several months and 11 years.

\section{Data collection and analysis}

Data were collected using (a) semi-structured interviews, (b) observations of subjects, and $|c|$ examination of nursing records. The procedure was as follows: the 
main researcher joined the paediatric nurse during a daytime shift, observing the nurses' activities related to pain assessment and implementation of pain-relieving interventions. At the end of the shift, an interview with the nurse, recorded on audio tape, took place. Owing to a technical malfunction, one interview was lost. For data management the computer program KWALITAN 3.1 (Peters, 1991) was used. KWALITAN has been deweloped for analyzing data according to the grounded theory approach (Wester, 1991). By using KWALrAN, the data can be processed, structured, sorted, selected, altered, and printed. Furthermore, the program offers the ability to write, process and print le.g. theoretical and methodologicall memos. In short, the computer program offers the ability to apply the procedures for data-analysis systematically on large amount of data. However, it should be mentioned that it is not KWALITAN, but the researcher who analyzes and interprets the data.

During data analysis, memos were constantly written. Data were analyzed using the following procedures. The main researcher and a second researcher independently coded the first interview. After comparing the codes, differences were discussed and agreement was obtained on terminology that should be used. The meaning of the codes was described in the memos. With these codes as a starting point, the main researcher coded a second interview. After the third interview was coded, no new codes could be formulated by the researcher, and the codes that were formulated seemed to be applicable to the different interviews.

At this time, procedures in data analysis were verified. First, both the content of the memos and the process of coding were discussed with the researcher who also coded the first interview. Next, they were checked by two other reseachers, who assigned codes to randomly selected interview scenes. Results were tested using a similarity coefficient, the Jaccard index (see below). Based on the results of these measures, codes were readjusted. Data resulting from interviews, observations and nursing records were analyzed on the basis of these codes.

\section{Reliability and validity}

In order to improve the reliability of data (Smaling. 1987), interviews were tape recorded and transcribed. The computer program KWALITAN 3.1 was used in the data analysis. During the interviews the statements of the subjects were frequently summarized and restated by the main researcher. After doing the second interview, the interview technique was evaluated and discussed with three other researchers. During the data analysis, the main researcher regularly discussed methods and findings with colleagues, which supports reliability (Nievaard, 1990; Smaling, 1987). To improve reliability and validity, the principle of triangulation (Denzin, 1978; Kimchi et al., 1991) was also used. First, data triangulation was used by collecting data from a general and from a university hospital (dissimilar settings, Denzin, 1978). Next methodological triangulation was used by applying several methods of data collection; namely, interview, observation, and analysis of nursing records (withinmethod triangulation, Denzin, 1978). Finally, the research results were compared with the literature.

As mentioned earlier, the Jaccard index was used as a measure of similarity in coding between the main researcher and two other reseachers (I and II). The procedure was as follows. Researchers $I$ and $\| l$, neither of whom were trained in coding, 
had to code 10 randomly chosen interview scenes. They were given a list off 34 codes, each with a description of the meaning. They were allowed to use more than one code for a single interview scene, but not all codes had to be used. For every interview scene a Jaccard index could be calculated as a measure of similarity between two researchers (see Table 1/. According to Dormaar (1989), the Jaccard index is used in order to reduce the likelihood that two units would be considered similar because neither contains many of the attributes.

Table: 1 . The calculation of the Jaceard index according to Dormaar 119894

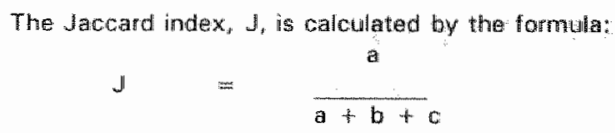

whereby $a, b$, and $c$ refer to the contingency table of attributes present $\|1\|$ or absent $(0)$ :

Researcher 2

Rosearcher

("II)

(10)

(1)

a

b

(0)

c

(d)

In this study, after readjustment of codes, the weighted simillarity rates $\left[\left(J_{1}+J_{2}+\ldots+J_{i}\right) /(n)\right]$ were: $J=0.5$ (main researcher - researcher $\|$, $J=0.5$ ( main researcher - researcher $\| I$, and $J=0.4$ (researcher $\|$ - researcher $\|$ ). These results have been interpreted to have reasonable similarity.

\section{METHODS STUDY ॥}

\section{Subjects}

Study II was a replication of study 1 . The subjects $(n=10)$ were a convenience sample of nurses ( 8 women and 2 men, average age 36 years) working in a paediatric ward in both a general and a university hospital in the western part of the Netherlands. All nurses were specialized in paediatrics. Experience in nursing varied between 5 and 33 years; experience in paediatrics between 2 and 28 years.

Because it was a replication of a study, procedures and methods for data collection were the same as those described in study 1 . As for reliability and validity, except for the use of the Jaccard index, those mentioned in study I were also applicable in the second study. There were, however, some differences, principally with respect to data analysis. 


\section{Data collection and analysis}

Although the computer program KWWALITAN 3.1 was used and memos were constantiy written, data were collected and analyzed by another researcher who did not participate in the first study. This researcher was trained in the interview techniques used in study I. Moreover, to make the results of this study comparable to those of the first, the codes of the first study were used as a starting point in analysing the data. However, it should be noted that the researcher was not informed about the results of study l.

\section{RESULTS STUDY I}

Factors found to influence both nurses' assessments of pain in children and the implementation of pain-relieving interventions are summarized in Figure 1. These different factors will be discussed in succession.

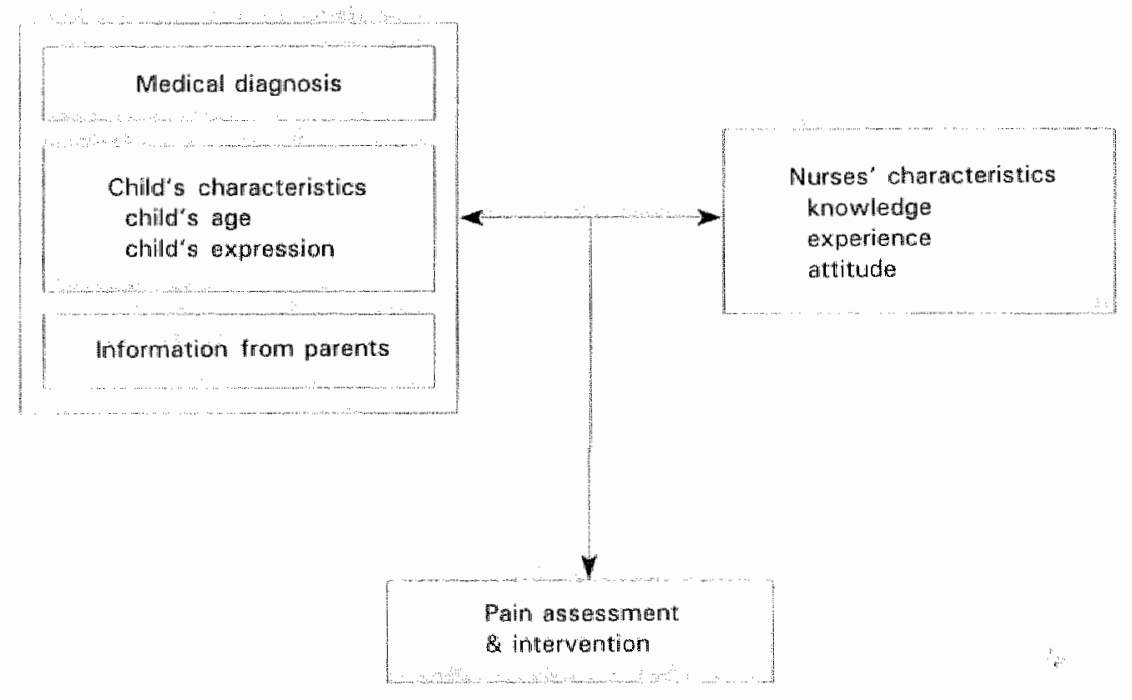

Figure 1. Factors anfluencing nurses" pain assessments and interwentions in children 
Pain-relieving interventions can be divided into phamacological and nonphamacological interventions. Pharmacological interventions can be further divided into opioids/narcotics (e.g. morphine) and non-opioids/non-narcotics (e.g. paracetamol). However, in this report, when pharmacological interventions are mentioned, they refer to non-narcotics.

\section{Medical diagnosis}

The medical diagnosis (surgery, syndrome, or indication for admission) is a factor that seems to influence nurses' pain assessments. Nurses seem to attach a great deal of importance to the medical diagnosis, since all 10 nurses mentioned it. However, depending on the severity of the medical diagnosis, one may conclude that the more severe the diagnosis the more pain the patient experiences. As a nurse commented:

The surgical removal of the tonsils Isevere diagnosis! is more painful than the surgical removal of the adenoids. Imild diagnosis!.

In fact, the presence of a medical diagnosis seems to justify being in pain.

The assessment of pain also depends on the reason for the patisnt's admission to the hospital. A patient who is admitted with a medical cliagnosis for which you can expect pain, is "allowed" to be in pain. It is to be expected.

This observation also holds for the implementation of pain-relieving interventions. Medical diagnoses partly seem to justify the administration of analgesics.

In the case of a child who has undergone surgery and complains about pain, there is a clear relationship batween the operation and the reported pain. But when a child complains about pain as his parants are leaving. then distraction will be used las an intervention].

As in the assessment of pain, there is probably a relationship between the severity of the medical diagnosis and the nurse's decision, in this case the implementation of a pain-relieving intervention. One will be more inclimed to administer an analgesic with a severe diagnosis than with a mild diagnosis.

\section{Characteristics of the child}

Certain characteristics of the child will influence nurses' pain assessments, mainly. the child's expressions and the child's age.

\section{The child's expressions}

The child's expressions seem to be an important cue in pain assessment. Although there are many ways (vocaliverbal, facial, behavioral, body movements) in which a child can express pain, vocal and verbal expressions are those that influence the assessment the most. Crying seems to be the most reliable source. In other words. the likelihood that a child will be in pain increases if the child is crying. This conclu- 
sion is based on the large number of scenes in which respondents mention the importance of this cue.

All nurses state that a child can be asked if he is in pain and that children can and do report their pain verbally. However, nurses have their doubts about the reliability of this source of information.

older children can express this verbally. They say: "I hawe a stomachache:. Then wou need to wateh and see if that fally is true or whather what they really mean to say is, "I want to go home".

As with pain assessment, vocal and verbal expressions also seem to influence the implementation of pharmacological interventions. In other words, a shouting or crying child will receive a pain medication sooner than a child who is not reacting in such a verball manner.

When the child is lvirg in bed screaming in pain. there is not much point in trying to reposition him. You just reach for some medication.

\section{The child's age}

With regard to age, respondents distinguish between "Younger children" (up to 4 vears old), 'older children' (starting at 5 years old) and "adults". The majority of the subjects think of age as a factor that influences pain assessment. However, they do not agree on the nature of the influence. Some of the nurses think adults experience more pain than children in the same situation. Reasons given are:

I think children forget it more quickly. An adutt who has a hernia will stay in bed for about 2 days and take it cas $\gamma$. while a child will start walking around or playing within a couple of hours. He won't think about it that inicicto.

However, the majority of the nurses think children experience more pain than adults in the same situation. Several arguments are brought up; for instance:

An adult may be able to handte it better than a child. When a child is in pain , he is tottally overwhelrned by it. He car think of nothing alse. He can't even play anymore.

It is less clear whether nurses think that younger children have more or less pain than older children in the same situation. Ome subject stated:

The conclusion that the child is in pairn will be drawn more quickly for younger children than for older children. With the vounger child you platy it safe, with the dder one, you check it.

Age also seems to influence the implementation of pharmacological interventions. Several nurses think adults receive pain medication sooner than children.

Compared to children, edults receive medication more quickly.

One nurse thinks the decision to administer an analgesic is made more quickly in vounger children than in older children. 
In infants you tend to give something lanalgesicl more quickly. If the child remains resthess, twem he is experieno ing pain. This conclusion will be drawn earlier than in older children.

\section{The child's parents}

In general, subjects think it is obvious to use information obtained from the child's parents. After all, 'Nobody knows the child better than his own parents". However, information obtained from parents does not seem to be reliable all the time. When a parent states her child is in pain, this information is usually checked by the nurse.

Parents do recognize the child's pain behaviar, it is specific for their child. Still, you first have to assess the situation yourself. If the child hears a parent say "if i had undergone that operation / would have had pain", he will begin to experience pain himself.

Other nurses check whether the pain is severe enough to administer pain medication.

In that case I will go back with them lparents] to their child, and tallk with the chilld himself fif that"s possiblel. That way. I can decide whether to administer pain medicalion of not.

The reliability of the parent's information depends on the subject's image of the parents.

Sometimes it's obvious that the parents are exaggerating.

\section{Characteristics of the nurse}

Nurses appear to know that they make different decisions when confronted with the same situation. These differences can be partly attributed to nurses' characteristics, including their knowledge, experience and attitude.

\section{Knowledge and experience}

Professional experience seems to be a main factor influencing nurses' pain assessments and their implementation of interventions. Nurses use their past experience to determine what to do in present or future situations.

Experience with the swndrome, experience with other children. You start making comparisons. Actually, I shouldn't be saying this, but is it logical to be in pain? You should beat in mind that every human being is uniqus. But the fact is you do it lcomparingl automatically, you cannot awoin it.

Knowledge about the effects of pain relieving interventions seems to influence nurses' implementation of them. Analgesics are generally expected to be effective. That cannot be said of nonpharmacological interventions. The nonpharmacological intervention most often mentioned is distraction. Some nurses think distration can be an effective way to relieve pain. Other nurses think distraction is a temporary solution, and not a sufficient one. Finally, other nurses think of distraction as a method of assessing, rather than relieving, pain. 


\section{Nurses' attitudes}

Nurses' attitudes seem quite likely to influence their decision to administer pain medication to children. It appears that nurses have negative feelings about pain medication, a conclusion derived from the vocabulary they use: "All pain will be treated, if necessary even with medicines"; "If I start stuffing them with medicine..."; "Then you don't need to start pushing medicines right away" "You shouldn"t pump it into the body if it is not necessary" 'You don 't need to swallow packets of pills'. These statements give the impression that the nurses are talking about large quantities of medicine. However, the context of these statements is the administration of 'paracetamol' pro re nata (p.r.n.). Moreover, it is striking that nurses postpone administering analgesics as long as possible.

In my opinion it not necossary to start with an aralgesic right away. In fach as far as that's concerned, would say, wat umtil the lasit possible moment.

Several arguments are given for postponing the administration of analgesics: 'because medicine is harmful": "because it is a poison'; 'because medicine has side effects'; 'because medicine suppresses other symptoms'; 'because you are afraid something is going to go wrong".

Finally, the majority of nurses think that pain is related to hospital admission. Some of them think pain can never be relieved completely.

"iry fact, some pain is allowed, for they are, after all, in the hospital.

\section{RESULTS STUDY \|}

An extensive overview of the results of this replication study is given by Schumacher (1993). Obviously, in general, the results of this study were comparable to those of the first one. The impact of the medical diagnosis on assessment and intervention was supported. This also held for the child's expressions, nurses' knowledge and experience, and nurses' attitude.

However, there were some differences with regard to the influence of the child's age on the pain assessment and administration of analgesics. In studly $I$, it was suggested that younger children would probably receive pain medication earlier than older children. Study II suggest conflicting results. On the one hand, the result is supported.

To older children, you can say: hang in there! ... but this is not going to work with younger children.

On the other hand, some subjects suggest the opposite; older children would receive pain medication earlier.

In younger ahilhdren pain is managed less extensively than in older children.

In younger chlidren, you first try out other [nonpharmacologicall interventions. 
Although the influence of the child's parents is supported, the examination of infor. mation from parents was not mentioned. However, the parent's influence on the nurse's decision to adminster an analgesic seems rather small.

You only have a fow alternatives and the parents don't have much to say in the matter.

Finally, an interesting result found in this study was the influence of 'workload' on the administration of analgesics.

My first reaction is not very acceptable, but it depends on how much time you thave awatable. When vou are caring for 13 children all by yourself, or with another colleague. then you do not have enough time to sit down with each child.

When it is very busy, and you are caring for 12 children all by vourself, then you naturally just give a paraceta" mol.

In such cases, time seems to be a determining factor in the administration of analgesics.

\section{DISCUSSION}

Decision-making processes related to pain assessment and interventions in children are complex. In a qualitative study, followed by a replication study, factors influencing these processes have been explored. It should be mentioned that the overview is not complete. For example, organizational aspects (Broome \& Slack, 1990) were left aside, although there was an indication that workload also influences the administration of analgesics (study (I). Obviously, the subjects do not represent all paediatric nurses in the Netherlands, something which sets limitations on the range of these studies. However, it does not alter the fact that clear indications have been found about the influence of some factors on nurses' decision-making.

\section{Medical diagnosis}

A medical diagnosis seems to be a justification for being in pain. The importance of the medical diagnosis in pain assessment and interventions has also been reported in the literature (Arkesteyn, 1989; Burokas, 1985; Bush et al., 1989; Dudiey \& Holm, 1984; Halfens et al., 1990; Ross et al., 1991; Taylor et al., 1984). These findings lead one to believe that the worse the medical diagnosis, the higher the pain assessment and the sooner an analgesic will be administered.

\section{Child's expressions}

The finding that nurses use the child's expressions to assess pain seems very logical. The overview of the ways in which a child can express pain is comparable to overviews which exist already (Koolen \& Perduijn, 1991; McGrath \& Unruh, 1987). However, it is striking that mainly vocal and verbal expressions, especially crying. influence nurses' decisions. This finding is contrary to results of two other qualitative studies which suggest that nurses assessing pain pay the most attention to the 
child's behavior (e.g. reflecting boredom, introversion) (Koolen \& Perduijn, 1991) and facial expression (e.g. grimace, frown) (Dick, 1993). Dick's study (1993) also suggests that crying may be an important cue. A study by Wallace (1989) again sup. ports the finding that children who express pain intensively receive more postoperative analgesic medication than children who express pain less intensively.

\section{Age}

The influence of age on pain assessment and intervention is also worth noting. The majority of nurses believe that children have less pain than adults in the same situa tion. This is in contrast with McGrath et al. (1984), who found that paediatric nurses perceived the pain of children as severe as adult pain when no serious medical sequela is expected. The finding that adults seem to receive analgesics sooner than children is supported in the literature (Beyer et al., 1983; Eland \& Anderson, 1977; Elander \& Hellstrơm, 1992; Schechter et al., 19861.

The assumption that younger children, especially babies, do not feel pain seems to be obsolete. The present study even suggests that nurses conclude that younger children are in pain sooner than older children. A younger child is also likely to get analgesics sooner. An explanation for this could be that it is more complex to assess pain in younger children than in older children. As a result, nurses will administer analgesics sooner to be on the safe side. Moreover, it is assumed that pain assessment in older children is less complex because they can report their pain verbally. Some nurses, on the other hand, still debate the reliability of these reports. A child who reports pain may be simulating or exaggerating pain, something that is also suggested in the literature (Koolen \& Perduijn, 1991: Vortherms et al., 1992).

Regarding the influence of age on the administration of analgesics, conflicting findings exist not only in study 11 but also in the literature. According to Elander and Hellström (1992), older children received more narcotic analgesics but got the same amount of nom-narcotic analgesics as younger children. Gonzalez and Gadish (1990) suggest that younger children receive more non-narcotics than older children. However, nurses who participated in this study said age is not an important factor influencing the administration of analgesics. This idea is supported by Schechter et al. (1986). These researchers found that narcotic analgesics are prescribed less often in vounger children than in older children, but that there is no difference in the actual administration.

In summary, different results have been reported regarding the influence of age on pain assessment and interventions. Therefore, it remains questionable whether age (younger versus older children) influences the decision to administer analgesics.

\section{Influence of parents}

It is also questionable whether a child's parents influence nurses" pain assessments and interventions. Although subjects think information obtained from parents is important, study I suggests that this information must be confirmed. In any case. information obvained from parents seems unlikely to be a conditional factor for the administration of analgesics. These findings are supported by those of Koolen and Perduijn 11991). These authors also support the finding that the parents' role is age- 
related. In other words, if information obtained from parents influences nurses" decision-making, this influence decreases as the child grows older. In the literture the child's parents as an influencing factor on nurses. decisions is seldom described.

\section{Nurses: attitudes}

It seems logical to conclude that nurses" characteristics influence their decisions. However, nurses" attitudies towards analgesics are striking. In the literature (Eland \& Anderson, 1977; Ferrell et al., 1991; Schechter et al., 1986) it is often mentioned that many nurses are (sometimes unjustly) afraid of side effects of analgesics, like addiction. These studies, however, refer to narcotic analgesics, whille the qualitative study and its replication reflect negative views on non-narcotic analgesics, like paracetamol. It is possible that children receive insufficient analgesics as a result of this, or that analgesics are administered too late.

\section{Distraction}

Distraction seems to be the nonpharmacologicall intervention most often used, a finding supported by Burokas (1985). However, it seems that the range of nonpharmacological interventions used is less than the range of nonpharmacological interventions described in the literature (Huijer Abu-Saad, 1989; McGrath, 1990; Ross \& Ross, 1988). This observation is also made by Ferrell et al. (1991). An explanation could be that few nurses are acquainted with nonpharmacological interventions and their effects. Moreover, it is likely that several interventions that are described in the literature (e.g. hypnosis and biofeedback) are not considered within the nursing domain in the Netherlands.

\section{Implications for future research and clinical practice}

Based on this study several suggestions for further research can be made. The results of this study are hypothetical in nature. Testing hypotheses, particularly on the influence of medical diagnosis, the child's expressions and age, and the child's parents, should be the next step. Further research on nurses' attitude towards pain in children seems to be relevant, all the more so because nurses" attitudes seent to be responsible for differences between nurses' decisions to administer analgesics. Finally, one should investigate whether or not children receive sufficient analgesics. This study also has practical implications, especially for nursing education and nursing practice. It is suggested that nurse educators should pay more attention to pain assessment and to methods of relieving pain in children, taking into consider. ation analgesics and their side effects. In addition, the subjective nature of the experience and the developmental influences on pain perception, pain tolerance and pain expression in children should receive more attention in nursing school curricula. In the practice setting, refresher courses on pain in children are recommended for paediatric nurses because they are the ones who determine if a child is to be medicated or not and because they are seen as role models by potential nursing students in the practical setting. Refresher courses could address how children with different medical diagnoses and of different age groups perceive and react to painful experi. 
Factors intuencing nuses" pain asgessment and interventions in chtildren

ences. Myths regarding pain assessment and pain management in children could be discussed and as a result dispelled. 


\section{REFERENCES}

Arkesteyn, S.A.C. 11989\}. Onderzoek naar factoren die verpleegkundigen beinwoeden bif het toedienen van postoperatieve pijnmedicatie bij kinderen. (Research on factors influencing nurses" administration of analgesics in children postoperatively). Rijksuniversiteit Limburg, Maastricht. (unpublished master thesis)

Beyer, J.E., DeGood, D.E., Ashley, L.C. \& Russell, G.A. 119831. Patterns of postoperative analgesic use with adults and children following cardiac surgery. Pain, $17,71-81$,

Broome. M.E. \& Slack. J.F. 11990). Influences on nurses" management of pain in children. Maternal Child Nursing, 15, 158*162.

Burokas, $L$. (1985). Factors affecting nurses' decisions to medicate pediatric patients after surgery. Heart \& Lung, 14, 373-379.

Bush, J.P., Holmbeck, G.N. \& Cockrell, J.L. 11989). Patterns of PRN analgesic drug administration in children following elective surgery. Journal of Pediatric Psychology, 14,433-448.

Corcoran, S.A. (1986). Task complexity and nursing expertise as factors in decision making. Nursing Research, 35, 107-112.

Denzin, N.K. (1978). The research act. A theoretical introduction to sociological methods. McGraw-Hill, New York.

Dick. M.J. (1993). Preterm infants in pain. Nurses' and physicians perceptions. Clinical Nursing Research, 2, 176-187.

Dormaar, J.M. \{1989\}. Consensus in psychotherapy. Datawyse, Maastricht.

Dudley, S.R. \& Holm, K. (1984). Assessment of the pain experience in relation to selected nurse characteristics. Paim, 18, 179-186.

Eland, J.M. \& Anderson, J.E. (1977). The experience of pain in children. In: A. Jacox (Ed). Pain: A source book for nurses and other heatth professionals. Little Brown, Boston, pp. 453-473.

Elander, G. \& Hellström, G. (1992). Analgesic administration in children and adults following open heart surgery. Scandinavian Journal of Caring Sciences, 6, 17-21.

Ferrell, B.R., Eberts, M.T., McCaffery, M. \& Grant, M. (1991). Cinical decision making and pain. Cancer Nursing, 14, 289-297.

Gonzalez, J. Gadish, H. (1990). Nurses' decisions in medicating children postoperatively. In: D.C. Tyler \& E.J. Krane (Eds.). Advances in Pain Research and Therapy, 15, 37-4.1. Raven, New York.

Halfens, R., Evers, G. \& Abu-Saad, H. (1990). Determinants of pain assessment by nurses. International Journal of Nursing Studies, 27, 43-49.

Hamers, J.P.H., Huijer Abu-Saad, H. \& Halfens, R.J.G. 11994h. The diagnostic process and decision-making in nursing, a literature review. Aournal of Professional Nursing, $10,954-163$.

Huijer Abu-Saad, H. 11989\%. Pinninterventies bij kinderen (Paininterventions in children). Pijn. Informatorium, $15,1-13$.

Itano, J.K. (1989). A comparison of the clinical judgment process in experienced registared nurses and student nurses. Journal of Nursing Education, 28, 120-126.

Kimchi, J.; Polivka, B. \& Stevenson, J.S. (1991). Triangullation: operational definitions. Nursing Research, 40, 364-366.

Koolen, Y.H.E. \& Perduijn. M.D. 11991). Clinical Judgement. Acutely and chronically ill children in pain. Pilksuniversiteit Limburg, Maastricht. lunpublished maister thesis

McGrath, P.A. (1990). Pain in children. Nature, assessment \& treatment. Guilford, New York.

McGrath, P.J., Vair, C., McGrath, M.J., Unruh, E, \& Schnurr, R. 119841. Pediatric nurses" perception of pain experienced by children and adults. Nursing Papers, 16, 34-40.

McGrath, P.J. \& Unruh, A.M. (1987). Pain in children and adolescents. Elsevier, Amsterdam.

Nievaard, A.C. 119901. Validiteit en betronswbaarheid in kwalitatief onderzoek (Validity and reliability in qualitative research). In: I. Maso \& A. Smaling (Eds.). Objectiviteit in kwafitatief onderzoek fobjectivity in qualitative researchl. Boom, Meppel, pp. 75-96. 
Petars; V. 11991). Kwaltan, aanwullende handleiding bij versie 3.1. KKwalitan, manual for version 3. 1.1. Katholieke Universiteit Nijmegen, Nijmegen.

Ross, P.S. Bush, J.P., Crumette, B.D. (1991). Factors affecting nurses" decisions to administer PRN aralgesic medication to children after sufgery: an analog investigation. Journal of Pediatic Psyctiology, 16, 151-167.

Ross, D.M. B Ross, S.A. (1988). Chilhood pain. Current issues, research, and manage ment. Urbain \& schwarzenberg, Batimore.

Schechter, $\mathbb{N}_{\text {.L. }}$. Allen. D.A. Hanson, K. 11986/. Status of pediatric pain control: a comparion of hospital analgesic usage in children and adults. Pedfatrics, 77, 11-15.

Schumacher. J. (1993). Verpleegkundige bes/uitworming: pijn bij kinderen (Decision-making in mursing: pain in children). Rijksuniversiteit Limburg. Maastricht. (unpublished master thesis)

Smaling, A. (19B7). Methodologische objectiviteit en kwalitatief onderzoek (Methodological objectivity and qualitative reseanchl. Swets \& Zeitlinger, Lisse.

Tanner, C.A., Padrick, K.P.. Westfall, U.A. \& Putzier, D.J. (1987). Diagnostic reasoning strategies of nurses and nursing students. Nursing Research, 36, 358-363.

Tayor. A.G., Skelton. J.A. \& Butcher, J. (1984). Duration of pain condition and physical pathology as determinants of nurses" assessments of patients in pain. Nursing Research, 33, 4-8.

Vortherms, R., Fyan, P. \& Ward, S. 11992). Knowledge, attitudes toward, and barriers to pharmacologic management af cancer pain in a statewide random sample of nurses. Research in Nursing \& Health, 15, 459-466.

Wallece, M.R. 119891. Temperament: a variable in children's pain management. Pediatric Nursing, 15,118121 .

Wester, F. (1991). Strategieën voor kwalitatief onderzoek (Strategies for qualitative research). Coutinho, Muiderberg. 
The influence of children's vocal expressions, age, medical diagnosis and information obtained from parents on nurses' pain assessments and decisions regarding interventions ${ }^{\top}$ 


\section{SUMMARY}

This article reports on a study that examines the influence of task-related factors on nurses' pain assessments and decisions regarding interventions. In an experimental design pediatric nurses $(n=202)$, were exposed to different cases, each case being a combination of a vignette and a videotape. For every case subjects were asked to assess the child's pain and to state whether or not they would administer an analgesic. The results indicated that pediatric nurses attributed more pain and were more inclined to administer non-narcotic analgesics to children who vocally expressed their pain than to children who were less expressive. Furthermore, the interaction results between the child"s expression and the medical diagnosis revealed a trend indicating that nurses attributed the most pain to the child when the diagnosis was severe and the child vocally expressed his pain. 


\section{INTRODUCTION}

That nurses play a key role in pain assessment and intervention in children is generally recognized (Atchison et al., 1986; Broome \& Slack, 1990; Gonzalez \& Gadish, 1990). Since analgesics are often prescribed by physicians on a pro re nata (p.r.n.) basis, nurses are constantly being confronted with situations in which they must decide when to intervene when a child is in pain. Just which factors play a key role in the nurses" decision that pain is present and that it warrants intervention is a question posed by many researchers (Broome \& Slack, 1990; Hamers et al., 1994a) and clinicians and, as a result, merits further investigation.

In a qualitative study by Hamers et al. (1994b), factors influencing nurses' pain assessments and interventions were explored. See Figure 1.

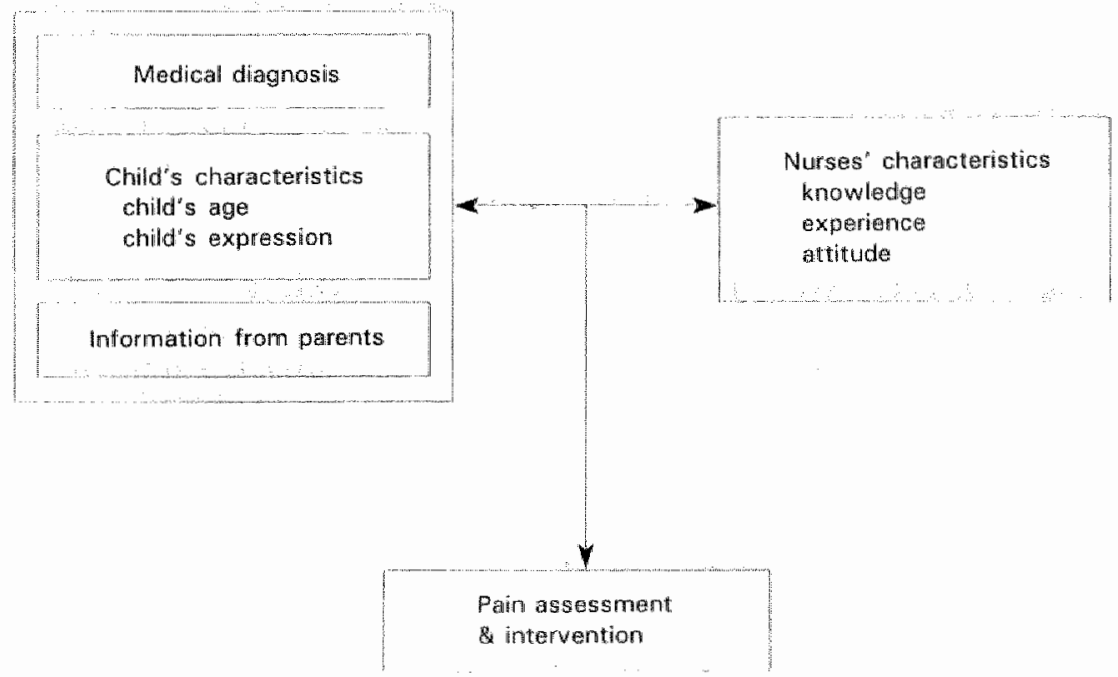

Figure 1. Factors influencing nurses ${ }^{*}$ pain assessments and interventions in chldren fFeprinted with permission from: Hamers, J.P.H., Hujjer Abu-Saad, H. Halfens, R.J.G. B Schumacher, J.N.M. (19941. Factor's influencing nurses" pain assessment and interventions in children. Jourmal of Advanced Nursing, 20, 853-860. Blackwell, Oxllard)

According to this study, a medical diagnosis seemed to justify being in pain. The importance of a medical diagnosis in pain assessment and interventions has also been reported in other sudies (Arkesteyn et al., 1990; Burokas, 1985; Bush et al., 
1989; Dudley : Holm, 1984; Gadish et al. 1988; Halfens et al., 1990; Taylor et al., 1984). Bush et al. (1989), for example, found seriousness of surgical procedure as the best predictor of analgesic medications. These findings lead one to expect that the more serious the diagnosis, the more pain will be attributed to the patient and the sooner an analgesic will be administered.

Another factor found to influence nurses" decisions was the child"s expressions, especially his vocal expressions (Hamers et al., 1994b). It is suggested that more pain is atributed and that analgesics are administered sooner to a child who expresses his pain vocally (e.g., by crying) than to a child who does not. Although Koolen and Perduinin $(1991)$ qualitative study suggests that nurses pay the most attention to the child"s behavior (e.g., acting bored or introverted). Dick's (1993) qualitative study supports the importance of crying. A study by Wallace (1989) on the child's temperament again supports the finding that children who express pain intensely (e.g., by crying) receive more postoperative analgesics than children who express pain less intensely.

Hamers et al. (1994b) further found conflicting results on the child's age as a factor that influences pain assessment and interventions. On the one hand, the data sug. gest that nurses would conclude that younger child (up to 4 vears old is in pain sooner than an older child $(5$ years or older), and that the younger child would also receive non-narcotic analgesics sooner than the alder child. On the other hand, there were data that suggested that older children would receive pain medication earlier. The literature (Elander \& Hellström, 1992; Gonzalez \& Gadish, 1990; Schechter et al., 1986 ) also reports conflicting results on the influence of age on the administration of analgesics. Based on these results, the question can be posed whether or not age influences nurses' decisions to administer non-narcotic analgesics.

One may also question the influence that information obtained from the child"s parents has on nurses" pain assessments and interventions. Although nurses think that information obtained from parents (e.g." "my child is in pain') is important, they usually try to verify the information (Hamers et al., 1994b). Hamers et all.'s study further suggests that information obtained from parents seems unlikely to be a conditional factor for the administration of analgesics. This finding is supported by the study by Koolen and Perduijn (1991). These two studies further suggest that the parents' role is age-related; in other words, if information obtained from the child's parents does, in fact, influence nurses decision-making, then this influence decreases as the child grows alder. The literature seldom refers to the child's parents as a factor inluencing nurses decisions.

it can be concluded that several studies have explored the factors that influence pain assessment and intervention in children. These studies used mainly qualitative, retrospective, or exploratory designs and served as a result to generate hypotheses on possible factors influencing nurses" decisions. Although these studies provided us with a great deal of information, the studies do not provide definite conclusions on the influence of some of these factors. In fact, the explaratory studies reveal often different, and sometimes ambiguous findings. As yet, the hypotheses generated have never been tested in controlled clinical studies, mainly due to the difficulties encountered in conducting such studies. Laboratory type studies provide as a result a complementary approach that may disentangle different effects that are confounded in the natural environment. 
The aim of the present study was to examine the influence of the medical diagnosis, the child"s age and expressions, and parents' input on nurses" pain assessments and their decisions to administer non-narcotic analgesics (paracetamol), controlling for the effects of nurses' characteristics (knowledge, experience) and the type of hospital. In three experimental cases (see design) the following hypotheses were tested. The first case tested whether nurses" attributions of pain and their administrations of analgesics were influenced by the child"s vocal expression of pain and by the sever. ity of the medical diagnosis. It was expected that the combination of vocal expression and severe diagnosis, in particular, would prompt nurses to assess pain as more severe and to intervene pharmacologically.

The second case tesited the hypothesis that attributed pain and the administration of drugs are not affected by the child's age or by information obtained from parents as such, but that the child"si age and parents' information interact. It was expected that information obtained from parents would only affect nurses" behavior in cases of relatively young children.

In the third case the testing of hypotheses on the influence of vocal expression (see first case) and child's age (see second case) was replicated. However, these factors were not expected to interact.

\section{METHODS}

\section{Design}

The study consisted of three experimental cases, which each formed a cell in a separate $2 \times 2$ factorial design (Figure 2). As can be seen from Figure 2, in each case two factors (e.g., medical diagnosis \& child's expression) are manipulated. A factor can be present (e.g., severe diagnosis; vocal expression) or absent (e.g., mild diagnosis; less vocal expression). Using all the possible combinations of factors $(2 \times$ 21 . each case consists of four different subcases or tasks. The advantage of this design is that several hypotheses on main effects and interaction effects of two different factors can be tested in one single experiment.

\section{Subjects}

A convenience sample of 207 pediatric nurses selected from 11 hospitals in the Netherlands were included in the study and received a small remuneration for their participation. Only registered nurses who were currently working on a pediatric ward were included. Three nurses were excluded because they did not meet this criterion, and two nurses were excluded because they deviated from the procedure (see procedure). There were 202 nurses in the final sample (180 women and 22 men). Their mean age was 32.1 years $(S D=7.0$; range $=22-56)$. 


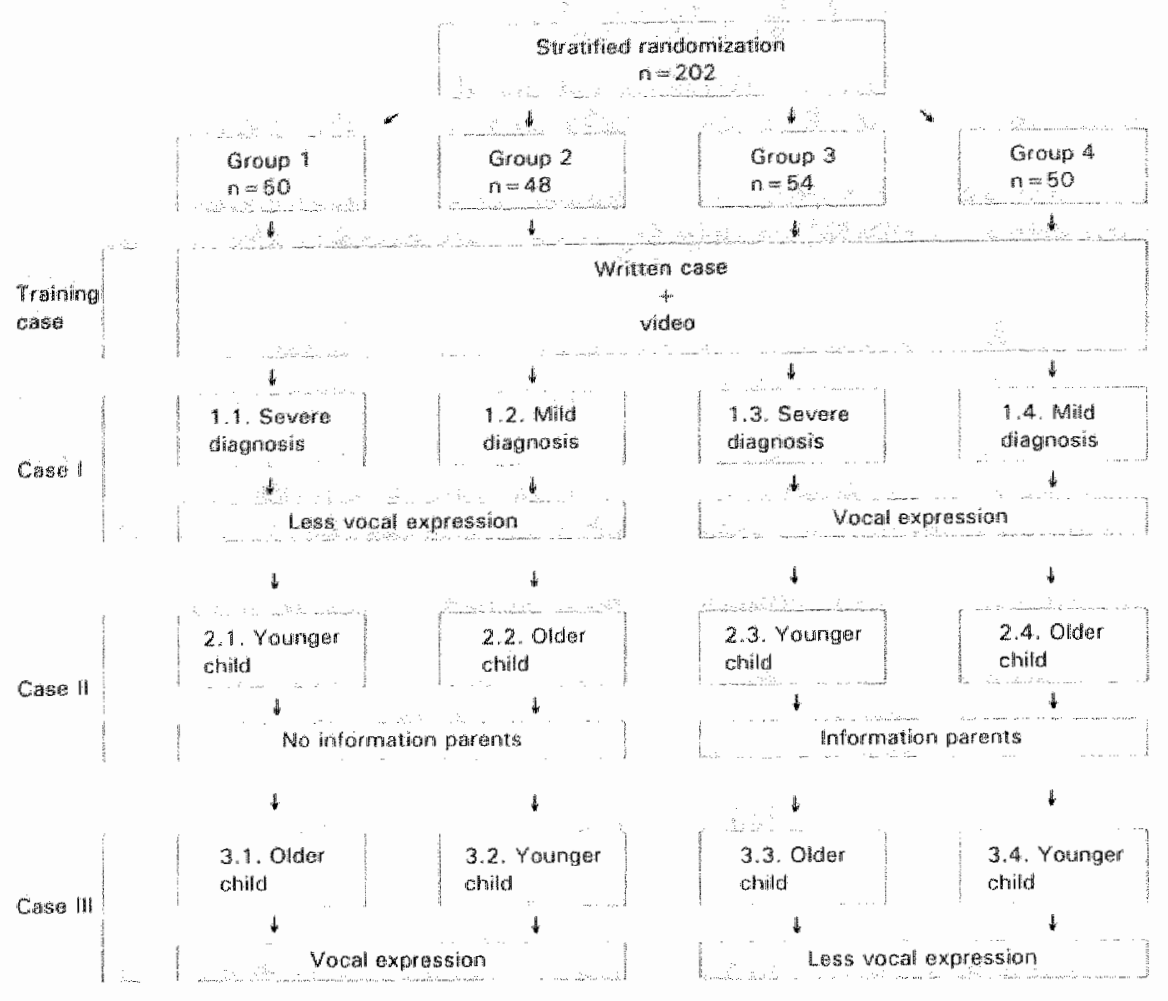

Figure 2. Illustration of the factorial study design

As can be seen in Figure 2, nurses were randomized into four groups after prestratification. Per hospital, nurses were stratified for experience $10-3 ; 4-7 ; 8-11 ; 12-15$; $\geq$ 16 years in pediatrics respectively) and knowledge (specialized education in pediatrics: yes or no).

\section{Procedure}

As can be seen from Figure 2, each group was exposed to four sequential cases, each of which consisted of a vignette and a videotape in which the different factors were operationalized. Although the nurses were unaware of it, they started with a training session, so that they could get used to the task.

Medical diagnosis (mild: 'adenoidectomy', severe: 'closure of anus preaternaturalis'), child's age (younger: ' 3 years old', older: ' 5 years old'), and information obtained from the child's parents l' $x$ 's mother draws your attention to the fact $x$ is in pain' versus no information) were operationalized via vignettes. An illustration of vignettes 
is given in Table 1. The child's expressions lless vocal versus vocall were opera tionalized via videotapes of the same child.

Table 1. Alitustration of two vignettes

\begin{tabular}{|c|c|}
\hline Vignette 1 & Vignette 2 \\
\hline Jolkn is a 16 month old boy. & John is â $16 \mathrm{~m}$ mrith old boy. \\
\hline $\begin{array}{l}\text { He was admitted with the indication "adenoidectomy" } \\
\text { Isurgical remowal of adenoids?. } \\
\text { This moming he has undergome surgery. John may } \\
\text { have paracetamol, } 120 \text { mg p.r.n. for the pain, a maxi- } \\
\text { mum of four times a day. }\end{array}$ & $\begin{array}{l}\text { He was admitted with the indlication "cilosure ap" (clo- } \\
\text { sure of anus praeternaturalis). } \\
\text { This morning he has ardergone surgery. John may" } \\
\text { have paracetamol, } 120 \text { mg pir.n. for the pain, a maxi- } \\
\text { mum of four times a day. }\end{array}$ \\
\hline $\begin{array}{l}\text { Wh this information you enter John's room. At that } \\
\text { me it is several hours after the surgery. }\end{array}$ & $\begin{array}{l}\text { With this information vol enter John's room. At that } \\
\text { time it is several hours after the surgary. }\end{array}$ \\
\hline
\end{tabular}

Note. In this illustration the medical diagnosis (mild $=$ adenoidectomy, severe $=$ clostire ap) is operationalized. Vignette 1 corresponds to cases 1.2 and 1.4 in Figure 2 , vignette 2 to couses 1.1 and 1.3 .

Data collection took place during 15-minute sessions. At each session; a standardized introduction was given about the procedure. Extra attention was paid to the correct way of filling in the rating scales and to the fact that inurses were not allowed to communicate with each other during the task. However, during one session, two nurses started talking and they have, as a result, been excluded from the samplle.

Each nurse was confronted with four different subcases or tasks (the training case included). For every case the procedure was as follows: (1) nurses read the vignette, (2) the videotape was shown, (3) nurses answered three questions (see measurements). At the end of the session, the purpose of the study was explained, and discussions about the study took place with the nurses.

\section{Measurements}

Nurses rated their answers to the following questions on a 100-millimeter Visual Analogue Scale (VAS):

- Please rate the pain experienced by the child in this case.

- How sure are you that your pain assessment is the correct one?

- Would you administer an analgesic to the child in this case?

At the left end of the scale the indications ' $O$, no pain at all', ' 0 , completely unsure', and ' $O$, surely would not administer' were printed for the three different questions, respectively, and at the right end '100, extreme pain". '100, completely sure', and '100, would surelly administer", respectively. The distance from zero to the vertical mark of the nurse was measured in millimeters. 


\section{Reliability and vallidity}

In order to improve reliability and validity, the vignettes and the accompanying video scenes (each lasting about 30 seconds) were developed systematically, according to guidelines comparable to those proposed by Lunney (1992).

Children recovering from minor operations (e.g., adenoidectomies, tonsillectomies) in an outpatient ward in a general hospital were videotaped. Videotapes of 7 children were edited into 21 videoscenes. In a first pilot study, these scenes were randomlly shown to 18 registered nurses, who were asked to rate their answer to the following questions on a 100 -millimeter VAS: (1) Please, estimate the possibility that the child is in pain; (2) Please rate the pain that is experienced by the child. Additional questions were further posed regarding the child's age lwould you be surprised knowing that this child is ' $x$ ' years old $(x=3,4,5,6,10,16$ years ald $) 1$ and to the type of surgery ldoes it seem likely to you that this child is recovering from a type of surgery' (type of surgery = adenoidectomy/tonsillectomy! appendectomy/ heart surgery/ renal surgeryll. Based on their answers and their verbal comments, 6 videoscenes from 4 children were selected to represent the natural setting.

After editing and selecting the tapes, simulated vignettes were developed. The vignettes contained the following information: the child's name, the child's age, the type of surgery, and the amount of non-narcotic analgesics (paracetamol) pro re nata. The amount of information was limited, so cases would be applicable in different hospital settings. The vignettes were based on the results of a review of the literature and a qualitative study, and were judged by two experts in pediatric nursing and one expert in pain in children. An illustration of a vignette is given in Table 1. Seven pediatric nurses and six nurse researchers participated in two separate pilot studies which aimed at testing the face and content validity of the combination vignettes and videoscenes. Based on their comments and feedback, the vignettes were revised. Finally, the combination of revised vignettes and videoscenes were tested in a fourth pilot study in which 16 pediatric nurses from a university teaching hospital participated. Based on the results of this study no further revisions were needed, and it was decided that the materials were reasonably reliable and valid to use in the main study. It should be mentioned that the hospitals where the pilot studies took place did not participate in the main study.

\section{Anallyses}

VAS scores were analyzed by ANOVA. Since the different factors presented in the three cases are independent and hence inappropriate for combined analysis using one multivariate technique, seperate ANOVAs including the stratification variables experience and knowledge for each case have been conducted. However, as depicted in Figure 2, the factors child's expression and age were present in two cases. For these factors an overall analysis was carried out using techniques for analysis of cross-over designs (Altman, 1991; Armitage \& Berry, 1987). 


\section{RESULTS}

As can be seen in Table 2 the prestratification was succesful; there were no differences among groups regarding knowledge and experience.

Table 2. Distributions of respective years of experiente in pediatrics, level of specialized aducation, and hospital where subjects were employed un the four experimental groups.

\begin{tabular}{|c|c|c|c|c|}
\hline & Group 1 & Group 2 & Group 3 & Giroup 4 \\
\hline N subjects & 50 & 48 & 54 & 50 \\
\hline $\begin{array}{l}\text { Awerage years of expertience in pediatrics } \\
\text { lsd }\end{array}$ & $\begin{array}{l}7.3 \\
15.94\end{array}$ & $\begin{array}{c}7.1 \\
(5.4)\end{array}$ & $\begin{array}{c}6.5 \\
(5.7)\end{array}$ & $\begin{array}{r}7.8 \\
\{6.1\}\end{array}$ \\
\hline $\begin{array}{l}\text { Level of specialized education } \\
\text { m subjects holding a specialization in pediatrics } \\
\text { m subjects attending the specilazization course } \\
\text { n subjects with nolother specializations }\end{array}$ & $\begin{array}{r}41 \\
5 \\
4\end{array}$ & $\begin{array}{r}37 \\
7 \\
4\end{array}$ & $\begin{array}{r}44 \\
6 \\
4\end{array}$ & $\begin{array}{r}40 \\
5 \\
5\end{array}$ \\
\hline $\begin{array}{l}\text { Hospital where employed } \\
\text { m subjects employed in general hospital } \\
\text { n subjects employed in children"s hospital } \\
\text { n subjects amployed in university hospital }\end{array}$ & $\begin{array}{l}14 \\
12 \\
24\end{array}$ & $\begin{array}{l}14 \\
11 \\
23\end{array}$ & $\begin{array}{l}14 \\
19 \\
21\end{array}$ & $\begin{array}{l}13 \\
19 \\
13\end{array}$ \\
\hline
\end{tabular}

The results of the hypotheses are presented by case sequentially.

\section{Case /}

The hypotheses regarding the influence of the child's expressions were supported. Pediatric nurses attributed more pain to the child who expressed his pain vocally than to the child who didn"t $\left(F_{1,194}=107.78 ; p<0.001\right)$. They also said they were more inclined to administer an analgesic to the child who expressed his pain vocally than to the one who didn't $\left(F_{1,194}=134.42 ; p<0.001\right)$.

The hypotheses regarding the influence of the medical diagnosis on assessment and intervention were not supported. No main effects were found for pain assessment $\left(F_{1,194}=1.33 ; p=0.25\right)$ or for the administration of analgesics $\left(F_{1,194}=1.24 ; p=0.27\right)$. As can be seen from Figure 3 , both pain assessment and intervention scores were especially high when the diagnosis was relatively severe and there was vocal expression. However, these effects proved not to be statistically significant; onlly a trend was found for assessment $(p=0.08)$.

For the stratification variables a statistically significant main effect was found for experience in pediatric nursing on nurses' intervention only. Nurses with more than 10 years experience were less inclined to administer an analgesic $\left(F_{2,194}=5.22\right.$; $p=0.01$ ). 
A

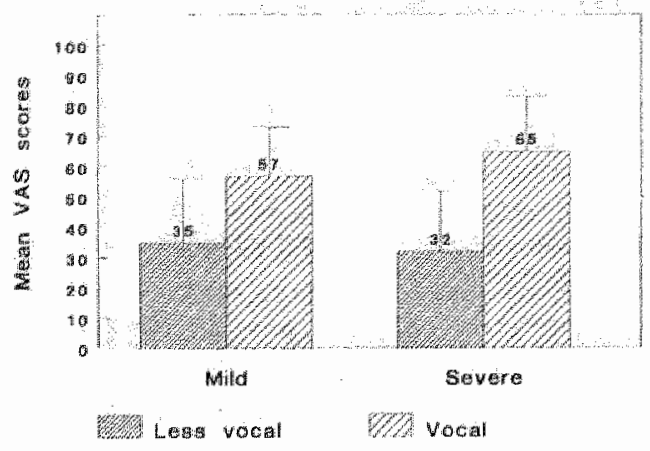

8

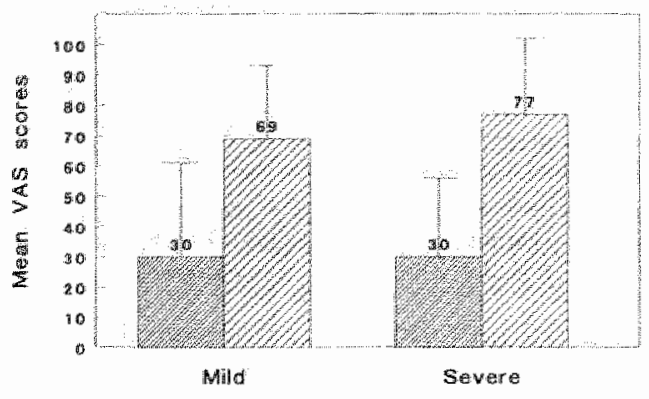

Figure 3. Mean ( 1 SD) VAS $10-100$ ) ratings of pain assessment $(A)$ and adiministration of analgesics $(B)$. No statisitically significant interaction-ffects were found:

\section{Case /I}

The hypotheses regarding the influence of information obtained from parents and of age an pain assessment and intervention were supported; no main effects were found. There were also no main or interaction effects for the stratification variables.

A.

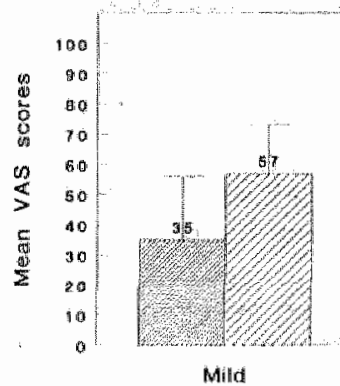

Prothes vocil

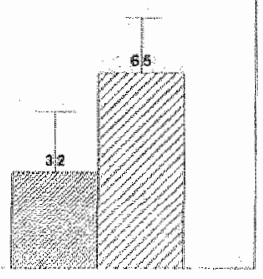

Sowere

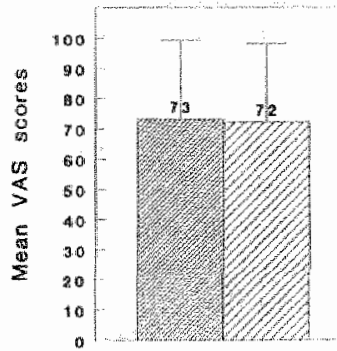

Young

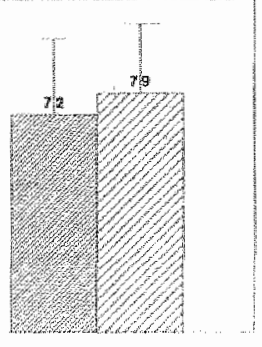

Older Hacal

Figure 4. Mean (w SD) VAS $10-100$ ) ratings of pain assessment (A) aind administration of analgesics (B). Mo statistically significant interaction-effects were found.

Yet, as can be seen from Figure 4 , a trend $\{p=0.06)$ was found indicating that nurses attributed more pain to the older child. The expected interaction between information obtained from parents and child's age on both assessment and intervention was not found; no interaction-effects were found to be statistically significant. 


\section{Case $/ I$}

The results for case 111 are presented in Figure 5. Hypotheses regarding the influence of the child's expressions were replicated. Again, nurses attributed more pain to the child who expressed his pain vocally $\left(F_{1,194}=21.61 ; p<0.0011\right.$ and said they were more inclined to administer an analgesic to this child than to the one who did not express himself vocally $\left(F_{1.194}=5.08 ; p=0.03\right)$. Age appeared to have no influence on nurses" pain assessments or on the administration of analgesics. In contrast to the result presented in case 11 , no trend was found. There were also no main or interaction-effects for the stratification variables.

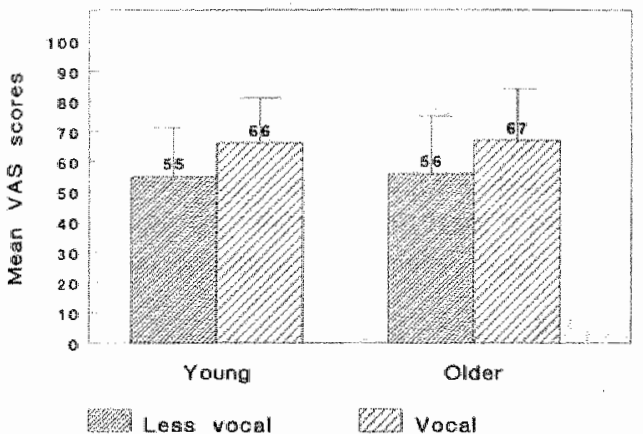

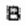

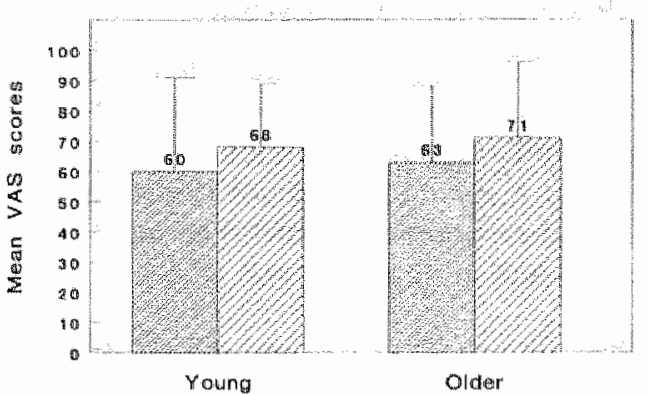

Figure 5. Mean ( 1 SD) VAS (O-100) ratings of pain assessment (A) and administration of analgesics (B). No statistically significant interaction-effects were found.

Since child's expression and age were present in two cases an overall analysis for each of these factors was carried out. In order to examine the effect of the child's expression an overall analysis for the cases I and III was carried out. Using a twoway ANOVA a main effect for the child's expression for both the pain assessment $\left(F_{1,198}=144.80 ; p<0.001\right)$ and intervention $\left(F_{1,198}=135.15 ; p<0.001\right)$ was found. These findings indicated that nurses attributed more pain, and were more inclined to administer an analgesic, to the child who expressed his pain vocally than to the child who did not. As expected, these results were similar to those of cases I and III. However, it should be stressed that further analysis indicated that the effect for expression in case I was different from the effect in case III for both assessment $\left(F_{1,198}=19.43 ; p<0.001\right)$ and intervention $\left(F_{1,198}=35.21 ; p<0.001\right)$; the effect in case III was smaller. As a result, the overall test for expression should be interpreted as a test for the mean effect over both cases.

To examine the effect of the child's age an overall analysis for the cases II and III was conducted. A trend was again found indicating that nurses attributed more pain to the older child $\left\langle F_{1,198}=3.97 ; p=0.05\right)$. However, there was no main effect for the intervention $\left(F_{1.198}=1.99 ; p=0.15\right)$. These results were similar to those presented by cases II and III. Although the p-value for assessment in the overall analysis was 
decreased, it still did not reach statistical significance. There were also no differences in the effect for age between the two cases for both assessment $\left(F_{1,198}=0.76\right.$; $p=0,38)$ and intervention $\left(F_{1,198}=0 ; p=0.99\right)$.

In none of the three cases were there any significant differences between groups in ratings on the question about confidence that pain assessment was correct. In the first case, ratings ranged from 61 to 66 , in the second from 69 to 72 , and in the third from 60 to 63 .

Finally, as shown in Table 3, VAS scores on pain assessment correlated strongly with VAS scores on the administration of analgesics in all cases.

Table 3. Correlations between patr assessment and interventon based on VAS Scores

\begin{tabular}{lcc} 
& $r$ & $<$ \\
Casse ! & 0.81 & $<0.001$ \\
Casie 1. & 0.71 & $<0.001$ \\
Case III & 0.66 & $<0.001$ \\
\hline
\end{tabular}

\section{DISCUSSION}

The predominant finding from this study is that pediatric nurses attribute more pain to children who vocally express their pain than to children who express themselves less vocally or not at all. Moreover, the same nurses were more inclined to administer non-narcotic analgesics to children who vocally express their pain. Nurses apparently consider vocal expression a reliable and valid cue for the diagnosis of pain in children. This funding confirms results from earlier studies (Wallace, 1989; Hamers et al., 1994b). Especially in infants, crying is reported to be an important and potent source of information (Grunau \& Craig, 1987; Shapiro, 1993; Craig \& Grunau, 1994; Hudson, 1994). However, according to Craig and Grunau (1994) crying acts as a warning alarm, but facial activity provides more discriminating information. In the present study the vocal expressions were operationalized via videoscenes, which means that nurses also saw glimpses of the child's facial expression. Since a change in vocal expression sometimes may result in a change in facial expression, it could be that the effect of vocal expression found in the present study, was modified by the facial expression.

Nevertheless, one must question the implications these findings have for children who express their pain less vocally. It should be noted that expression of pain intensity and subjective ratings of patients' pain are only weakly correlated (Hester, 1979; Beyer et al., 1990; Vlaeyen, 19911, while the tendency to vocally express pain is mediated by cultural factors and personality traits. Considering this, there is a real risk that children who do not vocally express pain are undermedicated.

The observation that there is no effect of severity of diagnosis on pain assessment and intervention contradicts earlier findings. For this, several explanations can be put forth. 
First, the concept of 'mild' and 'severe' medical diagnosis has been interpreted differently in different studies, which makes it difficult to compare the results. In the present study, a 'severe diagnosis' is synonymous with "painful surgery". Like Bush et al.'s (1989) study painfullness of a surgery was based on experts" judgments: Probably, the contrast between the mild and severe diagnosis in the present sudy (adenoidectomy versus closure of anus praeternaturalis) was too small. Furthermore, one could question in general if experts" judgments on the painfullness of a surgery are sufficiently valid. In a study by Kokke et al. (1993) it appeared that there were huge differences in experts' (pediatricians, surgeons, anesthesiologists and nurses) ratings of painfulness. For example, when 71 experts were asked to rate on a VAS how painfull a circumcision is, 19 subjects rated between $0-3$, while 21 subjects rated between of 8-10.

Next, as mentioned earlier, the designs of existing studies are weak with respect to the ability to draw conclusions on causal relationships. Most of the studies are exploratory (Burokas, 1985; Arkesteyn et al., 1990), in which subjects had to; among other things, complete questionnaires about 14 factors that they thought would influence their decisions. However, Burokas (1985) found that answers to the questionnaires did not always coincide with actual behavior; although subjects stated that the type of surgery was most influential, it was not proven in actual chart data.

Finally, it may be that the operationalization of the severe diagnosis in the present study is somewhat biased. Although the cases in pilot studies were tested extensiveIy, four nurses from three hospitals questioned the validity of the combination of the vignette of the severe diagnosis (Table 1) and the videotape of the child expressing his pain less vocally. Two nurses thought children with the stated diagnosis generally would express more pain, while two other nurses questioned whether the analgesic that had been prescribed was adequate. However, the four nurses stated that they answered the questions assuming the cases were valid. Future research could certainly replicate this part of the study with other medical diagnoses.

The criticism regarding operationalization of the diagnosis, raises another relevant question with regard to the present study, namely: are the decisions based on the vignettes and videos comparable to real-life situations? Obviously, the cases are simulations, but from discussions with the nurses it appears that most of them think the cases come very close to reality. An indirect indication comes from the high ratings on the VAS for all of the cases when nurses were asked how confident they were that their pain assessment was correct. These results support the validity of the cases.

Although the hypothesis was that there would be an interaction between medical diagnosis and child's expressions only a trend was found for assessment. Nurses tended to attribute the most pain to the child when the diagnosis was severe and the child vocally expressed his pain. However, this was no reason for nurses to say that they were more inclined to administer the non-narcotic analgesic. This finding is remarkable, especially in view of the fact that strong correlations were found between the pain assessment and administration of analgesics (See Table 3). As mentioned above, this could be explained by the phenomena that subjects' answers 
regarding their actions not always concide with their actual behaviors. However, it is also known that nurses" attitudes towards analgesics in general, may keep them from administering analgesics (Arkesteyn et al., 1990; Elander et al. 1991). In several studies (Elander et al. 1991; Hamers et al, 1994b; Mather \& Mackie, 1983) pediatric nurses were found to postpone non-narcotic analgesics as long as possible. These findings also may explain why, in the present study, no significant findings were found for the diagnosis $x$ expression interaction for intervention (Figure 3 ).

Since no information was avaliable in this study on nurses' attitudes towards acute pain and its management in children, it is not known whether attitudes differed between the groups and how they influenced nurses' answers. However, there was information on two other nurses' characteristics: knowledge (specialized education) and experience (in pediatric nursing). Although knowledge didn't have impact on the nurses ${ }^{\prime}$ decisions in all the cases, experience did influence the nurses decision to administer the analgesic in case l. However, since experience didn"t have impact on the pain assessment in case I and on assessment or intervention in cases $\mid I$ and $I I{ }_{\text {. }}$ this finding also could be a statistical artifact.

As expected, the child's age does not seem to determine nurses decisions in general. Indeed, there are no theoretical reasons to believe that an older child would experience more pain than a younger child, or why the reverse would be the case: Although the nurses tended to attribute more pain to the older child, this did not necessarily imply that older children would receive a non-narcotic analgesic earlier. However, it should be mentioned that operationalization of age was difficult; age was manipulated in the vignettes, but the nurses saw the same videotape. This means that it had to appear as though the child on the videotape was both 3 and 5 vears old. From the discussions it is clear that just a few nurses had doubts about the correspondence of age in the vignette and the video. However, a more serious question is whether the present operationalization was strong enough to measure if the child's age influenced the nurses' decisions. In future research, this part of the study could be replicated, with the contrast between age groups increased (e.g.. 3 versus 7 vears old).

Finally, information obtained from the parents did not seem to determine nurses' decisions. This finding confirms earlier findings (Hamers et al., 1994b). Although it is ganerally assumed that such information is important in nurses' decision-making, one may question what the rationale for this is. In comparing the pain ratings of parents, children, and nurses no real differences were found; in fact, nurses tended to overestimate paim rather than to underestimate it (Boonstra et al., 1992). Furthermore, Manne et al. (1992) suggest that parents ratings may not provide a good indication of pain the child experiences, and that nurses' ratings of acute pain may more closely approximate an objective assessment of pain. Finally, Finley et al. (1993) found in their study that most parents gave inadequate doses of presciribed analgesics, even when they realized that their children were in pain. The role of parents is obviously still obscure and, as a result, warrants further investigation. 


\section{REFERENCES}

Altman, D.G. (1991). Practical statistics for medical research. Chapman \& Hall, London.

Arkesteyn, S., Huijer Abu-Saad, H. \& Halfens, R. 11990). De attifude van verpleagkundigen (Nurses: attitudes). Tijdschrift Voor Ziekenverpleging, 100, $396-398$.

Armitage, P. \& Berry, G. (1987). Statistical methods in medical research. Blackwell, Oxford.

Atchison, N., Guercio, P. \& Monaco, C. (1986). Pain in the pediatric burm patient: nursing assessment and perception. Issues in Comprehensive Pedatric Nursing, 9, 399-409.

Beyer, J.E., McGrath, P.J. \& Berde, C.B. (1990). Discordance between self-report and belnavioral pain measures in children aged 3-7 years after surgery. Journal of Pain and Symptom Managagentent. 5. 350-356.

Boonstra, L.C., Teule, J.A., Kastermans, M. \& Dassen. Th. (1992). Pijnbeoordeling bij kinderen, een onderzoek bij kinderen met pijn ten gevolge van medisch onderzoek en ten gevolge van ziekte (Pain assessment in children, an investigation of children in pain caused by medical tests and illness). Verpleegkunde, 7, 147-151.

Broome, M.E. \& Slack, J.F. (1990). Influences on nurses' management of pain in children. Maternal Child Nursing, 15, 158-162.

Burokas, L. (1985). Factors affecting nurses' decisions to medicate pediatric patients after surgery. Heart \& Lung, 14,373-379.

Bush, J.P., Holmbeck, G.N. \& Cockrell, J.L. (1989). Patterns of PRN analgesic drug administration in children following elective surgery. Journal of Pediatric Psychology. 14,433-448.

Craig, K.D. \& Grunau, R.V.E. (1994). Infant pain behaviors and clinical decision-making: judging pain in newborns, Abstractbook, pp. 227. Third international Symposium on Pediatric Pain, Philadol. phia.

Dick, M.J. (1993). Preterm infants in pain. Nurses' and physicians perceptions. Clinical Nursing Research, 2, 176-187.

Dudley, S.R. \& Holm, K. 11984). Assessiment of the pain experience in retation to selected nurse characteristics. Pain, 78, 179-186.

Elander, G., Lindberg. T. \& Quarnström, B. 11991\%. Pain relief in intants after major surgery: a descriptive study. Journal of Pediatric Surgery, 26, 128-131.

Elander, G. \& Hellström, G. (1992). Analgesic administration in children and adults following open heart surgery. Scandinavian Journal of Caring Sciences, 6, 17-21.

Finley, G.A., McGrath, P.J., McNeill, G., Forward, P. \& Filzgerald, P. (1993). Severity and parents' management of postoperative pain in children, IASP Abstractbook pp. 307. 7th World Congress on Pain. Paris.

Gadish, H.S., Gonzalez, J.L. \& Hayes, J.S. (1988). Factors affecting nurses" decisions to administar pediatric pain medication postoperatively. Jounnal of Pediatric Nursing, 3, 383-390.

Gonzalez, J. \& Gadish, H. (1990). Nurses" decisions in medicating children postoperatively, In: D.C. Tyler \& E.J. Krane (Eds.l. Advances in Pain Research and Therapy, 15, 37-41. Raven, New York.

Grunau, R.V.E. \& Craig, K.D. (1987). Pain expression in neonates: facial action and cry. Pain, 28, $395-410$.

Halfens, R., Evers, G. \& Abu-Saad, H. 11990/. Determinants of pain assessment by nurses. International Journal of Nursing Studies, 27, 43.49.

Hamers, J.P.H. Huijer Abu-Saad. H. \& Halfens, R.J.G. (1994). The diagnostic process and decisionmaking in nursing, a literature review. Journal of Professional Nursing, 10, 154-163.

Hamers, J.P.H., Hujer Abu-Saad, H. Halfens, A.J.G. \& Schumacher, J.N.M. (1994). Factors influencing nurses* pain assessment and interventions in children. Journal of Advanced Nursing, $20,853-860$.

Hester, N.K. 11979|. The pre-operational child"s reaction to immunization. Nursing Research, 28, 250. 255. 
Kokke, F.T.M., Van der Heide, D.H. B Boelen-Van der Loo, W.J.C. (1993). Postoperatieve pinbe Gtrijing in orie Nederlandse ziekenhuizen: een pilotstudie (Post-operative pain managment in three Dutch hospitals: a pilot study). Tijoschirft voor Kindergeneeskunde, $61,48-51$.

Koolen, Y.H.E. Perduin, M.D. (1991). Clinical Judgement. Acutely and chronically ill children in pain. Rijksuniversiteit Limburg. Maartricht. (unpublished master thesis)

Lumey, M. (1992). Development of written case studies as simulations of diagnosis in nursing. Nursing Diagnosis, 3, 23-29.

Manne, S.L., Jacobsen, P.E. \& Redd, W.H. 119921. Assessment of acute pediatric pain: da child selfreport, parent ratings, and nurse ratings measure the same phenomenon? Pain, 48, 45-52.

Mather, L. \& Mackie. J. (19B3). The incidence of postoperative paim in children. Pain, 15, 271-282.

Schechter, N.L. Allen, D.A. \& Hanson, K. 11986 . Status of pediatric pain control: a comparison of hospital analgesic usage in children and adults. Pediatrics, 77, 11-15.

Shapiro, C.R. (1993). Nurses' judgments of pain in term and preterm newborns. Journal of Obstetric Gynecologic Neonatal Nursing, 22, 41-47.

Taylor, A.G., Skelton, J.A. \& Butcher, J. (1984). Duration of pain condition and physical pathology as determinants of nurses' assessments of patients in pain. Nursing Research, 33, 4-8.

Vlaeven, J.W.S. 119911. Chronic low back pain. Assessment and treatment from a behavioral rehabilitation perspective. Swets \& Zeitlinger, Amsterdam.

Waliace, M.R. (1989). Temperament: a variable in children's pain management. Pediatric Nursing. 15. $118-121$. 
Differences in pain assessment and decisions regarding the administration of analgesics between novices, intermediates and experts in pediatric nursing'

${ }^{1}$ Hamers, J.P.H., Van den Hout, M.A., Halfens, R.J.G. Huijer Abu-Saad, H. \& Heijltios, A.E.G. Submitted for publication. 


\section{SUMMARY}

This article describes a study examining the influence of expertise on nurses' pain assessments and decisions regarding pharmacological interventions in children. In an experimental design, novices $(n=271)$, intermediates $(n=222)$, and experts $(n=202)$ in pediatric nursing, were presented with various cases. Each case consisted of a combination of a vignette and a video. Subjects were asked (1) to assess the child's pain intensity, (2) to specify their confidence in the assessment, and (3) to state whether or not they would administer a non-narcotic analgesic. The results indicated that expertise did not influence assessments of pain intensity. However, expertise did have a distinct impact on both the subjects' confidence in their decisions, and the decision to administer analgesics; experienced nurses were most confident and were most inclined to administer analgesics. 


\section{INTRODUCTION}

Knowledge and experience seem to affect both nurses' pain assessments and their interventions in children (Hamers et al., 1994a). It is generally assumed that education and practical experience increases accuracy in decision-making. Several theoretical approaches to decision-making are, in fact, based on this assumption le.g. Benner, 1984; Boshuizen, 1989; Schmidt et al., 19901.

In the nursing literature, a number of stuidies on decision-making with regard to general nursing problems are described which seem to confirm this assumption. In such studies performances of experts are compared with those of novices. Trends found by Corcoran (1986) and Tanner et al. (1987) indicate that experts performed better and were more accurate than novices in diagnosing and planning. However, it should be stressed that research on accuracy in decision.making in nursing is hampered since it is often not know what an accurate decision is (Hamers et al., 1994b). Other decision-making studies investigated the assumption that expertise influences problem-solving skills. A study by ttano (1989) demonstrated differences in decisionmaking between experts and novices; experts used more and different cues than novices. Howewer, Sanford et al. (1992) did not find differences in decision-making skills between nurses with different levels of educational preparation. Schmidt et al. (1990) report similar results in the medical literature. According to these authors experts do not have superior reasoning skills but their decisions, in contrast to those of novices' are based on cognitive structures that describe the features of prototypical or even actual patients.

Since expertise does influence decision-making it may be expected that experts and novices differ in their decisions regarding pain assessment. One may question how knowledge and experience influence pain assessments. Do experts generally assess pain as more severe than novices? Or is the reverse the case?

Several studies revealed different results. Shapiro (1993) suggested that knowledge and experience do not influence assesments of pain intensity. However, Lenburg et all. (1970) suggested that knowledge influences pain assessments; first-year studients attributed more pain to hypothetical patients than second-year students. This was supported by Davitz and Davitz (1980) who found that the estimated intensity of patients' physical pain decreases in the course of nursing education. However, Halfens et al. (1990) reported conflicting results with regard to the influence of knowledge on pain assessment. They found that assessments of pain increase in the course of education; student nurses in the last two years of their education assess pain as more intense than student nurses in the first year of their education.

Mason's (1981) study suggests that it is not nurses' educational preparation which affects pain assessment, but nursing experience; assessments of pain of nurses with less than one vear experience are the highest, assessments of nurses with six to ten years experience the lowest. In other words, Mason's study shows that the assessed intensity of pain decreases with increasing vears of experience. However, the assessed intensity of pain increases when nursing experience exceeds ten years, which means that there is an inverted U-shaped relationship between years of exper. ence and assessed intensity of pain. In addition. Halfens et al. (1990) reported 


\section{METHODS}

\section{Design}

This study used the materials of a previous study (Hamers et al., in press). In an experimental design, subjects were presented with various cases. See Figure 1.

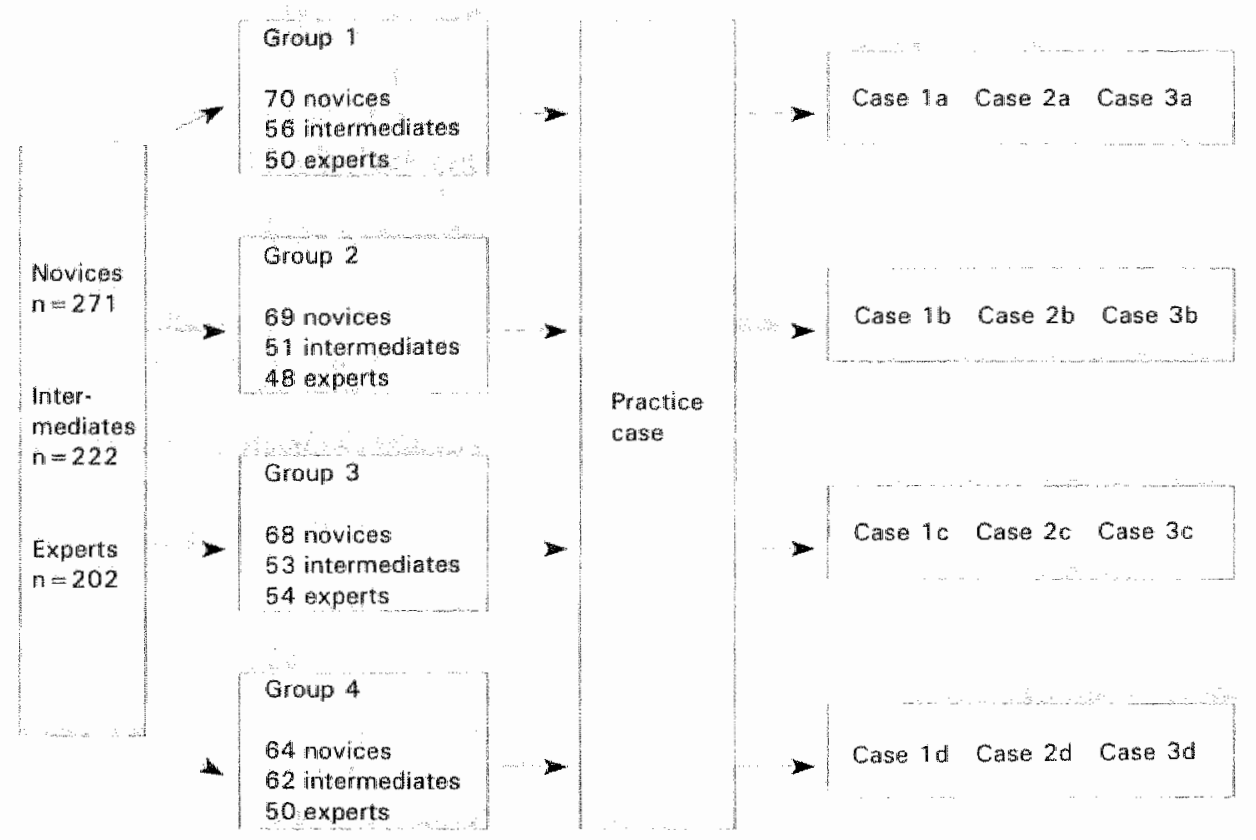

Figure 1. Illustration of the study dasign

As can be seen from Figure 1, each subject was presented with 4 different cases, including a practice case. To control for unintended idiosyncracies of cases, different sets of cases were used. For this reason, subjects were assigned to four different groups.

\section{Subjects}

695 subjects participated in this study. The population was composed of three samples: novices, intermediates and experts.

Novices were 271 nursing students ( 239 females and 32 males). who were attending the first year of a B.S.N.-program. They were selected from 6 nursing schools in 
different regions of the Netherlands. Their mean age was 19.4 years $1 \mathrm{SD}=2.1$; range $=17-35)$. Intermediates were 222 nursing students 1194 females and 28 males), who were attending the fourth year (graduation year) of a B.S.N.-program. They were selected from 5 nursing schools in different regions of the Netherlands. Their mean age was 22.2 years $(S D=2.2$; range $=20-43)$. Experts were 202 pediatric nurses (180 females and 22 males) from 11 hospitals in the Netherlands, who had participated in a previous study (Hamers et al., in press; see chapter V). Their mean age was 32.1 years $(S D=7.0$; range $=22-56)$.

The novices and the intermediates were randomly assigned to four experimental groups after prestratification for nursing school. The experts were assigned to the experimental groups after prestratification for experience $[0-3 ; 4-7 ; 8-11 ; 12-15 ; \geq$ 16 years in pediatrics), knowledge (specialized education in pediatrics: yes or no), and type of hospital (ward).

\section{Procedure}

As can be seen from Figure 1, each of the 695 subjects was presented with four different cases. A case consisted of a vignette and a video scene llasting about 30 seconds). Although the subjects were unaware of it, the first case was a practice case, so that they were able to get used to the task.

Each vignette contained standardized information about the child's name, age, type of surgery, prescription af analgesic pro re nata (p.r.n.). An example of a vignette is given in Table 1.

The video scene showed a hospitalized child recovering from surgery. In order to improve reliability and validity, the vignettes and the accompanying video scenes were tested in pillot studies (Hamers et al., in press; see chapter V).

Data was collected by two researchers during 15-minute sessions. At each session, standardized intstructions were given about the procedure. Special attention was paid to the correct way of filling in the rating scales and to the fact that subjects were not allowed to communicate with each other during the task.

Each subject was presented with four different cases. The procedure for all cases was as follows: (1) subjects read the vignette, (2) the video was shown, (3) subjects answered three questions (see measurements). The time to answer each question was restricted by the researcher: subjects had to rate their answers immediately after the reseacher had asked the question alloud.

Table 1. Example of a vignette.

Jef is a boy.

He was admitted with the indication 'llonsillectomy" lsurgical remowal of the tonisilsh.

He underwent surgery this moning. Jef may have paracetamol (rectally), 240 mg p.r.n. to reduce pain, a maximum of tour times a day

Jet is 5 years old.

With this information you enter jefts room.

At that time it is several hours after the surgery. 


\section{Measurements}

Subjects rated their answers to the following questions on a 100-millimeter Visual Analog Scale (VAS):

- Please rate the pain experienced by the child in this case;

- How sure are you that your pain assessment is correct?;

- Would you administer an analgesic to the child in this case?

The scales ranged from ' $O$, no pain at all' to ' $100_{x}$ extreme pain', from ' 0 , completely unsure' to '100, completely sure', and from ' $O$, would definitely not administer' to '100, would defenitely administer', respectively. The distance from zero to the vertical mark of the subject was measured in millimeters.

\section{RESULTS}

Table 2 shows the distribution of subjects over the four groups. As can be seen from Table 2, randomization and stratification were successful. The mean VAS scores were analyzed by means of 'expertise' $x$ 'group' ANOVAs. The variable 'group' was included because each group was shown a different series of cases. If ANOVA revealed significant findings, indicating that at least two mean scores differed, Tukey's multiple comparisons procedure was applied in order to detect which means differed. The results for the hypotheses are presented for each hypothesis separately below.

Table 2. Distribution of subjects over the four research groups.

\begin{tabular}{|c|c|c|c|c|}
\hline & Group 1 & Group 2 & Group 3 & Grokip 4 \\
\hline Novices: & 70 & 69 & 68 & 64 \\
\hline intermediates" & 56 & 51 & 53 & 62 \\
\hline Experts" & 50 & 48 & 54 & 50 \\
\hline
\end{tabular}

\section{Hypothesis on pain assessment}

Our hypothesis regarding the influence of expertise on pain assessment was not supported. Contrary to our hypothesis, Figure 2 suggests that there were no systematic differences in pain assessments between novices, intermediates and experts; the expertise main effect was not significant.

However, a main effect was found for group $\left(F_{3,683}=6.95 ; p<0.001\right)$, indicating that 
certain characteristics of the cases shown to the subjects were responsible for differences in their pain assessments. As can be seen from Figure 2, the assessment scores in group 3 were the highest.

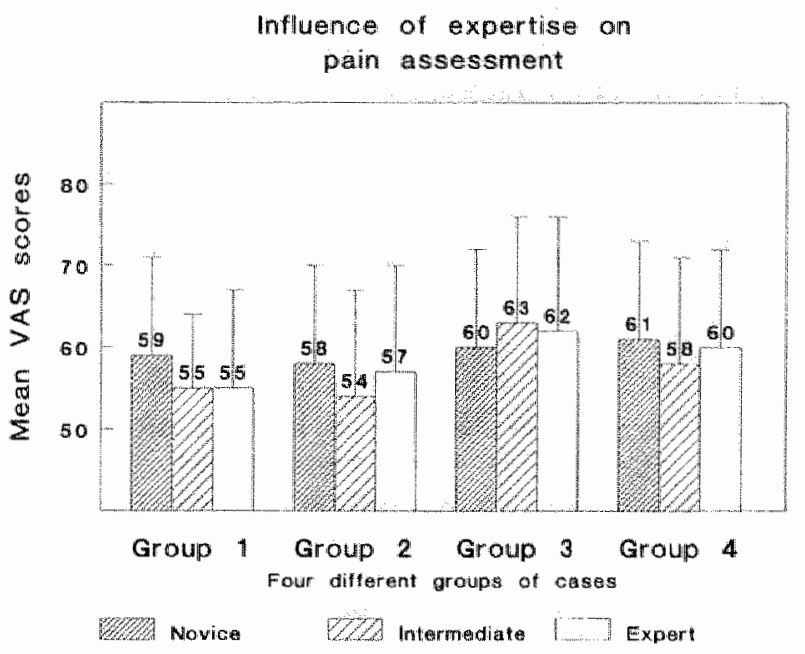

Figure 2. Mean $( \pm$ SD) VAS (0-100) ratings of pain assessment of novices, intermediates and experts for tour different groups of cases

Note. Tukey's multiple comparisons test revealed statistically significant differences between groups 1 and 3,1 and 4,2 and 3, and 3 and $4(p<0,01)$.

Hypothesis on confidence in making correct decisions

The pattern of the influence of expertise on the subjects' confidence in their decisions is presented in Figure 3.

As expected, a main effect was found for expertise $\left(F_{2,883}=21.91 ; p<0.001\right)$. However, as can be seen from Figure 3, the hypothesis on confidence in decisions was only partly supported. Experts were indeed most confident that their pain assessments were correct $(p<0.01)$. However, intermediates were expected to be more confident than novices, but we found the reverse pattern, which proved to be statistically significant $(p<0.01)$.

\section{Hypothesis on decisions regarding the administration of analgesics}

Our hypothesis regarding the influence of expertise on decisions regarding the administration of analgesics was not supported. We found a main effect for expertise $\left(F_{2,682}=26.91 ; p<0.001\right)$, indicating that novices, intermediates and experts differed in their decisions to administer analgesics. As can be seen from Figure 4, experts were more inclined than both novices and intermediates to administer analgesics $(p<0.01)$. 


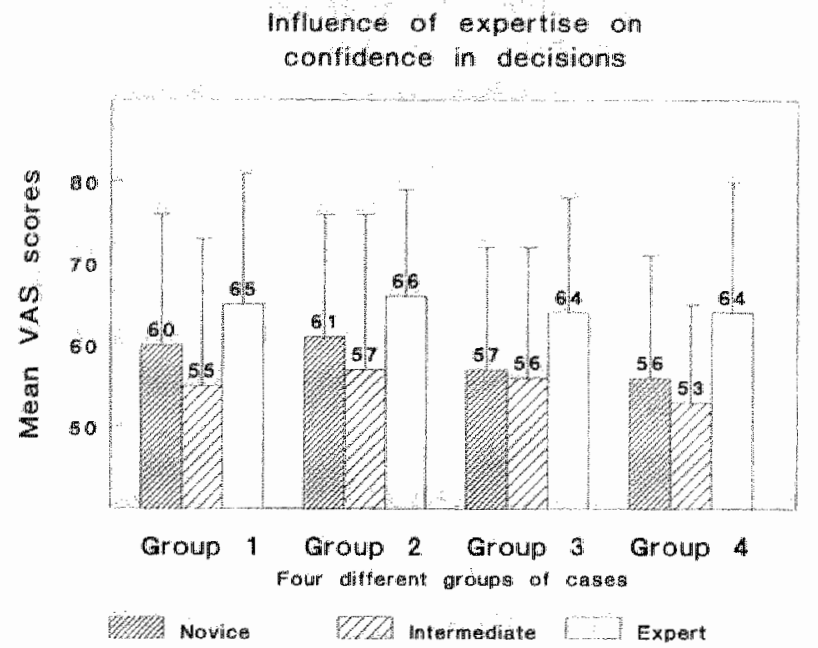

Figure 3. Mean ( \pm SD) VAS 10.100 ) ratings representing subjects' confidence in their decisions for four different groups of cases

Note. Tukey's multiple comparisons test revealed statistically significant differences between experts and intermediates, between experts and novices $\{p<0.011$, and between nowices and intermediates ( $\mathrm{p}<0.011$.

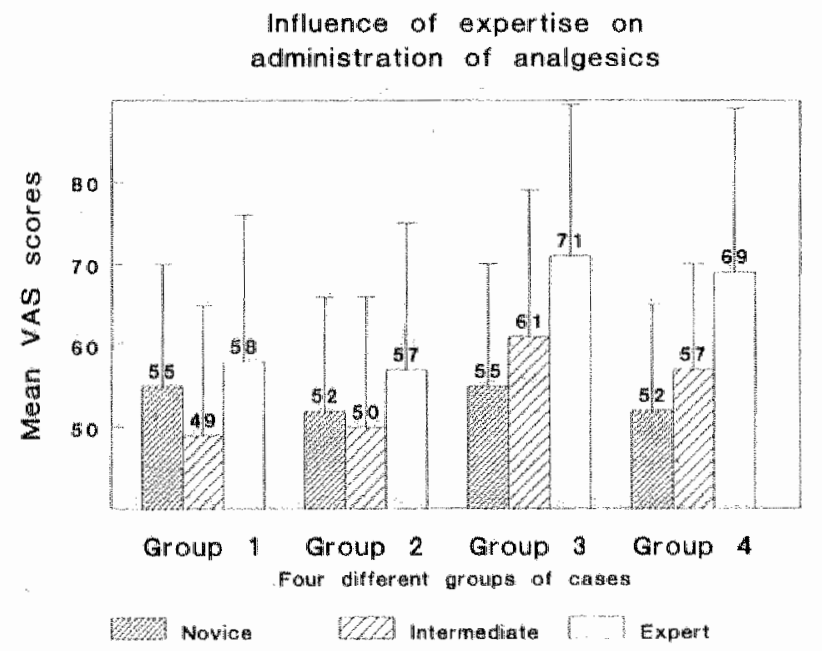

Figure 4. Mean (IESD VAS (0-100) ratings regarding the administration of analgesics by novices, intermediates and experts for four different groups of cases

Note. Tukey"s multiple comparisons test revealed statistically significant differences between experts and both intermediates and novices $(p<0.011$. Furthermore, statistically significant differences were found between groups 1 and 3,2 and $3(p<0,01)$, and 4 , and 2 and $4(p<0,05)$. 
As was the case with assiessment, a main effect was found for group $\left(F_{3,6} \leq 9.97\right.$ : $p<0.0011$. This means that certain characteristics of the cases that were shown to the subjects seem to influence their decisions regarding the administration of analgesics. However, this group effect was moderated by a statistically significant interaction with expertise $\left(F_{6.682}=3.59 ; p<0.01\right)$. As can be seen in Figure 4, novices in the four groups did not differ in their decisions regarding the administration of analgesics. This means that they were inclined to administer an analgesic, irrespective of the characteristics of particular cases. However, it can also be seen in this Figure that the intermediates and experts from groups 3 and 4 were more inclined to administered analgesics than those in groups 1 and 2 . Furthermore, experts appear to be influenced most by certain characteristics of the cases in their decisions about the administration of analgesics.

\section{DISCUSSION}

A remarkable finding in this study is that expertise does not influence pain assessments. The expectation that assessed pain intensity would decrease with an increasing level of expertise was not supported. Novices, intermediates and experts did not differ in their assessments of children's pain intensity in 12 different cases. Several explanations could be suggested. First, it could be argued that the simulations (vignettes and videosi are not comparable with real-life situations. However, this is unlikely because several pediatric nurses participating in the study remarked that the cases closely resembled reality. These remarks were supported by the high ratings on the VAS when these nurses were asked how confident they were that their assessment was correct. Another explanation could be that the cases were too uncomplicated; it is quite clear in the vignette and the video scene whether the child is in paim or not. However, it is hardly reasonable to assume that this was the case for all 12 different cases.

Furthermore, there are several theoretical explanations. The level of expertise, probably, does not determine final pain assessments, but may determine how fast one reaches a decision regarding assessment. In a study by Hamers et al. (1993) it was indicated that expertise influences the amount of time needed to come to a decision; experts make up their minds more quickly. This finding is consistent with the results in Schmidt et al. 1990\%, who suggested that intermediates require more time to carry out a task. Although the time needed to make a decision was restricted in this study, no differences were found between novices and experts to support the results mentioned earlier. Although, time limits in the present were rather arbitrary, it is noteworthy that intermediates from two different nursing schools argued that they did not have enough time to make their assessments.

As mentioned before, there is growing evidence that mainly practical experience is responsible for differences in decision-making between novices and experts (Hobus 1994; Radwin, 1995; Schmidt et al., 1990; Tanner et al., 1993). Schmidt et al. "s $(1990)$ theory on the development of expertise assumes that experts' decisionmaking is based on cognitive structures that describe the features of prototypical or even actual patients, so-called 'illness scripts', which contain a wealth of clinically 
relevant information about disease, its consequences, and the context under which illness develops. Hiness scripts consist of three parts: enabling conditions, the fault and consequences (Boshuizer, 1989; Schmidt et al. 1990). Enabling conditions, or contextual information (Hobus, 1994), are factors le.g., age, sex, risk behavior, social class) that make the occurence of a disease more likely. The fault is a description of the malfunction. The consequences are the signs and symptoms le.g. laboratory data, complaints) that arise from the fault. The assumption is that experts for each disease do have an illness script. Furthermore, thils theory on medical expertise implies that experts only have scripts about deseases in which they have practical experience. In other words, one becomes an expert as he has the availability over certain scripts. In the present study experts were pediatric nurses who were working in different fields (e.g., general surgery, oncology, ear nose and throat (ENT), inten. sive care) of pediatrics, while the cases presented in the experiment almost all were related to the ENT-field. As a result, it could be that the nurses in the present study actually were no experts. This might explain why pediatric nurses and novices and intermediates did not differ in their pain assessments.

Next, in recent studies Hobus (1994) has demonstrated that experts decision-making is highly based on the usage of contextual information. Differences in accuracy in decision-making between experts and nowices decreased when no contextual information was given. The fact that in the present study limited contextual information was given may also explain why there were no differences in pain assessments between novices, intermediates and experts.

A final explanation for this finding could be that the subjects in the experimental study were not asked to make a diagnosis $(\mathrm{e} . \mathrm{g}$. . the child is in pain, the child misses his mother, the child is sick) but to estimate the child's pain intensity. This might have reduced the novices' and intermediates' cognitive strains, and as a result they were able to perform the task on a level which comes close to the level of the expert.

In conlusion it can be said that more research will be needed on the impact of both knowledge and experience on pain assessments.

The observation that experienced nurses were most confident that their pain assessments were correct, is in line with with our assumption. However, the results of this study have shown that there is no linear relationship between level of expertise and subject's confidence; novices were more confident of the correctness of their decio sions than intermediates. In other words, the subjects ${ }^{*}$ confidence in their decisions seems to decrease during their education. This pattern is consistent with general theories on decision making (Benner, 1984; Schmidt et al., 1990).

While novices in this study make their assessments off the cuff, intermediates compare data again and again before they come to a final decision. During the datacollection sessions intermediates from two different nursing schools were the ones who argued that they had to make their assessments too quickly; they would have litked more time to think their decisions over.

Nursing students are probably taught to make decisions systematically, and to use all kinds of data, so that they pass through every stage of the decision-making process consciously. Furthermore, the students may have learned that assessing patients' pain is a complicated matter and that the experience of pain may be influenced by 
many factors. It is possible that the intermediates struggle with the information about the cases, because they are taught to be careful when judging a patient's situation.

Experienced nurses, on the other hand, do not go through the stages in the decisionmaking process consciously. As Benner (1984) states, experts no longer use rules or formulas to guide their practice. Pediatric nurses have already seen many children in pain, and they often have to assess their pain. This practical experience has given them confidence in their decisions.

Although this was not hypothesized, the level of expertise had a distinct impact on the administration of non-narcotic analgesics. Experienced nurses were more inclined to administer analgesics than both novices and intermediates, which might indicate that differences in knowledge and experience account for this finding. However, with respect to knowledge acquired during basic nursing education, we did not find any differences in the decisions regarding the administration of analgesics between novices and intermediates. Although we hypothesized that this would be the case, this finding is still remarkable because in the literature a lack of knowledge is mentioned as one of the causes of the insufficient administration of analgesics. These results suggest that mainly practical experience is determining decision-making regarding the administration of analgesics. However, with respect to the influence of knowledge (acquired during education) it should be mentioned that the literature reported that formal nursing educational programs inadequately cover pain management and analgesics (Sheidler et al., 1992).

Furthermore, of importance to note is that an effect was found for group, which was moderated by level of expertise. This means that experts, in particular, were influenced by characteristics of some cases. These characteristics and their relationship with assessment and intervention will be the subject of another article (see chapter V). As was shown in Figure 4, intermediates and experts in groups 3 and 4 administered analgesics sooner than those in groups 1 and 2 . This finding could be due to sampling errors. But this explanation is not plausible mainly for two reasons. First, randomization and stratification were successful, as became clear from Table 2 . Experts from the different research groups had the same amount of practical experi. ence in pediatric nursing as well as the same kind of specialized education. Furthermore, stratification for cype of hospitall (ward) was done, because the pain policies of (wards in) the hospitals could be different. Second, a clear patterin in the data was found. While novices did not differ in the administration of analgesics over all cases, there was an increase in the administration of analgesics with an increase of expertise in groups 3 and 4.

Seeing that experienced nurses were more inclined to administer analgesics to children than nursing students are, is gratifying. This may be related to the nurses" practical experience, but also to the knowledge obtained through specialized (pediatric) education.

In the last decade, the literature has often suggested that nurses' knowledge about analgesics should be improved and that nurses administer analgesics insufficiently. The results of the present study may indicate that the administration of analgesics by pediatric nurses has improved. However, further research will be needed to answer this question. 


\section{REFERENCES}

Benner, P. (19841. From novice to expert: excellence and power in chinical nursing practice. AddisonWesley, Menio Park.

Boonstra, L.C., Teule, J.A., Kastermans, M. \& Dassen, Th, (1992). Pijnbeoordeling bij kinderen, een onderzoek bij kinderen met pijn ten gevolge van medisch onderzolk en ten gevolge van ziekte IPain assessment in children, an investigation in children with pain induced by medical examination and illiess: Verpleegkunde, 7, 147-151.

Boshuizen, H.P.A. 119891. De ontwikkeling van medische expertise. Een cognitief psycholagische benadering the development of medical expertise. A cagnitive psychological approach). Krips, Meppel.

Burokas, L. 119851. Factors affecting nurses' decisions to medicate pediatric patients after surgery. Heart \& Lung, 14,373-379.

Chang. A.M. \& Gaskill, D. 11991). Nurses' perceptions of their problem-solving ability. Journat of Advanced Nursing, 16, 813-819.

Cohen, F.L. (1980). Postsurgical pain relief: patients' status and nurses' medication choices. Pain, 9. $265 \times 274$

Corcoran, S.A. (1986). Task complexity and mursing expertise as factors in decision making. Nursing Research, 35, 107-112.

Davitz, L.L. \& Davitz, J.R. (1980). Nurses" responses to patients' suffering. New York: Springer.

Duidey, S.R. \& Holm, K. (1984). Assessment of the pain experience in relation to selected nurse characteristics. Pain, 18, 179-186.

Fothergill-Bourbonnais, F. \& Wilson-Barnett, J. (1992). A comparitive study of intensive therapy unit and hospice nurses' knowledge on pain management. Journal of Advanced Nursing, 17, 362-372.

Gadish, H.S., Gonzalez, J.L. \& Hayes, J.S. (1988). Factors affecting nurses' decisions to administer pediatric pain medication postoperatively. Journal of Pediatric Nursing, 3, 383-390.

Halfens, R., Evers, G. \& Abu-Saad, H. 1999 al. Determinants of pain assessment by nurses. Interna tional Journal of Nursing Studies, 27, 43-49.

Hamers, J.P.H. Huijer Abu-Saad, H. \& Halfens, R.J.G. (1993). Factoren die verplleegkundigen beïnwoeden bij het inschatten van pijn bij kinderen en het kiezen van pijnverlichtende interventies (Factors influencing nurses" pain assessment and pain-relieving interventions in children). Verpleegkunde, $8,141-157$.

Hamers, J.P.H. Huijer Abu-Saad, H., Halfens, R.J.G. \& Schumacher, J.N.M. (1994a). Factors influencing murses' pain assessment and interventions in children. Journal of Advanced Nursing, $20,853-860$.

Hamers, J.P.H., Huliar Abu-Saad, H. Halfens, R.J.G. (1994b), The diagnostic process and decisionmaking in nursing, a literature rewlew. Journal of Professional Nursing, 10, 154-163.

Hamers, J.P.H., Huijer Abu-Saad, H. Valn den Hout, M.A., Haltens, R.J.G. \& Kester, A.D.M. (in press). The influence of children's vocal expressions, age, medical diagnosis and information obtained from parents on nurses. pain assessments and decisions regarding interventions. Pain

Hobus, P. 1994J. Expertise van huisartsen. Praktijkervaring, kennis en diagnostische hypathese vorming. (Explertise of general practitioners. Practical experience, knowledge and diagnostic hypotheses). Thesis, Amsterdam.

Holden, G.W. \& Klinger, A.M. (1988). Learning from experience: differences in how novice vs. expert murses diagnose why an infant is crying. Journal of Nursing Education, 27, 23-29.

Itano, J.K. 119891. A comparison of the clinical judgment process in experienced registered nurses and student nurses, Jownal of Nursing Education, 28, 120-126.

Lenburg, C.B., Burnside, H. \& Davitz, L.J. 11970). Inferences of physical pain and psychological distress. III. in relation to length of time in the nursing education program. Nursing Research, 19, $399-401$.

Mason, D.J. (1981). An investigation of the influences of selected flactors on nurses' inferences of patient suffering. International wournal of Nursing Studies, 18, 251-259. 
Radwin, L.E. (1995). Conceptualizations of decision-making in nursing: analytical models and 'knowing the patient'. Nursing Diagnosis, $6,16-22$.

Ross, R.S., Bush, J.P. \& Crummette, B.D. 119911. Factors affecting nurses' decisions to administer FRN analgesic medication to children after surgery: an analog investigation. Joumal of Pedatric Psychology, 16, 151-167.

Sanford, M., Genrich, S. \& Nowotny, M. 1992). A study to determine the difference in clinical judgment abilities between BSN and non-BSN graduates. Journal of Nursing Education, 31, 70.74. Schmidt, H.G., Norman, G.R. \& Boshuizen, H.P.A. 11990). A cognitive perspective on medical expertise: theory and implications. Academic Medicine, 65, 611-621.

Shapiro, C.R. (1993). Nurses" judgments of pain in term and preterm newborns. Joumal of Obsterric Gynecalogic and Neonatal Nursing, 22, 41-47.

Sheidler, V.R., McGuire, D.B., Grossman, S.A. \& Gilbert, M.R. (1992). Analgasic decision-naking skills of nurses. Oncology Nursing Forum, 19, 1531-1534.

Tanner, C.A. (1984). Factors influencing the diagnostic process. In: D.L. Carnevali, P.H. Mitchell, N.F. Woods \& C.A. Tanner (eds.M. Diagnastic reasoning in rursing. Lippincott, Philadelphia , pp. 61. 82.

Tanner, C.A., Padrick, K.P., Westfall, U.A. \& Putzier, D.J. (1987). Diagnostic reasoning strategies of murses and nursing students. Nursing Research, 36, 358-363.

Tanner, C., Benner, P.. Chesla, C. \& Gordon, D. (1993). The phenomenology of knowing the patient. Image, 25, 273-280. 


\section{The effect of paracetamol, fentanyl, and systematic assessments on children's pain following (adeno)tonsillectomy'}




\section{SUMMARY}

This article reports on a study which addressed three questions: $(1)$ is a high loading dose of paracetamol $[30-50 \mathrm{mg} / \mathrm{kg}$ ) in combination with fentanyl $1 \mathrm{mcg} / \mathrm{kg}$ more effective than paracetamol $(30-50 \mathrm{mg} / \mathrm{kg})$ only in relieving children's early postoperative pain following (adeno)tonsillectomy?, (2) Do systematic pain assessments (SPA) enthance the effects of analgesics?, and (3) Is the pain management adequate? In order to answer these questions, this study employed a double-blind, randomized, placebo controlled $(2 \times 2)$ design. Children who had been admitted for an (adeno)tonsillectomy $(n=83)$ were randomly assigned to one of the experimental conditions. The children's pain was measured using observation scales (CHEOPS and FLACC), VASs (by researcher and parent), and self-report measures (Faces Pain Scale and Oucher).

The main conclusion to be drawn from this study is that a high loading dose of paracetamol in combination with fentanyl given intraoperatively to relieve children's early postoperative pain following (adeno)tonsillectomy, did not lead to improved analgesia compared with the combination of paracetamol and a placebo. Furthermore, systematic pain assessments did not enhance the effect of analgesics. According to the hospital's standard of adequate pain management (management is inadequate if score on self-report scale $(0$ to 10$)$ is greater than or equal to 5$)$, pain management appeared to be inadequate in about $60 \%$ of the children 1 hour after their return to the ward. 


\section{INTRODUCTION}

Patients undergoing tonsillectomy (with or without adenoidectomy) are in great pain on the day of the operation (Bone \& Fell, 1988; Dommerby \& Rasmussen, 1984). In a recent study by Kokke et al. (1993), physicians and nurses judged tonsillectomies as one of the most painful types of surgery in children during the first 24 hours after surgery. Furthermore, it has been suggested that (adeno)tonsillectomies constitute a traumatic experience, mainly due to postoperative pain (Boelen-Van der Loo \& Driessen, 1992). It is, therefore, important to investigate if postoperative pain management is effective, the more so because it is known that (adenoltonsillectomies are among the most frequently performed operations in children (Hoogendoorn, 1988; Kaufmanm Rauen \& Holman, 1989; Kruyt, 1994).

In the last decade several studies have examined the effects of different analgesics on pastoperative pain after (adeno) tonsillectomies. Among them were studies which examined the pain-relieving effect of acetaminophen (Boelen-Van der Loo \& Dries* sen, 1992; Gaudreault et al., 1988; Lindgren \& Saarnivaara, 1985; Pasquale et al., 1993; Rusy et al., 1995), pethidine (Gaudreault et al., 1988; Watters et al., 1988), nimesulide (Pasquale et al., 1993), acetaminophen-codeine (Boelen-Van der Loo \& Driessen, 1992), aminophenazone-diazepam (Lindgren \& Saarnivaara, 1985), papaveretum (Bone \& Fell, 1988), diclofenac (Bone \& Fell, 1988; Dommerby \& Rasmussen, 1984: Watters et al, 1988), and ketorolac (Rusy et al., 1995). See Table 1.

The question which analgesic reliewes postoperative pain adequately after (adeno)tonsillectamy is difficult to answer, as can be seen from Table 1. First, it should be noted that the effects of analgesics were studied at different time intervals after surgery, ranging from 1 hour after surgery (studies 2 and 3 ) to 3 days after surgery (study 7). However, the results of the different studies indicate that none of the analgesics seems to be effective in the early postoperative period $(0-3$ hours after surgery).

Second, most studies (e.g. studies 4, 5 and 7) examined which one of two for three) analgesics was the most effective 1 e.g. analgesic $A$ is more effective than a pla cebol, but they did not examine a priori if postoperative pain management was adequate (e.g. analgesic $A$ relieves postoperative pain adequately). However, in three studies $(3,5$ and 8$)$ it was concluded that analgesics were not sufficiently effective because recovery personnel administered additional analgesics in the recovery room. Only two studies ( 2 and 6 ) examined a priori if the analgesics were sufficiently effective. According to Lindgren and Saarnivaara (1985) pain mamagement was adequate when the score on the 'anxiety and pain scale' (range $=0$-7) was less than 3 , and when the relief score (score on 'anxiety and pain scale' after administration of the analgesic minus the score on "anxiety and pain scale" before administrationl was greater than or equal to 3. A similar standard was used by Boelen Van der Loo and Driessen (1992). According to these researchers pain management was adequate when the score on the Oucher (range $=0-10$ ) was less than 3 . 
Table 1. Studite examining the efficacy of andgestics in reliewng postoperative pan loilowing ladenoltonillectomy

\begin{tabular}{|c|c|c|c|c|}
\hline $\begin{array}{l}\text { Aothors } \\
\text { pearl }\end{array}$ & $\begin{array}{l}\text { Subjects } \\
\text { foger in vearsi }\end{array}$ & Anatgesics lested (Dovel & $\begin{array}{l}\text { Aoninistration } \\
\text { ravte }\end{array}$ & $\begin{array}{l}\text { Firsul Analgesic } \\
\text { grven }\end{array}$ \\
\hline $\begin{array}{l}\text { Dommerby a } \\
\text { Adstrusgent } \\
(1984)\end{array}$ & $\begin{array}{l}n \pm 97 \\
(\geq 2)\end{array}$ & $\begin{array}{l}\text { 1. Diciofenec } 1100 \mathrm{mg} / 50 \mathrm{mgl} \\
50 \mathrm{mgh} \\
\text { I. Placetso }\end{array}$ & $\begin{array}{l}\text { 1. supp } \\
\text { H. supp }\end{array}$ & $\begin{array}{l}\text { Immediately after } \\
\text { operation }\end{array}$ \\
\hline
\end{tabular}

\begin{tabular}{|c|c|c|c|c|}
\hline $\begin{array}{l}\text { 2. Lindgren } \\
\text { Samarivadar } \\
\text { (1985) }\end{array}$ & $\begin{array}{l}n=82 \\
|+3-12|\end{array}$ & $\begin{array}{l}\text { I. Paracetamol } 110 \mathrm{mg} / \mathrm{kgh} \\
\text { 11. Aminophenazone }(4 \mathrm{mg} / \mathrm{kg}) \\
\text { diazepam }(0.2 \mathrm{mg} / \mathrm{kg})\end{array}$ & $\begin{array}{l}\text { 1. supp } \\
\text { II. supp }\end{array}$ & $\begin{array}{l}\text { after surgery, if } \\
\text { needed }\end{array}$ \\
\hline $\begin{array}{l}\text { 3. Gaudreauliti } \\
\text { et al. (11988) }\end{array}$ & $\begin{array}{l}n=40 \\
(1-6)\end{array}$ & $\begin{array}{l}\text { I. Acetaminophen }(20 \mathrm{mg} / \mathrm{kg}-\mathrm{l}) \\
\text { I1. Meperidine }(1 \mathrm{mg} / \mathrm{kg}-1 \mathrm{l})\end{array}$ & $\begin{array}{l}\text { 1. intrarectal } \\
\text { sotution } \\
\text { f. im. }\end{array}$ & $\begin{array}{l}\text { Both drugs were } \\
\text { given after induction } \\
\text { of anaesthia }\end{array}$ \\
\hline
\end{tabular}

\begin{tabular}{|c|c|c|c|c|}
\hline $\begin{array}{l}\text { 4. Watters et } \\
\text { all. }(1988)\end{array}$ & $\begin{array}{l}n=75 \\
15-12\rceil\end{array}$ & $\begin{array}{l}\text { 1. Diclofenac }(1 \mathrm{mg} / \mathrm{kg}) \\
\text { II. Pethidine }(1 \mathrm{~kg} / \mathrm{kg}) \\
\text { II. No analges }\end{array}$ & $\begin{array}{l}\text { 1. inn. } \\
\text { \#i. im. } \\
\text { lil. }\end{array}$ & $\begin{array}{l}\text { Both drugs ware } \\
\text { given after induction }\end{array}$ \\
\hline
\end{tabular}

\begin{tabular}{|c|c|c|c|c|}
\hline $\begin{array}{l}\text { 5. Bone \& Fell } \\
(1988)\end{array}$ & $\begin{array}{l}n=60 \\
(3-13)\end{array}$ & $\begin{array}{l}\text { 1. Diclofienac }(2 \mathrm{mg} / \mathrm{kg}) \\
\text { 11. Papaweretum } 10.2 \mathrm{mg} / \mathrm{kg} \text { ) } \\
\text { II. No amalgesia }\end{array}$ & $\begin{array}{l}\text { I. ractal } \\
\text { II. i.m. } \\
\text { utt. - }\end{array}$ & $\begin{array}{l}\text { Both drugs were } \\
\text { given after nduction } \\
\text { of anaesthia }\end{array}$ \\
\hline
\end{tabular}

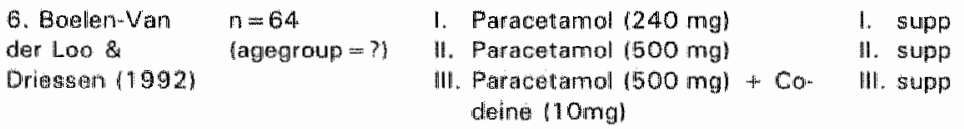

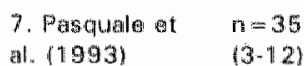

8. Fusy at al. $n=50$

$(1995)$
1. Paracatenol $15-12 \mathrm{ml}, 2.4 \%$ syrum

1. Nirnesulide $(1.5 \mathrm{mg} / \mathrm{kg})$

1. Ketorolac $[1 \mathrm{mg} / \mathrm{kg}$.

II. Acetarninophem $135 \mathrm{mg} / \mathrm{kg})$
1. oral

1. Dral

1. inv.

Ill. supp
All digugs were given ewery $4 h$, starting th before operation

Note. Abbreviationg: $\operatorname{supp}=$ suppository. VAS $=$ Visual Analog Scale $h=$ hour, i. $v_{*}=$ intravencus, i.m. =intiramuscular, ? = not cllear from article.

- Anxiety and Pain score $(A+B+C$; range $0-7)$. A. Silent $10 /$ wincing $(1) /$ crying $(2) B$. Calm $(0) / \mathrm{mov}$ ing (1)/restless (2) C. No pain expressed verbally (O) fpain expressed verbatly (3). "Pain evaluation scate $(A+B+C$ range $0-6):$ A. Agitation, Patient asteep or calm $12 \%$ mild agitation (1)/ uncontrollable $101 \rightarrow$ 


\section{Pain measure}

(rater)

1. VAS 10 to 100$)$ (patient)

2. VAS 10 to 1001 lphysiciant

Anxiety and Pain score 10 to 7$\}^{\circ}$ (nurse)

1. Pain evaluation scale 10 to 6$)^{*}$ (researcher)

2. Personnel working in recovery gave extra dase of analgesic tyestnol

1. VAS-toy 10 to 10) [child]

2. VAS 10 to 10 ? (nurse)

Pain was assessed as none/insignificant or pain present (researcher)

Oucher 10 to 100$)$ (chilid)
Time of measurement

1. Day of operation: $15.00 \mathrm{~h}$, 21. Oon: sit postoperative day: $9.00 \mathrm{~h}, 915.00 \mathrm{~h}$, $21.00 \mathrm{n} ; 2$ nd day: $9.00 \mathrm{~h}$

2. Day of operation: 15.00h: 1 st postoperative dey: 9.00h, $15,00 \mathrm{~h} ;$ 2nd day: $9.00 \mathrm{~h}$.

Every 10 minutes during the first 70 minutes after surgery

When the child woke up in the recovery room
Authors conctusionds.

Diclofenac is more effective than placebo

No differences in efficacy between the drugs Both dirugs are poor analgesics fpain relief was only acceptable when pettidine $i . v$. was admunistered as an extre analigesicl

No differences in efficacy between the drugs Both drugs do not adequately prevent occurrence of pain in recowery room
1. awakeming, 30 minutes, $1 \mathrm{~h}, 4 \mathrm{~h}, 24 \mathrm{~h}$ postoperatively

2. awakening, 30 minutes, th

$1 \mathrm{~h}, 3 \mathrm{~h}, 6 \mathrm{~h}$ postoperatively and on the following morning

自, 3h, 6h postoperatively
No differences in efficacy between the drugs However, there were differences in analgesic requirements between the groups; nurses gave more paracetamol to childran who had received papaveretum or no analgesic than to children who had received diclofenac

None of the drugs is effective Ith after surgery There are differences in atficacy between the drugs; only paracetamol 500 ma is effective 3 h after surgery: paracetamo $500 \mathrm{mg}$ and paraceta$\mathrm{mol} 500 \mathrm{mg}+$ codeine $10 \mathrm{mg}$ are affective $6 \mathrm{~h}$ after surgery; paracetamol $240 \mathrm{mg}$ does not adia. quately relieve pain 16 , ah and 6h after siturgery

Day of operation, and day 9, * No differences in elficacy between the two drugs 2 and 3 after surgery

Pain is absent 101 mild (1), moderate $(2)$ or severe (3)

(rater $=$ ?)

Objective Pain Score (range $=$ ? $)^{\cdots *}$

(two observets)
Immed hately, 30 minutes, $1 \mathrm{~h}$, $2 h, 3 h$ postoperatively
However, on the 3rd day after surgery, nimesulide is more effective than paracetamol

No differences in efficacw between the two drugs Neither acetaminophen nor ketorolac were sulfi cient for complete analgesia

Continued. B. Crying. Nat crying (2)/ respond to tender loving care $111 /$ crying and does not respond to tender loving care (O) C. Pain verbalization, Asleep or no compilant (2)/cannot localize pain (1), can localize pain 10 ). "* Objective Pain Score (OPS). The only information about this measure given by the authors is that it takes into account blood pressure, crying, agitation, movememt and verbal report. 
Third, the studies all used different measurement tools to detect the effects of analgesics as can be seen from Table 1 . Some of these tools were simple observation scales (e.g. pain is present or absent) whose reliability and validity have not been tested, which casts doubt on their suitability as outcome measures. The child was asked to rate its pain in only three studies $(1,4$ and 6$)$. This is rather surprising, since methods to obtain self-report measures in children are available (see e.g. Mathews et al., 1994; Wong \& Baker, 1988). Furthermore, observational measures (used in most studies) should be interpreted carefully, since it has been reported that they do not always correlate with patients' self-reports (Beyer et al., 1990; Hester, 1979).

Finally, most studies $(2,5,6,7$ and 8$)$ used only one method for measuring efficacy, while the use of multiple measurements (self-reports, observation scales etc.) can be much more powerful in detecting effects of analgesics in children as was demonstrated by Schachtel and Thoden (1993).

It can be concluded that none of the above-mentioned analgesics seems to be sufficiently effective in the first three hours after surgery. Further research, using multiple pain measures, should examine whether increased doses of the above-mentioned analgesics, within safety margins, will relieve childrens' early postoperative pain adequately. According to Lindgren and Saarnivaara (1985) more potent analgesics, such as opiates, which are more suitable for the immediate treatment of postoperative pain following ladenoltonsillectomy, should be the subject of further investigation. Because of rapid onset, brief duration, and short recovery time fentanyl has become a favorite analgesic for short painful procedures (Billmire et al., 1985; Shannon \& Berde, 1989; Yaster \& Maxwell, 1994), especially for outpatient use (Billmire et al., 1985). Furthermore, it has been reported that fentanyl has less sideeffects (pruritus, nausea, vomiting) than opiates like morphine (Lejus et al., 1994). The first aim of this study was to examine the efficacy of high loading dose paracetamol suppositories $(30-50 \mathrm{mg} / \mathrm{kg})$ in combination with a placebo versus paraceta$\mathrm{mol}(30-50 \mathrm{mg} / \mathrm{kg})$ in combination with intramuscularly fentanyl $(1 \mathrm{mcg} / \mathrm{kg})$ in relieving postoperative pain following (adeno/tonsillectomy.

Furthermore, it has been suggested in the literature ICBO, 1994; Kaufmann Rauen \& Holman, 1989; McGrath, 1990) that non-pharmacological interventions like distraction could enhance the effectiveness of analgesics. It has also been stressed that clinicians will first have to recognize that a child is in pain (Huijer Abu-Saad, 1989; Mcllvaine, 1989). Ellis (1988) and Faries et al. (1991) suggested that systematic pain assessments might improve pain management. The rationale behind this is that when caregivers, in this case nurses, are aware that the patient is in pain they will try to relieve the pain using non-pharmacological interventions. In adults it was demonstrated that the use of pain records resulted in a decrease in patients ${ }^{r}$ pain intensity (Faries et al., 1991). In the case of (adeno)tonsillectomies in children it would be logical to expect that nurses who think that a child (still) suffers pain will do something (e.g. try to distract the child, call the physician) to relieve that pain. Because it is reasonably easy and inexpensive to introduce systematic pain assess ments by means of Visual Analog Scales (VASs), the second aim of this study was to investigate whether such assessments would result in additional pain-relieving effects. 
In summary, this study addresses the following questions:

- Is the combination of a high loading dose of paracetamol $(30-50 \mathrm{mg} / \mathrm{kg}$ ) and fentanyl $1 \mathrm{mcg} / \mathrm{kg}$ more effective than paracetamol $(30-50 \mathrm{mg} / \mathrm{kg})$ only in relieving children"s early postoperative pain following (adenoltonsillectomy?

- Do systematic pain assessments (SPA) enhance the effects of anaigesics?

- Is the pain management adequate?

\section{METHODS}

\section{Design}

In order to examine the effect of analgesics as well as SPA, this study employed a double-blind, randomized, placebo controlled $(2 \times 2)$ factorial design. All subjects received paracetamol suppositories $(30-50 \mathrm{mg} / \mathrm{kg})$ after the induction of anesthesia. Children who had been randomly assigned to the experimental condition, received fentanyl $(1 \mathrm{mcg} / \mathrm{kg}$ ) intramuscularly as well, while children who had been randomly assigned to the control condition received a placebo $(0.9 \% \mathrm{NaCl})$ intramuscularly. SPA was introduced for both groups halfway through the study when $n=40$ for practical and methodological reasons. Since children and their parents stayed in one room after the operation it would not be ethical for nurses to assess the pain of one child systematically, and, as a result pay systematic attention to that child, while another child does not receive systematic attention. On the other hand, it would be reasonable to expect that nurses' pain assessments and management in general will be influenced by the introduction of SPA, so that it would not be a case of comparing SPA with no SPA, but SPA with probably some SPA.

When SPA was introduced, nurses were asked to assess the children's pain at regular intervals (see procedure), using a $100 \mathrm{~mm}$ Visual Analog Scale (VAS). It should be noted that nurses were not explicitly instructed to intervene if the VAS score exceeded a particular value. However, the hospital protocol for postoperative pain management (Geisler \& Pfaff, 1993) indicates that nurses should intervene if scores on a numerical rating scale $(0-10)$ exceed the value of 5 .

Consequently, the following 4 experimental conditions can be distinguished: 1 . placebo (group I), 2. fentanyl (group II), 3. placebo + SPA (group III), 4. fentanyl + SPA (group IV).

\section{Subjects}

Subjects were healthy children (ASA I and II) between 3 and 12 years of age, who had been admitted for an (adeno)tonsillectomy. After approval had been given by the local ethics committee, parents were informed by letter, while written parental consent was obtained on the day of the operation. Children who were unable to use self-report scales (see measurements) were exluded from the study. Since it is known that older children use more gradations in their reports of pain than younger children due to the development of their cognitive abilities (McGrath, 1990; McGrath \& Unruh, 1987), subjects were stratified for age (age 3-6 versus age 7 and overi. 
After stratification, subjects were assigned to one of the treatment groups by computer-generated randomization.

\section{Anesthesia and operation}

All children were premedicated $20-25$ minutes before the start of induction with rectal midazolam $0.5 \mathrm{mg} / \mathrm{kg}$ and atropine $0.025 \mathrm{mg} / \mathrm{kg}$. An inhalation induction with halothane in $\mathrm{N}_{2} \mathrm{O}: \mathrm{O}_{2}$ of $2: 1$ was performed with a stepwise rise to 4 vol\%. After the induction of anesthesia, an intravenous cannula was introduced into the dorsum of the left hand. Next, $1-1.5 \mathrm{mg} / \mathrm{kg}$ succinylcholine was given intravenously and oral intubation was performed. Immediately after intubation an intramuscular injection of $1 \mathrm{mcg} / \mathrm{kg}$ of fentanyl or an equivalent amount of saline was given in the left upper leg. The anesthesia was maintained with halothane $1.5=2.5$ vol $\%$ in $\mathrm{N}_{2} \mathrm{O}: \mathrm{O}_{2}$ of $2: 1$. All children breathed spontaneously with an end tidal $\mathrm{CO}_{2}$ of $4-5 \mathrm{kPa}$. All children underwent tonsilectomy by means of the dissection method, and $98 \%$ also underwent adenoidectomy. At the end of the operation the administration of halothane and $\mathrm{N}_{2} \mathrm{O}$ was stopped. The child was placed in a lateral position and extubated. The child stayed in the recovery room until further recovery. After responding to the recovery nurses, the child was returned to the ward, where the parents were allowedl to take part in the care of their children.

\section{Measurements}

Besides demographic data, like the child's sex, age and weight, additional data were collected on variables which might influence the child's pain. Surgeons were asked to rate the difficulty of the operation on a 3-point scale (easy, moderate or difficult). as well as the extent to which they had had to coagulate (not at all, a little or much). The child's pain was measured using observation scales, VASs, and self-report measures.

\section{Observation scales}

Two observation scales were used by the (blinded) researcher: the CHEOPS (McGrath et al., 1985) and the FLACC (Merkel \& Voepel-Lewis, 1994).

The CHEOPS (McGrath et al., 1985) consists of 6 items (Cry, Facial, Child-Verbal, Torso, Touch and Legs) representing different behaviors with different scores. The item 'cry', for example, consists of the behaviors (scores) 'no cry' (1), 'moaning' (2), 'crying' (2), and 'scream' (3). Addition of the scores of the 6 items yields a total score on the CHEOPS, ranging from 4 (no pain) to 13 (severe pain). According to MaGrath et al. (1985) and Tyler et al. (1993) the CHEOPS is a valid and reliable measure of postoperative pain in children. McGrath et al. (1985) reported high interrater reliabiltity scores and high correlations between the CHEOPS and nurses' VAS scores; Tyler et al. (1993) reported strong correlations between the CHEOPS and self-report measures (a faces scale and a VAS). However, Beyer et al. reported weak correlations between the CHEOPS and self-report measures (Oucher and Analogue Chromatic Continuous Scale). Finally, changes in the CHEOPS scores as a response 
to analgesic medication have been reported (McGrath et al., 1985; Tyler et al., 1993).

As can be seen from Table 2, the FLACC consists of 5 items 1 See Table 2 ) representing different behaviors with different scores. By adding up the scores of the 5 items, a total score on the FLACC is obtained ranging from 0 (no pain) to 10 (severe pain). Research on the reliability and validity of the FLACC is limited. According to Merkell and Voepel-Lewis (1994) the FLACC is valid and reliable; they reported high inter-rater reliability scores and changes in the FLACC scores following the administration of analgesics.

Table 2. The FLACC (face, legs, activity, cry, consollability) Scale

$0 \quad 1$

Face

Legs

Activity

Cry

Consolability
No particular axpression or smile

Normal position or relaxed

Lying quietly, normal position, moves easily

No cry (awake or asleep)

Moans or whimpers: occasional complaint

Reassured by occasional touching, hugging or "talking to", distractable
2

Frequent to constant frown, ollenched jaw quiwering chin

Kicking or lags drawn up

Archesd, rigid of jerking

Crying steadily, sereams or sobs, frequent com* plaints

Difficult to console or comfort

Reprinted from: Merkel, S.I. \& Voepel-Lewis; T. (1994). Reliability of the FLACC pain assessment tool, Department of Anesthesiology, Section of Pediatrics, C.S. Mott Children's Hospital, University of Michigan Medical Center, Anni Arbor. Michigan.

\section{Visual Analog Scales}

Visual Analog Scales (VASs) are generally considered as sensitive and reliable measures of the intensity of pain (Huskisson, 1983; McGuire, 1988; Price et al., 1983; Taenzer, 1983). VASs were filled in by the (blinded) reseacher and the (blinded) parent. In the second half of the study VASs were also filled in by (blinded) nurses and used for SPA. It should be noted that the researcher was not blinded to the SPA condition (see design).

Every houlr (see procedure) researcher, parent and nurse independently rated their answers to the question 'How much pain does this child experience?". Unlike the researcher, the parent stayed with the child all the time. In order to obtain an hourly VAS score representing the child's pain on that particular moment, parents were also asked to first rate their child's pain during the last hour. All the 100 millimeter VASs ranged from ' $O$, no pain' to "100, extreme pain'.

Since children with a sore throat were expected to refuse to drink, parents were also asked at each postoperative measure (see procedure) whether the child had drunk (yes or no). 


\section{Self-report scales:}

The children rated their pain using two different self-report scales: the Faces Pain Scale (Bieri et al., 1990) and the Oucher (Beyer et al., 1993). The Faces Pain Scale (Bieri et al., 1990 ) consists of 7 faces. The scores on this scale range from 0 ino pain) to 6 (worst possible pain). Although there are indications that the Faces Pain Scale is reliable, it is also possible that the scale is a general measure of reactions to distress instead of a measure of severity of pain only (Bleri et al., 1990). According to Bieri et al. (1990) children as young as 3 have used the Faces Pain Scale with good comprehension.

The Oucher (Beyer et al, 1993) conisists of two scales: a 0-100 numerical scale for older cildren and a six-picture photographic scale for younger children. The scores on the Oucher range from 0 (no pain) to 100 (severe pain). The Oucher has been reported to be a reliable and valid self-report measure (Beyer \& Aradine, 1986, 1987. 1988; Beyer et al.. 19931. According to the authors it can be used to measure pain in children aged $3-12$.

The pain protocol used in the hospital where this study was conducted served to answer the question whether the pain management was adequate. According to this protocol pain management is inadequate if the patient's self-report score (range 0 to 10 ) is greater than or equal to 5 (Geisler \& Pfaff, 1993). Applied to the self-report measures in this study, this would mean that pain management is inadequate when scores are greater than or equal to 50 (Oucher) or 3 (Faces Pain Scale).

\section{Procedure}

The present study was conducted in Maastricht University Hospital in the Netherlands. In this hospital, (adeno)tonsillectomies are performed as an out-patient procedure. Patients are usually discharged 4 hours after the operation.

For every subject there were 4 measures, including a pretest. The sequence of the measures is summarized in Table 3.

Tiable 3. Owarwiew and sequence of the different meastures

\begin{tabular}{|c|c|c|}
\hline Fater & & \\
\hline & Pretest & Posttest $\left(1 h_{i} 2 h, 3 h\right)$ \\
\hline Aes detrcher & $\begin{array}{c}\text { CHEOPS } \\
\downarrow \\
\text { FLACC } \\
\downarrow \\
\text { VAS }\end{array}$ & $\begin{array}{c}\text { CHEOPS : } \\
+ \\
\text { FLACC } \\
4 \\
\text { VAS }\end{array}$ \\
\hline$\downarrow$ & 1 & $\downarrow$ \\
\hline Partint & WAS & $\begin{array}{c}\text { VAS } \\
+ \\
\text { Did child drink? }\end{array}$ \\
\hline$\downarrow$ & $\downarrow$ & " \\
\hline Child & $\begin{array}{c}\text { Faces Pain Scale } \\
\text { Oucher }\end{array}$ & $\begin{array}{c}\text { Faces Pain Scale } \\
\text { Oucher }\end{array}$ \\
\hline
\end{tabular}


As can be seen from Table 3, the researcher, the parent and the child rated the child's pain intensity independently. The pretest measure was conducted before the child was premedicated. After premedication the child was moved from the ward to the operating room. Immediately after the operation the child went to the recovery room for about 30 minutes before returning to the ward. The postoperative measures took place 1, 2 and 3 hours after the child had returned to the ward, while the nurses' systematic pain assessments (SPA) took place 30 minutes, 1.5 and 2.5 hours after the child had returned from recovery. According to the policy on the ward children had to swallow regularly after the operation. Therefore, children who had been asleep for at least 30 minutes were often woken up to drink some icewater. As far as possible this was combined with measurement of the child's pain.

\section{Problems with self-report measures: sleeping and refusing children}

A serious problem in this study was caused by the number of missing values, mainly on the self-report scales. As can be deduced from Table 6 (see results), $33 \%$ of the postoperative values on the Faces Pain Scale while on the Oucher $37 \%$ were missing. The missing values were due to two main causes: children were sleeping or children refused to participate.

The problem of children refusing to participate has, to the best of our knowledge, not been reported in the literature. In the present study, however, this problem accounted for almost 65 percent of the missing values on the self-report scales. Although pre-operatively children were very enthousiastic about cooperating in the present study, they often refused to rate their pain postoperatively.

The problem of sleeping children has been reported before (Hoekstra, 1994; Walson et al., 1992). Walson et al. (1992) and Hoekstra (1994) solved this problem by recoding the missing values as values representing little or even no pain. Barrier et al. (1989) and Lejus et al. (1994) also assumed that children who are asleep do not experience any pain. However, there are also researchers (Beyer \& Hester, personal communication October 1994; Kaufmann Rauen \& Holman, 1989) who think that such a score is not valid.

In the present study, cases with missing values were first removed from the ofiginal analyses. However, in an additional analysis the missing values were recoded (see analysest.

\section{Analyses}

Pretest data were analyzed using ANOVA with the exception of scores on the CHEOPS and the FLACC, which were analyzed using nonparametric tests (KruskalWallis One-Way Analysis of Variancel.

Due to the large number of missing values on the different measures in generall and on the self-report measures in particular, data analysis using one multivariate technique was not appropriate. As a consequence, data for each measuring moment ( 1 , 2 and 3 hours after surgery, see procedure) were analyzed separately. Scores on the VASs, Faces Pain Scale, and Oucher were analyzed using Multiple Regression techniques, while scores on the CHEOPS and the FLACC were analyzed using KruskalWallis One-Way Analysis of Variance. In all of these analyses the pretest score was 
used as a covariate, while cases with missing values were excluded.

In order to deal with the problem of missing values for the self-report scales, an additional analysis was done using Logistic Regression techniques. To this end, the scores on both the Faces Pain Scale (0-6) and the Oucher (0-100) were dichotomized. Faces Pain Scale scores ranging between 0 and 2 were categorized as "no or mild pain' and scores equal to or greater than 3 as 'severe pain'. Oucher scores ranging between 0 and 49 were categorized as 'mo or mild pain" and scores equal to or greater than 50 as "severe pain". Next, the missing values were recoded; missing values due to sleeping children were coded as "no or mild pain", while refusing chillden were coded as "severe pain".

Finally, an additional analysis was carried out for the nurses" pain intensity assessments. Since nurses, like the other raters, were blinded to the experimental and control conditions, we examined whether their pain intensity scores for children who had received fentanyl were different than those for children who had received the placebo. The nurses' VAS scores were analyzed using One-Way Analysis of Variance.

\section{RESULTS}

\section{Subjects}

The subjects were 83 children (41 boys, 42 girls). Their mean age was 5.6 years $(\mathrm{SD}=2.2 ;$ range $=3-12)$ and their mean weight $22.9 \mathrm{~kg}(\mathrm{SD}=7.01$.

Table 4. Patients' characteristics, intraoperative data and time in recovery of the four treatment groups

\begin{tabular}{|c|c|c|c|c|}
\hline & $\begin{array}{l}\text { Group }) \\
(n=18)\end{array}$ & $\begin{array}{l}\text { Group II } \\
(n=24)\end{array}$ & $\begin{array}{l}\text { Group }\|\| ! \\
(n=21)\end{array}$ & $\begin{array}{l}\text { Group IV } \\
(n=20)\end{array}$ \\
\hline Variable & placebo & fentanyl & placebo + SPA & fentanyl + SPA \\
\hline $\begin{array}{l}\text { Age } \\
\text { (yoars) }\end{array}$ & $6.1 \pm 2.2$ & $5.5 \pm 2.3$ & $5.4+2.3$ & $5.4 \pm 1.8$ \\
\hline $\begin{array}{l}\text { Woight" } \\
\text { (kgl }\end{array}$ & $\begin{array}{c}23.4=7.1 \\
M V=2\end{array}$ & $\begin{array}{c}22.3 * 6.9 \\
M V=3\end{array}$ & $\begin{array}{c}22.3 \pm 0.3 \\
M V=2\end{array}$ & $\begin{array}{c}23.6 \pm 8.0 \\
M V=2\end{array}$ \\
\hline $\begin{array}{l}\text { Sex } \\
\text { (malar tornala) }\end{array}$ & $8 / 10$ & $11 / 13$ & $10 / 11$ & $12 / 8$ \\
\hline $\begin{array}{l}\text { Difficulty operation } \\
\text { (enasy/ moderates diffi= } \\
\text { cuill }\end{array}$ & $\begin{array}{l}3 / 12 / 1 \\
M W=2\end{array}$ & $\begin{array}{l}3 / 15 / 4 \\
M V=2\end{array}$ & $\begin{array}{c}8 / 8 / 2 \\
M W=3\end{array}$ & $\begin{array}{l}6 / 8 / 4 \\
M W=2\end{array}$ \\
\hline $\begin{array}{l}\text { Extent to coagulati } \\
\text { mot/little muchi }\end{array}$ & $\begin{array}{l}3 / 1: 1 / 3 \\
M \vee:=1\end{array}$ & $\begin{array}{l}13 / 8 / 1 \\
M N=2\end{array}$ & $\begin{array}{c}7 / 8 / 4 \\
M V=2\end{array}$ & $\begin{array}{c}8 / 6 / 4 \\
M V=2\end{array}$ \\
\hline $\begin{array}{l}\text { Tifne in recowery } \\
\text { "minutes. }\end{array}$ & $\begin{array}{c}31 \pm 11 \\
M V=1\end{array}$ & $\begin{array}{c}40 \pm 24 \\
M V=7\end{array}$ & $\begin{array}{l}38 \pm 21 \\
M V=3\end{array}$ & $\begin{array}{c}29 \pm 10 \\
M V=1\end{array}$ \\
\hline
\end{tabular}

Note. Abbreviations: SPA $\Rightarrow$ Systematic Pain Asisessment MV = Missing Value.

"Plus minus velues are means th $\mathrm{SD}$. "Plusminus values are imeans $\pm S D$. There werce no statistically significant differences beteen the groups according to the One.Way Analysis of Wariance. 
The characteristics of all 83 children are described in Table 4 . As can be seen from Table 4, there were no differences between the groups regarding patients' characteristics and intraoperative care. Furthermore, patients who had received fentanyl did not stay in the recovery room longer than children who had received the placebo. For two subjects no postoperative data were collected; one child remained in recovery and was later admitted to the hospital as a result of a haemorrhage, while the blinding was broken by a clinician in the case of the other child. In the analyses these cases have been treated as missing values.

The mean pretest and posttest scores for each measure are both presented in Figure 1.
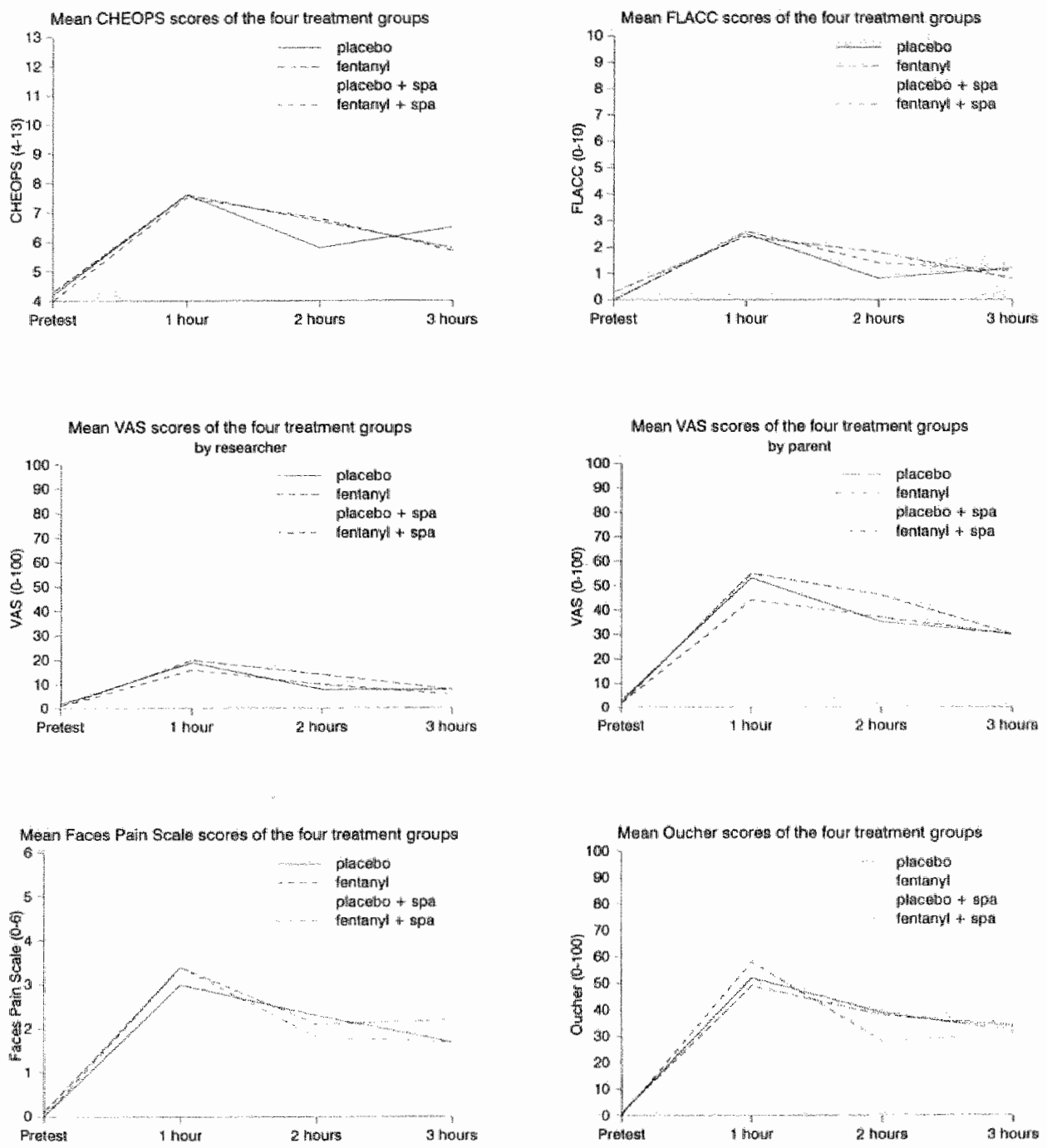

Figure 1. Mean pain intensity scores of the four treatment groups 


\section{Pretest: differences in pain intensity}

As can be seen from Figure 1, the pretest scores of the 4 groups seem to be equal. However, the researchers" VAS scores 10-100) differed between the treatment groups (see Table 5). According to the mean $( \pm S D)$ pretest scores $[2 \mathrm{~mm}(1), 1 \mathrm{~mm}$ (1). $1 \mathrm{~mm}$ (1), and $1 \mathrm{~mm}$ (1)1, children in group / experience 'more pain' before the operation.

Table 5. Difforences in prestets scores for the different measures of pain intensity

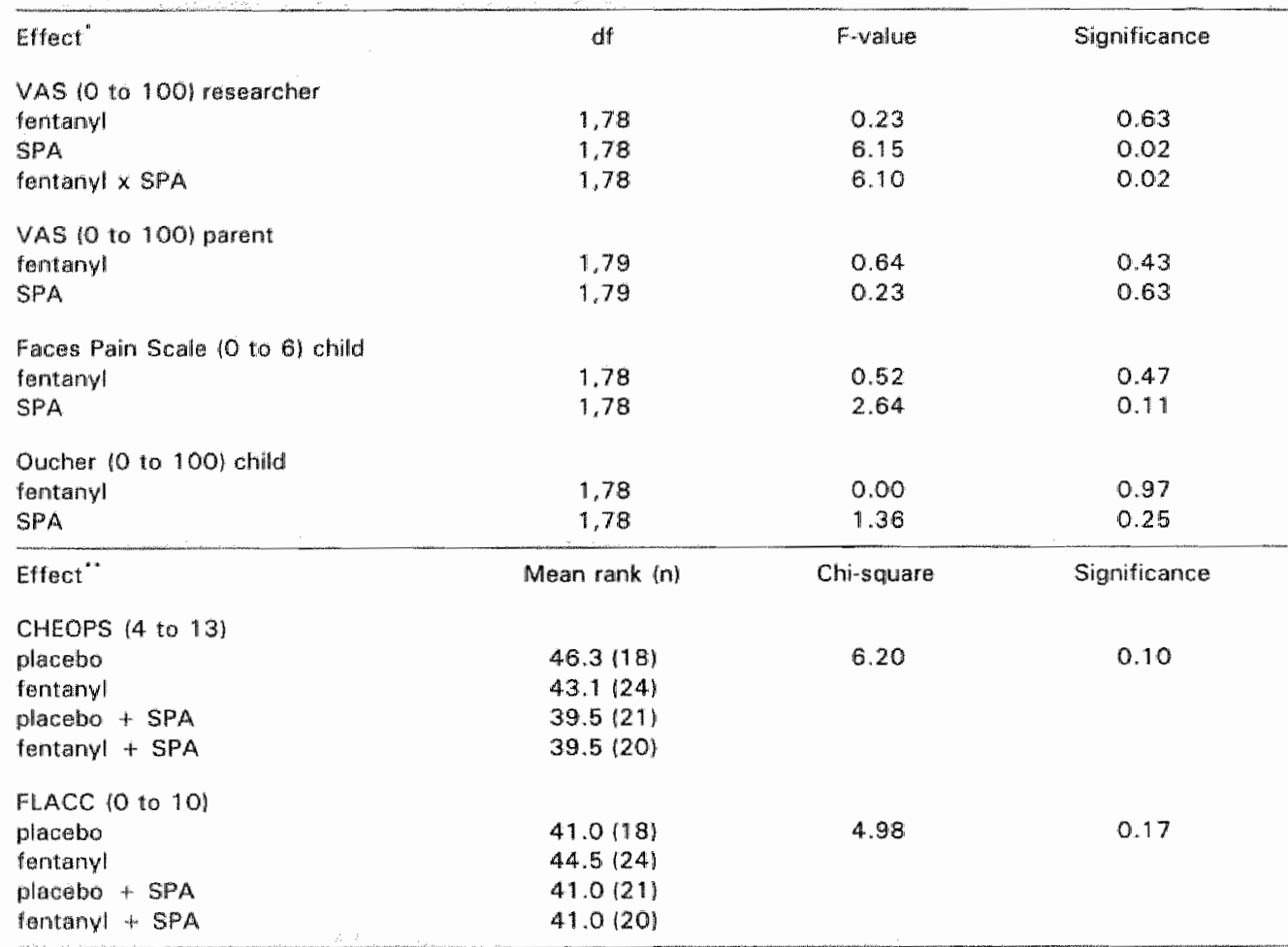

Nore. Abbreviations: VAS Visual Analog Scale, SPA = Systematic Pain Assessment.

"Scores were analyzed whth ANOVA. The child's age was a cowariate. Interaction effects are reported only whan they were statistically significant. "Scores were analyzed with Kruskal-Wallis One Way Analysis of Variatice.

However, since the researcher"s mean $( \pm S D)$ pretest scores on the VAS $(0-100)$ for the different groups were very small it is questionable whether this finding has clinical significance.

\section{Posttests: differences in pain intensity}

The results of the analyses of the posttest scores for VASs, Faces Pain Scale and Oucher are presented in Table 6 , and the results of the analyses of the posttest scores for the CHEOPS and the FLACC are summarized in Table 7. 


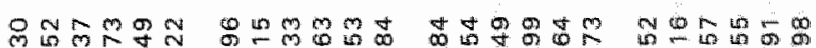
00000000000 00000

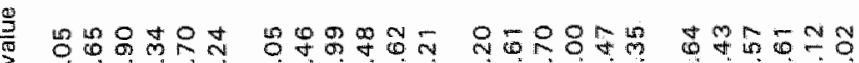

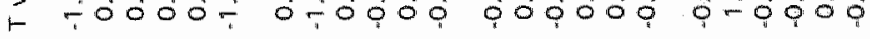

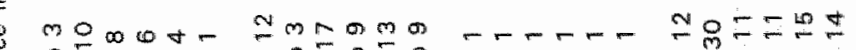

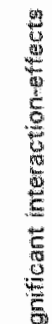

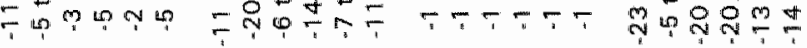

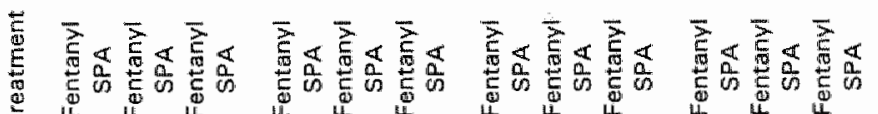

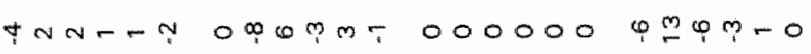
$\sum^{10}$

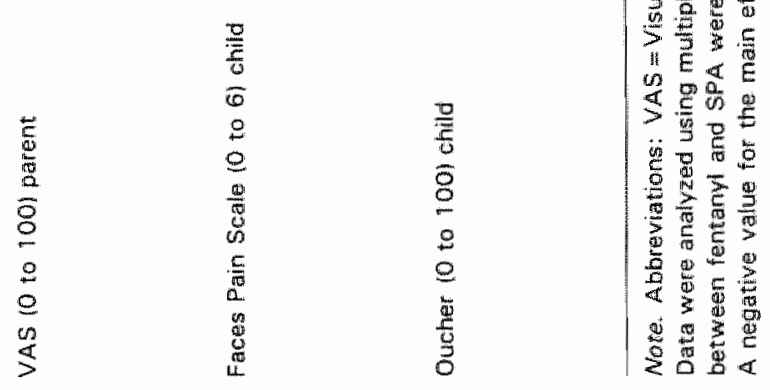




\section{REFERENCES}

Barrier, G., Attu, L., Maver, MN. Anielitison, Cl. S Sthider, S.M. 11989/. Measurement of postoperative pailn and narcotic administration in intants using a new clinical scoring system. Intensive Care Medicine, 15, S37-539.

Berde, C.B. (1989). Pediatric postoperative pain management. Pediatric Clinics of North America, 36 . 9219940 .

Beyer, J. \& Aradine, C. (1986). Content validity of an instrument to measure young children's perceptions of the intensity of their pain. Journal of Pedatric Nursing, $1,386-395$.

Beyer, J. A Aradine, C. (1987). Patterns of pediatric pain intensity: an methodological investigation of a self report scale. The Chincal Journal of Pain, $3,274-282$.

Beyer, J \& Aradine, C. (1988). The convergent and discriminant validity of a self-report measure of pain intensity for children. Chifdren's Health Care, $16,274 \times 282$.

Bever, J.E., McGrath, P.J. \& Berde, C.B. 119901. Discordance between self-report and behavioral pain measures in children aged $3-7$ years after surgery. Joumal of Paim and Symptom Management, 5 . 350-356.

Beyer, J.E., Villaruel, A.M. \& Denyes, M. 11993). The owcher: the new user's manwal and technicat report:

Bieri, D., Reeve, R.A., Champion, G.D., Addicaat, L. \& Ziegler, J.B. (1990). The faces pain scale for the self-assessment of the severity of pain experienced by children: development, initial validation. and preliminary investigation for ratio scale properties. Pain. 41, 139-150.

Bilmire, D.A., Neale, H.W. \& Gregory, R.O. (1985). Use of IV fentanyl in the outpatient treatment of pediatric facial trauma. The Journal of Trauma, 25, $1079-1080$.

BoeleniVan der Loo, W.J.C. \& Driessen, F.G.W.H.M. (1992). Pijnpreventie en pijnbestrijding bil (adenoltonsillectomie (Prevention and management of pain following tadeno)tonsillectomy). Nederlands Tijdschrift woor de Geneeskunde, 136, 1409-1413.

Bone, M.E. \& Fell, D. (1988). A comparison of rectal diclofenac with intramuscular papaveretum or placebo for pain relief following tonsillectomy. Anaesthesia, 43, 277-280.

CBO (1994), Verpleegkunde bij pijn (Pain nursing». CBO, Utrecht.

Dommerby, H. \& Rasmussen, O.R. (1984). Diclofenac (voltaren). Pain-relieving effect after tonsil lectomy. Acta Otolaryngalpgica, 98, 185-192.

Ellis, J.A. (1988). Using pain scales to prevent undermedication. Maternal Child Nursing, 13, 180182.

Faries, J.E, Mills, D.S., Goldsmith, K.W. Phillips, K.D. \& Orr, J. (1991). Systematic pain records and their impact on pain control. A pilot study. Cancer Nursing, 14, 306 313.

Gaudreault, P., Guav, J., Nicol, 0 . Dupuis, C. 119881. Pharmacokinetics and clinical efficacy of intrafactal solution of acetaminophen. Canadian Jounal of Anaesthesia, 35, 149-152.

Geisler. F. \& Pfall, A. (1993). Protocol post-operatieve pijnstilling (Protocol postoperative pair management. Academisch Ziekenhuis Maastricht, Maastricht.

Hertzka, R.E., Gauntiett, I.5., Fisher, D.M. \& Spellman, M.J. (1989). Fentanylinduced ventilatory depression: effects of age. Anesthesiology, $70,213-218$.

Hester, N.K. (1979). The pre-operational child's reaction to immunization. Nursing Research, 28, 250255 .

Hoekstra, 1. 119941. De effectiviteit van patient controlled analgesia bij kinderen met postoperatieve pijn (Efficacy of PCA on pastoperative pain in children). Rijksuniwersiteit Limburg, Masastricht. (unpublished master thesis)

Hoogendoorn, D. (1988). Schatting van het aantal consillectomieèn en adenotomieën bij kinderen (The estimated number of tonsillectomies and adenoidectomies in children. Nederlands Tijdschrift woor de Geneeskunde, 132, 913.915.

Huijer Abu-Saad, H. (1989). Pijninterwenties bij kinderen (Pain relieving interventions in children). PijnInformatorium, 15 (VMO6501, 1-13.

Huskisson, E.C. (1983). Visual analogue scales. In: R. Melzack (Ed.). Pain measurement and assesisment. Raven, New York, 33-37. 
Kaufmann Rauen, K. \& Holman, J.B. (1989). Pain control in children following tonsillactomies: a retrospective study. Journal of Nursing Quality Assurance, $3(3), 45-53$.

Kokke, F.T.M., Van der Heide, D.H. \& Boelen-Van der Loo, W.J.C. (1993). Postoperatieve pinbestrij ding in drie Nederlandse ziekenhuizen: en pilotstudie (Postoperative pain management in three Dutch hospitals: a pilot study1. Tijdschrift woor Kindergeneeskunde, 61, 48-51.

Kruyt, J.M. (1994). Tonsillectomie volgens Sluder: hoe lang nog? (Tonsillectomy according to the Studer method: how much longer?]. Afdeling KNO Academisch Ziekenhuis Utrecht, Utrecht.

Lejus, C., Roussière, G., Testa, S., Ganansia, M.F., Meignier, M. \& Souron, R. (1994) Postoperative extradural analgesia in children: comparison of morphine with fentanyl. British Journal of Anaesthesia, $72,156-159$.

Lindgren, L. \& Saarnivaara, L. (1985). Comparison of paracetamol and aminophenazone plus diazepam suppositories for anxiety and pain relief after tonsillectomy in children. Acta Anaesthesion logica Scandinavica, 29,679-682.

Mathews, J.R., McGrath, P.J. \& Pigeon, H. (1994). Assessment and measurement of pain in children. In: N.L. Schechter, C.B. Berde \& M. Yaster (Eds.). Pain in infants, children and adolescents. Williams \& Wilkins, Baltimore, pp. 97-111.

McGrath. P.A. (1990). Pain in children: nature, assessment \& treatment. Guilford, Now York.

McGrath, P.J., Johnson, G., Goodman, J.T., Schillinger, J., Dunn, J. \& Chapman, J. (1985). CHEOPS: a behavioral scale for rating postoperative pain in children. In: H.lL. Fields, R. Dubner \& F. Cervero (Eds.1. Advances in Pain Research and Therapy, volume 9, 395-402. Raven. New York.

McGrath, P.J. \& Unruh, A.M. (1987). Pain in children and gdolescerbts. Elsevier, Ansterdam.

McGuire, D.B. (1988). Measuring Pain. In: M. Frank-Stromborg (Ed.). lisstruments for clinical nursing research. Appleton \& Lange, Norwalk, pp. 333-356.

Mclivaine, W.B. (1989). Perioperative pain management in childrent a review. Journal of Pain and Symptom Management, 4, 215-229.

Merkel, S. \& Voepel-Lewis, T. 119941. Reliability and walidity of the FLACC pain assessment tool. Abstractbook, p. 26. Third International Symposium on pediatric Pain, Philadelphia.

Pasquale, G., Scaricabarozzi, I., D'Agostino, R., Taborelli, G. \& Vallarino, R. (1993). An assessment of the efficacy and tolerability of nimesulide vs paracetamol in children after adenotonsillectomy. Drugs, 46, 234.237.

Price, D.D., McGrath, P.A., Rafi, A. \& Buckingham, B. (1983). The validation of visual analogue scales as ratio scale measures for chronic and experimental pain. Pair, 17, 45-56.

Ready, L.B. \& Edwards, W.T. (Eds.) 1992). Management of acute pain: a practical guide. IASP, Seattlle.

Rusy, L.M. Houck, C.S., Sullivan, L.J., OhIms, L.A., Jones, D.T., Gill, T.J. \& Berde, C.B. (1995). A double-blind evaluation of ketorolac tromethamine versus acetaminophen in pediatric tonsillectomy: analgesial and bleeding. Anesthesia Analgesia, 80, 226-229.

Schachtel, B.P. \& Thoden, W.R. (1993). A placebo-controlled model for assaving systemic analgesics in children. Clinical Pharmacology \& Therapeutics, 53, 593-601.

Shannon, M. \& Berde, C.B. (1989). Pharmacologic management of pain in children and adolescents. Pediatric Clinics of North America, 36, 855-871.

Smink, E.L.A. (1995). Protocolontwikkeling: wan planning naar implementatie Protocol development: from planning to implementation). Rijksuniversiteit Limburg, Maastricht Unpublished Master Thesis!.

Taenzer, P. (1983). Postoperative pain: relationships among measures of pain, mood, and narcotic requirements. In: R. Melzack (Ed. I. Pain measurement and assessment, Raven. New York, pp. 111 . 118.

Tyler, D.C., Tu, A., Douthit, J. \& Chapman, C.R. (1993). Toward validation of pain measurement tools for children: a pilot study, Pain, 52, 301-309.

Walson, P.D., Graves, P.S., Mortensen, M.E., Kern, R.A. Torch, M.A. 11992\%. Patient-controlled versus conventional analgesia for postsurgical pain relief in adolescents. Developmental Pharmacol. ogy Therapeutics, 19, 32-39.

Watters, C.H.,Patterson, C.C. Mathews, H.M.L. \& Campbell. W. 11988). Diclofentac sodium for posttonsillectomy pain in children. Anaesthesia, 43,641*643. 
Wong; D.L. Baker, C.M. (1988). Pain in children: comparison of assessment scales. Pediatric Nursing, 14,947 .

Yaster, M. \& Dewpande, JK. (1988). Management of pediatric pain with opioid analgesics. The Journal of Pediatrics, $113 ; 421 \% 429$.

Yaster, M. \& Maxwell, L.G. (1994). Opioid agonists and antagonists. In: N.L. Schechter, C.B. Berde \& M. Yaster (Eds.). Pain in infants, children, and adolescents. Willams \& Wilkins, Baltimore, 145 171. 
General discussion 


\section{INTRODUCTION}

This dissertation addressed the following three questions:

- Do children receive adequate analgesics for postoperative pain relief?

"Which factors influence nurses" acute pain assessments and interventions in children?

- Which pain protocal relieves postoperative pain in children following (adeno)tonsillectomy adequately?

The answers to these questions are summarized in this final chapter. In addition, the methods used in the different studies are analyzed critically. Furthermore, theoretical reflections are mentioned. Finally, practical implications are discussed and recommendations for future research are made.

\section{Do children receive adequate analgesics for postoperative pain relief}

Many research articles on pain in children start from the assumption that children receive inadequate analgesics postoperatively. Chapter II examined whether this assumption is based on empirical data. To this end, a critical analysis of the literature was conducted.

The literature revealed a number of indications that children may be undertreated postoperatively. The literature reported that physicians (surgeons) are cautious about prescribing opiates for children postoperatively, and that physicians and nurses have different expectations as to the severity of postoperative pain. For example, $30 \%$ of a mixed sample of nurses and physicians judged a circumcision to be extremely painful, while $27 \%$ judged it to be almost pairless (Kokke et al., 1993). It seems logical that pain management will also be different in these two groups. Furthermore, the literature reported that nurses sometimes seem to underestimate children's pain. while they postpone the administration of analgesics, or interpret pro re nata (p.r.n.) as "as little as possible'. This finding was supported by the results of two qualitative studies described in this dissertation (Chapter IV).

However, despite the above-mentioned indications, few 'hard' empirical data were found to support the assumption that children are undermedicated. For example, only a small number of studies have been carried out on the incidence of postoperative pain in children. Starting from McCaffery's definition that pain is whatever the experiencing person says it is, existing whenever he or she says it does (McCaffery, 1979), such studies should be based an children's self-reports. With the exception of Mather and Mackie's (1983) situdy, most studies which are frequently cited in the literature (Beyer et al., 1983; Eland \& Anderson, 1977; Schechter et all., 1986) did not use children's self-reports, but compared prescriptions with the actual adminis. tration of analgesics. Recent studies (Abu-Saad et al., 1994; Gauthier et al., 1994; Knight, 1994; Tesler et al., 1994.) published after completion of the study presented 
here, using children"s self-reports have revealed that children's postoperative pain really is undertreated. This finding was also supported by the results of the final study described in this dissertation (Chapter VII). However, this study ran into the problem of obtaining children's self-report scores in the early postoperative period. Since children sometimes refused to report their pain, it became rather difficult to gain a clear insight into the incidence of postoperative pain. In young children or like infants it will remain complicated or even impossible to obtain self reports.

There is growing evidence that postoperative pain in children is undertreated. However, it remains unclear whether very young or older children with other, diseaserelated, pain are also undertreated.

\section{Which factors influence nurses' acute pain assessments and interventions in children}

The main part of this dissertation (Chapters III - VI) addressed the question 'which factors influence nurses' acute pain assessments and interventions in chilldren'. To answer this question five different studies were designed.

\section{Study I}

In order to gain insight into the way in which nurses make decisions about nursing diagnoses and interventions, the first study (Chapter III) carried out a review of the literature on decision-making in general. This study vielded an overview of factors which may influence the decision-making process. These factors include the problem task (cues), characteristics of the person making decisions (his/her knowledge, experience, personal variabilityl, and the discipline. The conclusion was that the accuracy of nurses' decisions regarding diagnoses and interventions is difficult to examine since reliable and valid correlations between cues and diagnoses are lacking. It would, therefore, be relevant to the issue of pain treatment to examine on the basis of which information nurses make decisions regarding assessment and interventions. Since research on factors influencing nurses" decisions connected with the assessment of pain in children and interventions in this context was lacking, first two qualitative studies were conducted.

\section{Studies II and III}

The aim of the qualitative studies (Chapter (V) was to explore factors influencing pain assessments and interventions in children and to generate hypotheses about the impact of these factors. In line with the results of the literature review on decisionmaking (Chapter III), the factors that were found could be categorized into factors related to the task and factors related to characteristics of the person making the decisions, in this case the nurse.

Task-related factors that were found to influence nurses ${ }^{2}$ pain assessments and interventions were the medical diagnosis, the child's expressions and age, and information obtained from the child's parent. A medical diagnosis seems to be a 
justification for being in pain. Furthermore, suggested was that the severity of the diagnosis had a clear impact on both assessment and intervention. Hypothesized was that the more severe the medical diagnosis was, the higher the pain assessment would be and the sooner an analgesic would be administered. The child's expressions seem to be another important cue in pain assessment. Although there are many ways for a child to express pain, it was suggested that vocal expressions influence assessment and intervention most. In other words $s_{i}$ most pain was attributed to children who expressed their pain vocally, while they would also receive more postoperative analgesic medication. Suggested was that the child's age also influenced nurses ${ }^{\prime}$ decisions regarding assessment and interventions. However, due to contradicting findings in the two qualitative studies it remained unclear whether nurses attributed less or more pain to younger children than to older children, and whether or not younger children received analgesics sooner. Whether information obtained from parents is a determinative factor for nurses' decisions also remained uncertain. The parents' role is probably age-related. In other words, if information obtained from parents influences nurses' decision-making, this influence decreases as the child grows older.

Nurses' characteristics found to influence their decisions were knowledge, experience and attitudes. Suggested was that experience permits nurses to make more accurate assessments of pain, while knowledge rather influences decisions regarding pain-relieving interventions. The influence of nurses' attitudes towards analgesics was striking; nurses were found to have negative feelings about (non-narcotic) pain medication. Besides, it was suggested that they would postpone the administration of postoperative analgesics as long as possible.

\section{Study IV}

In order to examine whether the results regarding the task-related factors could be replicated in an experimental design, a fourth study was carried out (chapter V). In this study, nurses were exposed to different cases representing clinical situations. Nurses were asked to assess the child's pain intensity in each situation and to state whether they would administer an analgesic or not. To examine the influence of the task-related factors (e.g., the medical diagnosis) the information in the cases was manipulated (e.g., mild diagnosis versus severe diagnosis).

The hypotheses about the influence of the severity of the medical diagnosis on pain assessment and intervention were not supported. Nurses did not attribute more pain to children with a more severe diagnosis (closure of anus praeternaturalis) than to children with a mild diagnosis (adenoidectomy). Neither were they more inclined to administer an analgesic to the children with the more severe diagnosis. The hypotheses about the influence of the child's vocal expressions were supported, however. Nurses attributed more pain to children who expressed their pain vocally than to children who did not do so. Furthermore, they were more inclined to administer an analgesic to children who expressed their pain vocally than to children who did not do so. According to the results of the experimental study, neither the child's age nor the information obtained from parents influenced nurses' decisions regarding pain assessment and intervention. 
tiveness heuristic in which probabilities are evaluated by the degree to which $A$ is representative of $\mathrm{B}$. Crving is then considered to be highly representative of pain in children. Although this strategy can be quite useful, it sometimes leads to systematic errors like the "illusion of validity" (Tversky \& Kahneman, 1974), which refers to the unwarranted confidence produced by a good fit between the predicted outcome fin this case painl and the input information (in this case vocal expression). In contrast with Abu-Sald (1984), several other studies (Hester, 1979; Beyer et al., 1990) found that expressions of pain and subjective ratings of patients" pain were only weakly correlated. LeBaron and Zeltzer (1984), for example, found cases in which children who appeared calm reported that they experienced relatively severe pain, whille other children showed a reversal of this pattern. Furthermore, it has been reported that facial expressions provide more discriminating finformation than crying (Hadjistavropoulos et al. 1994). If this is the case, it is questionable whether vocal expression always is a valid cue for assessing pain. Moreover, there is a real risk that children who do not express postoperative pain vocally are undermedicated.

The finding that the severity of the diagnosis does not have an effect on pain assessment and intervention contradicts earlier findings. (Arkesteyn et al., 1990; Burokas, 1985; Bush et al., 1989; Gadish et al., 1988). Various explanations can be offered for this. First, the concept of "mild' and "severe" medical diagnoses was interpreted differently in different studies, which makes it difficult to compare the resuits. In the present study, a "severe diagnosis' is synonymous with "painful surgery". Like Bush et al. (1989), in the present study the assessment of painfulness of a particular operation was based on experts' judgments. However, as was already indicated in the methodological reflections, the study by Kokke et al. (1993) cast doubt on the validity of experts' judgments with regard to the painfulness of an operation.

Second, it is possible that the contrast between the mild and the severe diagnosis (adenoidectomy versus closure of anus praeternaturalis) was not strong enough in the present situdy. Besides, as was remarked before, the designs of existing studies are weak when it comes to drawing conclusions about causal relationships. Most of the studies are exploratory studies (Burokas, 1985; Arkesteyn et al., 1990) in which subjects were, among other things, asked to complete questionnaires about a number of factors that they thought would influence their decisions. However, Burokas (1985) found that answers to the questionmaires did not always coincide with actual behavior; although subjects stated that the type of surgery was the most influential factor, this was not proven by actual chart data.

Finally, the operationalization of the severe diagnosis in the present study may be somewhat biased. considering that four nurses from three hospitals questioned the validity of the combination of the vignette of the severe diagnosis (closure of anus praeternaturalis) with the video of the child which does not give much vocal expression to its pain. Twro nurses thought that children with the diagmosis in question would generally express more pain, while two other nurses doubted whether the analgesic that had been prescribed (paracetamoll was adequate. It would certainly be useful if future research were to replicate this part of the study with other medical diagnoses. 
As expected, the child's age did not seem to influence nurses' decisions in general. Indeed, there are no theoretical reasons to believe that an older child would experience more pain than a younger child, or that the reverse would be the case. However, a methodological comment regarding the operationalization of age seems in order here: age was manipulated in the vignettes, but the nurses all saw the same video. This means that it had to appear as though the child on the videotape was both 3 and 5 years old. Questionable is whether this operationalization was strong enough to measure whether the child's age influenced the nurses' decisions. A more marked contrast between the age groups (e.g. 3 versus 7 years old) might have given different results.

Finally, information obtained from the parents did not seem to determine nurses: decisions. Of importance to note is that in the present study this information was limited to statements indicating that the child was in pain. Because parents know their child best, it is generally assumed that such information is important in nurses" decision-making. However, doubtful is whether this is also the case in the assessment of postoperative pain, since most parents do not have any experience with surgery. In the intervention study (Chapter VII) some parents stated that they did not even recognize their child's behavior after the operation! Manne et al. (1992) suggested that parents' ratings may not be a good indication of the pain experienced by the child, and that nurses' ratings of acute pain may come closer to an objective assessment of pain. This is in contrast with the findings of Huijer Abu-Saad and Luckert (1994), who found significant correlations between child's and parent's postoperative ratings. In the final study of this dissertation it was found that parents' ratings of children's pain were higher than ratings of bath nurses and researcher. It was suggested that parent's ratings, in fact, are not ratings of pain intensity but rather ratings of general distress. This was supported by the results of other studies. First, the findings in a further study by Hamers et al. (in preparation) indicated that many parents who rated early postoperative pain following (adenoltonsillectomy as severe, later indicated that they had probably overestimated the child's pain. In addition, Gillies et al. (1994) found that when they were asked, less than half (46\%) of the mothers said that their child was in pain, but when they were using a Visual Analog Scale (VAS) most mothers $(94 \%)$ indicated that their child had pain. This shows that nurses' doubts about the soundness of parent's postoperative pain assessments, which were reported in Chapter IV, are probably justified.

\section{Nurses' characteristics}

From the findings of the different studies described here a conclusion is that inurses' characteristics influenced their decisions. Nurses' knowledge and experience had a clear impact on both their confidence in their pain intensity assessments and their decision to administer an analgesic. However, knowledge and experience were not found to determine pain intensity assessments.

Generally, the assumption is that education and practical experience increase accuracy in decision-making. To be more precise, there is growing evidence that it is mainly practical experience which is responsible for the differences in decision making between novices and experts (Hobus, 1994; Radwin, 1995; Schmidt et al., 
1990; Tanner et al., 1993). Schmidt et al.'s (1990) theory on the development of expertise assumes that expertise is not so much a matter of superior reasoning skills or in depth knowledge of pathophysiological states but is rather based on cognitive structures describing the features of prototypical or even actual patients. These structures are referred to as 'illness scripts' and contain a wealth of clinically relevant information about disease, its consequences, and the context in which illness develops. The assumption is that illness scripts consist of three parts: enabling conditions", 'the faut' and consequences' (Boshuizen, 1989; Schmidt et al. 1990). Enabling conditions, or contextual information (Hobus, 1994), are factors, like age, sex, risk behavior and social class, that make the occurrence of a disease more likely. The fault is the description of the malfunction. The consequences are the signs and symptoms (e.g., laboratory data, complaints) that arise from the fault. Since experts do have an illness script for each disease, problem-solving is a process of script search, script selection and script verification (in a routine case/ $/ 5 c h m i d t$ et al. 1990h. Intermediate-level students without clinical experience, by contrast, typically use pathophysiological, causal models of disease when solving problems; they have to confirm each issue suggested by the pathophysiological networks activated in response to the signs and symptoms presemted to them (Schmidt et al. $1990)$.

According to this theory one would expect novices, intermediates and experts to differ in their pain assessments. This is, however, not confirmed by the findings in the present study. How can this be explained?

First. Schmidt et al.'s (1990) theory on medical expertise implies that experts only have scripts about diseases based on clinical experience. In other words, persons become experts when they acquire certain scripts. In the present study, experts were pediatric nurses working in different branches of pediatrics (e.g., general surgery, oncology, ear nose and throat (ENT), intensive care), while the cases presented in the experiment were almost all in the field of ENT. As a result, it is possible that the nurses in the present study actually were not experts. This might explain why pediatric nurses, novices and intermediates did not differ in their pain assessments. Second, in recent studies Hobus (1994) demonstrated that experts" decision-making is tho a large extent based on the use of contextual information. Differences in accuracy in decision-making between experts and novices decreased when no contextual information was given. The fact that the contextual information provided in the present study was limited may also explain why there were no differences in pain assessments between novices, intermediates and experts.

A third explanation for this finding could be that the subjects in the experimental study were not asked to make a diagnosis (e.g., the child is in pain, the child misses its mother, the child is sick) but to estimate the child's pain intensity. This may have reduced the demands made on novices" and intermediates' cognitive abilities, so that they were able to perform the task on a level which comes close to the level of an expert.

However, the finding that experts are most confident that their pain intensity assess ment was correct might be an indirect indication that expertise does influence assessments of pain intensity. Although the pain intensity assessments of novices and intermediates were similar to those of experts, novices and intermediates did not have much confidence in the correctness of their assessments. The results, how- 
ever, have shown that there is no linear relationship beween level of expertise and subject's confidence; novices were more confident that their decisions were correct than intermediates. In other words, the subjects' confidence in their decisions seems to decrease during their education.

These findings are consistent with general theories on decision-making (Benner, 1984; Schmidt et al., 1990\%. While novices in this study make their assessments off the cuff, intermediates compare data again and again before they come to a final decision. During the data-collection sessions, intermediates from two different nurs ing schools argued that they had to make their assessments too quickly; they would have liked more time to think their decisions over.

Students are probably taught to make decisions systematically, and to use all kinds of data, so that they pass through every stage of the decision making process consciously. Furthermore, the students may have learned that assessing patients" pain is a complicated matter and that the experience of pain may be influenced by many factors. The intermediates possibly struggle with the information about the cases because they are taught to be careful when judging a patient's situation.

Experienced nurses, on the other hand, do not go through the stages in the decisionmaking process consciously. As Benner (1984) states, experts no longer use rules or formulas to guide their practice. Pediatric nurses have already seen many children in pain, and they often have to assess their pain. This practical experience gives them confidence in their decisions.

Knowledge and experience did have a distinct impact on the administration of analgesics. Experts were more inclined to administer analgesics than both intermediates and novices. This finding could again be explained by Schmidt et al. 's (1990) theory on medical expertise. Hobus (1994) found indications that knowledge about treatment and diagnosis are part of one illness script. As a result, practical experience would be responsible for the differences between pediatric nurses and nursing students in decisions regarding the administration of analgesics.

In addition to knowledge and experience, nurses' attitudes appear to infiuence their interventions. This was evidenced by the fact that nurses said that they would postpone the administration of analgesics postoperatively. The study of nurses" attitudes towards pain in children and (non)pharmacological interventions was bevond the scope of this dissertation and warrants further attention.

\section{Which pain protocol relieves postoperative pain in children following (adeno)tonsillectomy adequately}

This dissertation was completed by a study on the improvement of the treatment of postoperative pain in children following (adeno)tonsillectomy (Chapter VIII). This intervention study addressed the following questions: (1) is a high loading dose 130 . $50 \mathrm{mg} / \mathrm{kg}$ ) of paracetamol in combination with fentanyl $(1 \mathrm{mcg} / \mathrm{kg})$ more effective than paracetamol $(30.50 \mathrm{mg} / \mathrm{kg}$ ) only in relieving children's early postoperative pain following (adeno)tonsillectomy? (2) Do systematic pain assessments (SPA) enhance the effects of analgesics?, and (3) Is the pain management adequate?

To answer these questions, this study employed a double-blind, randomized placebo 
Furthermore, nurse educators should pay more attention to pain assessment and to methods of relieving pain in children, including analgesics and their side effects. In addition, the subjective nature of the experience of pain and developmental influences on pain perception, pain tolerance and pain expression in children should receive more attention in nursing school curricula.

With regard to nurses" attitudes, refresher courses on pain in children are recommended for pediatric nurses because nurses are the ones who determine if a child is to be given medication or not and because they are looked upon as role models by nursing students in the practice setting. Refresther courses could explain how children with different medical diagnoses and from different age groups perceive painful experiences and how they react to them. Myths about pain assessment and pain management in children could be discussed and subsequently dispelled.

The finding that fentanyl $1 \mathrm{mcg} / \mathrm{kg}$ administered intramuscularly is not effective makes it questionable whether it should be adminstered in this way.

As was said before the quality of nursing care could be improved by the implementation of systematic assessments. However "nurses should then be taught that their interventions should be based on their assessments. For these reasons, refresher courses on different non pharmacological interventions (see above) with regard to pain and their effects are recommended.

\section{RECOMMENDATIONS FOR FUTURE RESEARCH}

Further studies on the prevalence and incidence of pain in children are needed. As was shown by the present study, there is growing evidence for the undertreatment that postoperative pain in children is undertreated. However, this information is limited to certain types of surgery and to older age groups and is almost non-existent for other clinical populations, such as cancer patients or very young children. By studying the above-mentioned areas, problems will be brought to light, so that purposive intervention studies can be designed. In order to conduct studies on the incidence of pain and to examine the effects of pain relieving interventions, more research should be aimed at the development of reliable and valid instruments for measuring pain, especially in very young children.

Research on nurses attitudes was beyond the scope of this dissertation. Nevertheless, indications were found that nurses" attitudes seem to be responsible for differences between nurses as to their decisions to administer analgesics. Therefore, it is recommended that nurses' attitudes towards pain and pain management, as well as towards medication in general be studied more extensively.

Furthermore, the effect of knowledge and experience on pain intensity assessments should be explored further. As was illustrated in this chapter, the theory on medical expertise proposed by Sichmidt et al. (1990) could be used as a basis for the operationalization of variables and the construction of a study. The relevance and applicabillity of this theory to the domain of nursing should also be investigated, for it may have farmeaching implications for nursing education. In addition, further validation of nursing diagnoses is a prerequisite for the examination of accuracy in decision-making. 
The experimental studies on task-related factors influencing pain assessments could be replicated using different vignettes and videos and with different clinical situations and age groups. In addition, the role that parents play in the assessment and management of other pain than postoperative pain deserves more attention in future studies.

Finally, it is important to conduct further research on effective analgesia and other, non-pharmacological, methods for relieving childrens' early postoperative pain following (adeno)tonsillectomy. In addition, future research might examine the effects of standard pain assessment and giving information on strategies for nurses to alleviate pain in children. 


\section{REFERENCES}

Abu-Saad, H. (1984). Assessing children's responses to pain. Pain, 19; 163-171.

Abu-Saad, H.H., Pool, H. Kulkens, B. 119941. Further validity testing of the Abu-Saad pediatric pain asessment tool. Jowrnal of Advanced Nursing, 19, 1063-1071.

Arkesteyn, S. Huijer Abu-Saad, H.\& Halfens, R. 19901. De attitude van verpleggkundigen (Nurses" atitudes). Tijdschrift Voor Ziekenverpleging, 100, 396-398.

Benner. P. (1984). From novice to expent excellence and power in clinical nursing practice. AddisonWasley, Menlo park.

Beyer, J.E., DeGood, D.E., Ashley, L.C. \& Russell, G.A. (1983). Patterns of postoperative analgesic use with adults and children following cardiac surgery. Pain, 17, 71-81.

Beyer, J.E., McGrath, P.J. \& Berde, C.B. (1990). Discordance between self-report and behavioral pain measures in children aged $3-7$ years after surgery. Journal of Pain and Symptom Management, 5. 350-35e.

Boelen-Van der Loo, W.J.C. \& Driessen, F.G.W.H.M. (1992). Pijnpreventie en pijnbestrijding bij ladeno) tonsillectomia (Prevention and management of pain following (adeno) tonsillectomy). Neder lands Tijdschrift voor de Geneeskunde, 136, 1409-1413.

Bone. M.E. \& Fell, D. (1988). A comparison of rectal diclofenac with intramuscular papaveretum or placebo for pain relief following tonsillectomy. Anaesthesia, 43, 277-280.

Boshuizen. H.P.A. (1989). De ontwikkeling van medische expertise. Een cognitief psychologische benadering (The development of medical expertise. A cognitive psychological approach). Krips. Mappel.

Bouter, L.M., Van Dongen, M.C.J.M. (1991). Epidemiolagisch onderzoek, opzet en interpretatie (Epidemiologic research, design and interpretation). Bohn, Stafleu \& Van Loghum, Houten.

Broome, M.E. \& Slack, J.F. 11990 . Influences on nurses' management of pain in children. Maternal Child Nursing, 15, 158-162.

Burokas, L. (1985). Factors affecting nurses' decisions to medicate pediatric patients after surgery. Heart \& Lung, 14, 373-379.

Bush, J.P., Holmbeck, G.N. \& Cockrell, J.L. (1989). Patterns of PRN analgesic drug administration in children following elective surgery. Joumal of Pediatric Psychology, $14,4334448$.

Cohen, J. (1994). The earth is round $(p<0.05)$. American Psychologist, 49, 997-1003.

Dommerby, H. \& Rasmussen, O.R. (1984). Diclofenac (woltarenl. Pain-relieving effect after tonsillec tomy. Acta Otolaryngologica, 98, 185-192.

Eland, J.M. \& Anderson, J.E. (1977). The experience of pain in children. In A. Jacox (Ed.). Pain: A source book for nurses and other heath professionals. Littie Brown, Boston, pp. $453-473$.

Farrand, L.L., Holzhemer, W.L., Schleutermann, J.A. (1982). A study of construct validity: simula tions as a measure of nurse practitioner's" problem-solving skills. Nursing Research, 37, 37-42.

Fositer, R.L. \& Hester, N.O. (1990). The relationship between pain ratings and pharmacologic interventions for children in pain. In: D.C. Tyler \& E.J. Krane. Advances in Pain Research and Therapy, 15,31-35. Raven, New York.

Gadish. H.S., Gonzalez, J.L. \& Hayes, J.S. (1988). Factors affecting nurses' decisionis to adiminister pediatric pain medication postoperatively. Journal of Pediatric Nursing. 3, 383-390.

Gatudreault, P., Guay, J., Nicol, O. \& Dupuis, C. 11988). Pharmacokinetics and clinical efficacy of intrarectall solution of acetaminophen. Canadian Jaurnal of Anaesthesia, 35, 149-152.

Gauthier, J.C., Finley, G.A. \& McGrath, P.J. 11994). Children's self-report of postoperative pain intensity and adequacy of medication: establishing a link. Abstractbook, p.85, Third International Symposium on Pediatric Pain, Philladelphia.

Geisler F. \& Pfaff, A. (1993). Protocol post-operatieve pijnstilling (Pratocol postoperative pain management). Academisch Ziekenhuis Maastricht, Maastricht.

Gillies, M.L., Parry-Jones, W.L. \& Smith, L.N. (1994). The chief scientist reports .. postoperative pain in children under five years. Health Bu/letin, 52, 193-195.

Hadjestavropoulos, H.D., Craig, K.D., Grunau, R.V. \& Johnston C.C. (1994). Judging pain in newborns: facial and cry determinants. Journal of Pediatric Psychology, 19,485-491. 
Hester, N.K. 11979). The pre-operational child's reaction to immunization. Nursing Research, 28, 250255.

Hobus, P. (1994). Expertise van huisartsen. Praktijkervaring, kennis en diagnostische hypothese vorming (Expertise in general practioners. Practical experience, knowledge and generation of diagnostic hypatheses!. Thesis, Amsterdam.

Kerlinger, F.N. (1986). Foundations of behawioral research. Holt, Rinehart \& Winston, Fort Worth.

Knight, J.C. (1994). Post-operative pain in children after day case surgery. Paediatric Anaesthesia, 4. 45-5i.

Kokke, F.T.M., Van der Heide, D.H. \& Boelen-van der Loo, W.J.C. (1993). Postoperatieve pijnbestrị ding in drie Nederlandse ziekenhuizen: een pilotstudile (Postoperative pain management in three Dutch hospitals: a pilot study). Tijd'schrift woor Kindergeneeskunde, 61, 48-51.

LeBaron, S. \& Zeltzer, L. (1984). Assessment of acute pain and anxiety in children and adlolescents by self-reports, observer reports, and a behavioral checklist. Jounal of Consulting and Clinical Psychology, 52, 729-738.

Lindgren, L. \& Saarnivaara, L. (1985). Comparison of paracetamol and aminophenazone plus diazepam suppositories for anxiety and pain relief after tonsillectomy in children. Acta Anaesthesio. logica Scandinavica, 29, 679-682.

Mather, L. \& Mackie, J. 11983). The incidence of postoperative pain in children. Pain, 15, 271-282.

McCaffery, M. (1979). Nursing management of the patient with pain. Lippincott. Now York.

Pasquale, G., Scaricabarozzi, I., D'Agostino, R. Taborelli, G. \& Vallarino, R. (1993). An assessment of the efficacy and tolerability of nimesulide vs paracetamol in children after adenotonsillectomy. Drugs, 46, 234-237.

Powers, D.M. (1987). Ratings of pain from postoperatiwe children and their nurses. Nursing Papers, $19,49-58$.

Radwin, L.E. (1995). Conceptualizations of decision-making in nursing: analytical models and 'knowing the patient". Nursing Diagnosis, 6, 16-22.

Rusy, L.M. ,Houck, C.S., Sullivan, L.J. Ohims, L.A., Jones, D.T., Gill, T.J. \& Berde, C.B. (1995). A double-blind evaluation of ketorolac tromethamine versus acetaminophen in pediatric tonsillectomy: analgesia and bleeding. Anesthesia \& Analgesia, 80, 226-229.

Schechter, N.L., Allen, D.A. \& Hanson, K. (1986). Status of pediatric pain cantrol: a comparison of hospital analgesic usage in children and adults. Pediatrics, 77, 11-15.

Schmidt, H.G. Norman, G.R., Boshuizen, H.P.A. (1990). A cognitive perspective on medical expertise: theory and implications. Academic Medicine, 65, 611-621.

Sjöström, B. 119951. Assessing acute postoperative pain, assessment strategies and quality in relation to clinical experience and professional role. Acta Universitatis Gothoburgensis, Göteborg.

Sutters, K.A., Levine, J.D., Dibble, S., Savedra, M. \& Miaskowski, C. (1995). Analgesic efficacy and safety of single-dose intramuscular ketaralac for postoperative pain mantgement in children following tonsillectomy. Pain, 61, 1.45-153.

Tanner, C.A., Padrick, K.P., Westfall, U.A. \& Putzier, D.J. (1987). Diagnostic reasoning strategies of nurses and nursing students. Nursing Research, 36, 358-363.

Tanner, C., Benner, P., Chesla, C. \& Gordon, D. (1993). The phenomenology of knowing the patient. Image, 25, 273-280.

Tesler, M.D., Wilkie, D.J., Holzemer, W.L. \& Savedra, M.C. (1994). Postoperative analgesics for children and adolescents: prescription and administration. Joumal of Pain and Symptom Management, 9, 85-95.

Tversky, A. \& Kahneman, D. (1974). Judgment under uncertainty: heuristics and biases. Science, $185,1124.1131$.

Watters, C.H., Patterson, C.C., Mathews, H.M.L. \& Campbell, W. (1988). Diclofenac sodium for posttonsillectomy pain in children. Anaesthesia, 43,641-643. 
This dissertation deals with various aspects of postoperative pain assessment and intervention in children. In particular, the adequacy of postoperative pain relief and factors influencing nurses" acute pain assessments and interventions are investigated.

In chapter I, a general introduction to the field of research is provided and the re: search questions are presented.

Chapter II addresses the question whether children receive sufficient analgesics postoperatively. By means of a review of the literature it is examined whether the assumption that children are undermedicated is based on empirical data. The conclu sion is that there is growing evidence that postoperative pain in children is indeed undlertreated.

Chapters III, IV, $V$ and $V$ I focus on factors influencing nurses' decision-making. Chapter III is a theoretical chapter in which the results of a review of the literature on decision-making in general are described, while chapters IV, $V$, and VI focus specifically on decisilon-making in connection with pain assessment and intervention.

In chapter III research on decision-making in nursing is summarized. An important conclusion is that research on decision-making is hampered by the fact that it is very difficult to establish whether nurses' decisions regarding diagnoses and interventions are accurate, because unknown is often what correct decisions are.

Chapter IV presents two qualitative studies in which factors influencing nurses. pain assessment and intervention were explored. In both studies patients' vocal expressions were found to influence nurses' decisions. The relationship between the results of the two studies and information reported in the literature is also discussed in this chapter. Finally, hypotheses regarding the impact of some factors are proposed.

Chapter $V$ describes an experimental study which tested the hypotheses generated in the qualitative studies. This study examined the influence of the medical diagnosis, the child's age and expressions, and information obtained from the child"s parent on nurses' pain assessments and administration of non-narcotic analgesics. Once again, patients" vocal expressions were found to influence nurses' decisions; nurses attribute more pain and are more inclined to administer analgesics to children who express their pain vocally than to children who do not.

Chapter $V I$ focuses on other factors influencing pain assessments and interventions. The study described in this chapter examined whether qualified pediatric nurses (experts) differ from 4th-year nursing students (intermediates) and 1st-year nursing students (novices) with regard to postoperative pain assessments and pharmacological interventions in hospitalized children. The conclusion is that experts, intermediates and novices in this study do not differ in their assessments of pain intensity, but that compared to intermediates and novices, experts are most confident that their assessments are correct. Furthermore, experts are more inclined to administer analgesics than both novices and intermediates.

Chapter VII deals with the improvement of postoperative pain relief in children following (adeno) tonsillectomy. This chapter describes an intervention study evaluating the efficacy of paracetamol suppositories, intramuscular fentanyl and systematic pain assessments on children's postoperative pain. The conclusions of this study can be 
summarized as follows: First, paracetamol in combination with fentanyl did not lead to improved analgesia compared to paracetamol in combination with a placebo. Second, systematic pain assessments by nurses did not enhance the effects of the analgesics. Finally, the pain management used in this study was not adequate 1-2 hours after surgery.

Chapter VIII is a general discussion of the main findings of all studies presented in this dissertation. After a thorough examination of the results of the different studies the methods used are analyzed critically. Next, different theoretical explanations of the findings are proposed. Finally, practical implications are discussed and recommendations for future research are made. 
In dit proefschrift komen verschillende aspecten aan bod over het beoordelen van postoperatieve pijn bij kinderen en het kiezen van pijnverlichtende interventies: Nagegaan is of pijn voldoende wordt verlicht en welke factoren thet beoordelen van acute pijn en het kiezen van pijnverlichtende interventies beïnloeden.

Hoofdstuk I is een algemene inleiding op de verschillende onderzoeken. In dit hoofdstuk wordt een overzicht gegeven van de onderzoeksvragen van dit proefschrift.

In hoofdstuk II staat de vraag centraal of kinderen na een operatie voldoende pijnstillers krijgen. Door middel van een literatuuronderzoek is gekeken of de aanname dat kinderen te weinig pijnstilling krijgen gebaseerd is op empirisch onderzoek. De conclusie is dat er steeds meer aanwijzingen zijn dat postoperatieve pijn bij kinderen inderdaad onvoldoende wordt verlicht.

De hoofdstukken III, IV, V en VI gaan over factoren die van invloed zijn op besluitvorming door verpleegkundigen waarbij hoofdstuk III is een algemeen theoretisch hoofdstuk over besluitvorming en de hoofdstukken IV, $V$ en $V I$ gericht zijn op besluitvorming ten aanzien van het beoordelen van en interveniëren bij pijn bij kinderen.

In hoofdstuk III wordt onder meer onderzoek naar besluitvorming geïnventariseerd; meestal is dat onderzoek gericht op het vaststellen van (verpleegkundige) diagnoses. Wat daarbij opvalt is dat het doen van onderzoek naar de vraag of verpleegkundigen de correcte diagnose stellen, cq de juiste beslissing nemen, bemoeilijkt wordt omdat meestal niet bekend is wat de correcte diagnose is.

In hoofdstuk IV worden twee kwalitatieve onderzoeken beschreven waarmee de factoren die verpleegkundigen beïnvloeden bij het beoordelen van pijn bij kinderen en het kiezen van pijnverlichtende interventies geïnventariseerd zijn. Beide onderzoeken suggereren dat met name de vocale uitingen van patiëntjes van invloed zijn op beslissingen van verpleegkundigen. De onderzoeksresultaten zijn vergeleken met gegevens uit de literatuur. Tenslotte zijn verschillende hypotheses geformuleerd over de invloed van bepaalde factoren op de besluitvorming.

Vervolgens beschrijft hoofdstuk $V$ een experiment waarin de hypotheses uit de kwalitatieve onderzoeken zijn getoetst. In dit onderzoek is gekeken naar de invloed van de medische diagnose, de leeftijd en de uitingen van het kind, en informatie verkregen van de ouders van het kind op het beoordelen van pijn door verpleegkundigen en de keuze om een pijnstiller (niet-opiaat) toe te dienen. In overeenstemming met de kwalitatieve onderzoeken werd gevonden dat de vocale uitingen van de patiëntjes van invloed waren op de beslissingen van de verpleegkundigen; verpleegkundigen schatten de pijn hoger in en zijn eerder geneigd om pijnstillers te geven aan kinderen die hun pijn vocaal uiten dan aan kinderen die dat niet doen.

Hoofdstuk VI beschrijft een onderzoek dat gericht was op andere factoren die van invloed zijn op het beoordelen van pijn en het kiezen van interventies. In dit onderzoek is gekeken of verpleegkundigen met een specialisatie in de pediatrie afwijken van vierdejaars HBO-V studenten en eerstejaars HBO-V studenten als ze postoperatieve pijn bij kinderen beoordelen en als ze moeten beslissen om pijnstillers toe te dienen. De conclusie is dat er in dit onderzoek geen verschillen zijn gevonden tussen de inschattingen van pijnintensiteit door verpleegkundigen, eerste- en vierdejaars 
studenten. Wel waren de verpleegkundigen het meest zeker dat ze de pijn correct hadden ingeschat. Ook waren de verpleegkundigen eerder geneigd om pijnstillers te geven dan de studenten.

Hoofdstuk VII beschrijft een interventie-onderzoek dat gericht was op het verlichten van de postoperatieve pijn bij kinderen na het verwijderen van de keel- en neusamandelen (adenotonsillectomie). In dit onderzoek is gekeken of paracetamol (zetpillen), fentanyl (intramusculaire injecties) en systematische pijninschattingen door verpleegkundigen effectief zijn in het verlichten van postoperatieve pijn bij kinderen. De conclusies die dit onderzoek opleverde kunnen als volgt worden samengevat. Ten eerste wordt de pijn niet beter verlicht door een combinatie van paracetamol en fentanyl in vergelijking met een combinatie van paracetamol en een placebo. Vervolgens leidde de invoering van systematische pijninschattingen door verpleeglkundigen niet tot een betere verlichting van de postoperatieve pijn. Tenslotte werd vastgesteld dat de pijn in dit onderzoek in de eerste twee uren na de operatie onvoldoende is verlicht.

Hoofdstuk VIII is gewijd aan een algemene bespreking van de belangrijkste resultaten van de onderzoeken zoals die in dit proefschrift zijn beschreven. Nadat de resultaten van de verschillende onderzoeken uitgebreid zijn samengevat, worden kritische kanttekeningen geplaatst bij de onderzoeksmethoden. Verder worden theoretische verklaringen aangedragen voor de onderzoeksresultaten. Tenslotte worden enkele praktische implicaties besproken en worden aanbevelingen gedaan voor vervolgonderzoek. 
In oktober 1991 ben ik gestart met het promotie-onderzoek waar dit proefschrift verslag van doet. Dat dit onderzoek ruim binnen vier jaar is afgerond, is alleen mogelijk geweest door de medewerking van veel mensen. Een aantal daarvan wil ik met naam noemen.

Op de eerste plaats een woord van dank aan mijn promotoren Huda Huijer Abu-Saad en Marcel van den Hout en aan mijn co-promotor Ruud Halfens.

Huda, een betere promotor kan een promovendus zich niet wensen. Dankzij jou kan ik zeggen dat dit promotie-onderzoek mijn onderzoek is. Vanaf het begin tot het einde heb je mij de vrijheid gegeven om alle onderzoeken te bedenken, op te zetten en uit te voeren. Bij problemen kon ik altijd op je rekenen en dankzij jou heb ik in een aantal situaties doorgezet waar ik anders een makkelijkere, doch minder bevredigende, weg zou hebben gekozen. Ik hoop dat we nog vaak mogen samenwerken.

Marcel, ook jij bent een uitstekend promotor. Hoewell ik minder contact heb gehad met jou, heb ik enorm veel van je geleerd; met name over het opzetten van experi. menteel onderzoek. Een ander kenmerk dat ik zeer heb gewaardeerd is je supersnelle reactie op concept artikels.

Ruuld, wij werken al samen sinds mijn doctoraalonderzoek. Samen hebben wij in de afgelopen vijf jaar meer dan twintig artikels geschreven en evenzoveel abstracts gepresenteerd. Dat je mijn concept teksten echter nog steeds uiterst kritisch weet te lezen, stel ik zeer op prijs.

Alle (ex)medewerkers van de vakgroep Verplegingswetenschap bedank ik voor de prettige tijd die ik er tot nu toe heb doorgebracht.

Verder hebben de volgende mensen een bijdrage gehad aan het tot stand komen van dit boek. Els Boshuizen gaf adviezen over de opzet en analyse van 'het onderzoek met de video's. Jeroen Schumacher en Anita Heijltjes hebben in het kader van hun studie deelonderzoeken uitgevoerd. Arnold Kester en Hubert Schouten gaven statistische adviezen bij verschillende onderzoeken. Gerry van Wunnik verzorgde de opnaw me en montage van de video's. Marianne Tilly was behulpzaam bij het verzamelen van literatuur, het maken van figuren en bij de dataverzameling in het video-onderzoek. Van John Mullink kreeg ik assistentie bij het opzetten van databestanden en het bedenken van randomisatieprocedures. Pamela Falger en Marijke van der Horst hebben de Engelse teksten gecorrigeerd. Enny Beerden was behulpzaam bij en gaf adviezen over de lay*out van dit boek.

Verder dank ik de staf van zowel de vakgroep Anesthesiologie als de vakgroep KNO voor hun medewerking aan het 'ATE-onderzoek'. Met name de anesthesiologen Ferd Geisler en Hans van Suijlekom hebben een groot aandeel gehad in het slagen van dat onderzoek. Dit laatste geldt ook voor de verpleegkundigen werkzaam op het dagcentrum van het academisch ziekenhuis Maastricht, waarvoor dank. 
Dank ook aan alle kinderen en hun ouders die aan de verschillende onderzoeken hebben meegewerkt. Dit geldt ook voor de deehname van verpleegkundigen uit het Emma kinderziekenhuis te Amsterdam, het De Wever ziekenhuis te Heerlen, het St. Jozef ziekenhuis te Kerkrade, het academisch ziekenhuis Maastricht, het Radboud ziekenhuis en het Canisius ziekenhuis te Nijmegen, het Laurentius ziekenhuis te Roermond, het Sophia kinderziekenhuis te Rotterdam, het Maasland ziekenhuis te sittard, het Wilhelmina kinderziekenhuis te Utrecht; het St. Elisabeth ziekenhuis te Venray en het St. Jans Gasthuis te Weert. Verder geldt dat voor de HBO-V studen. ten van de Hogeschool Leeuwarden, de Hogeschool Leiden, de Hogeschool MiddenNederland, de Hogeschool Potterdam, de Hogeschool Sittard en de Hogeschool West-Brabant.

Zonder de medewerking van hen allen was dit boek eenwoudigweg niet verschenen.

Dank ook aan mijn familie en vrienden. Met name bij de voetbalvereniging WDZ heb ik veel ontspannende uren doorgebracht. Hans en Rob hebben mij regelmatig laten winnen met schaken, waarvoor dank. Met Henk en Sas hoop ik nog veel 'Groningse weekeinden' door te brengen. Anja en Pierre zorgen ook regelmatig voor de nodige ontspanning. Mijn zus, Marita, heeft mijn onderzoeksciarrière altijd met belangstelling gevolgd. Dat geldt ook voor mijn schoonouders, die daarbij ook nog zorgden dat de wintersportvakantie een jaarlijks terugkerend evenement werd.

Niet in de laatste plaats dank aan mijn ouders. Pap en mam, jullie steun en interesse zijn van een niet te onderschatten invloed geweest op mijn carrière. Vooral aan het begin van de middelbare school periode zijn jullie een duidelijke stimulans geweest en en hebben me toen voorgehouden dat ik jullie daar later dankbaar voor zou zijn. Bij deze: bedankt!

Tenslotte dank aan Stella, mijn echtgenote. Al vanaf de vierde klas van de HAVO heb je mij gesteund in studie en werk. Daarbij heb jij er voor gewaakt dat ik niet verstoken bleef van de leuke dingen in het leven. Daar ben ik je zeer dankbaar voor. 


\section{CURRICULUM VITAE}

Jan Hamers was born on June 3,1966 in Kerkrade, the Netherlands. Upon completion of Highschool in 1983, he began his studies in nursing at the Institute for Higher Professional Education in Sittard and received his BSN degree in 1987. Shortly hereafter, he enrolled as a student at the University of Limburg to study Health Sciences with the specialization Nursing Science. Between 1987 and 1990 he was also employed as a nurse in a nursing home. He received his MSN degree in 1990. Upon his graduation he was hired as an instructor at the department of Nursing Science of the University of Limburg. In 1991 he was employed as a PhD student at the same department. In this position he conducted this dissertation.

Jan Hamers is geboren op 3 juni 1966 in Kerkrade. Na het behalen van zijn HAVOdiploma in 1983 begon hij aan de HBO-studie verpleegkunde an de Hogeschool Sittard. Nadat hij daar het HBO-V diploma in 1987 had behaald begon hij in hetzelfde jaar aan de studie Gezondheidswetenschappen aan de Rijksuniversiteit Limburg. Van 1987 tot 1990 was hij ook werkzaam als verpleegkundige in een verzorgingshuis in Heerlen. In 1990 behaalde hij het doctoraaldiploma met als afstudeerrichting verplegingswetenschap. In dat jaar trad hij als toegevoegd docent in dienst bij de Rijksuniversiteit Limburg, vakgroep verplegingswetenschap. In 1991 kreeg hij een aanstelling als AIO. In het kader van die laatste functie is het promotie-onderzoek uitgevoerd. 